\title{
A checklist of vascular plants in limestone areas on the Korean Peninsula
}

\author{
Jung-Hyun KIM, Gi-Heum NAM ${ }^{1}$, Seung-bae LEE $^{2}$, Sookyung SHIN ${ }^{3}$ and Jin-Seok KIM ${ }^{4 *}$
}

\author{
Plant Resources Division, National Institute of Biological Resources, Incheon 22689, Korea \\ ${ }^{I}$ Strategic Planning Division, National Institute of Biological Resources, Incheon 22689, Korea \\ ${ }^{2}$ Geological Museum, Korea Institute of Geoscience and Mineral Resources, Daejeon 34132, Korea \\ ${ }^{3}$ Exhibition and Education Division, National Institute of Biological Resources, Incheon 22689, Korea \\ ${ }^{4}$ Geumsugangsan, Uijeongbu 11625, Korea
}

(Received 6 August 2021; Revised 28 August 2021; Accepted 9 September 2021)

\begin{abstract}
Limestone areas are sedimentary rock outcrops consisting of calcium carbonate created several hundreds of millions of years ago by calcium-secreting marine organisms and subsequently lifted above sea level by tectonic movement. Limestone areas support very high levels of endemic species of plants and are recognized as biodiversity areas with much biological information. The purpose of this study is to devise a strategy for the comprehensive conservation of the vegetation of limestone areas through analyses of the floristics and plant species compositions in ten limestone areas on the Korean Peninsula. The results of 153 field surveys from April of 2010 to October of 2016 identified 1,202 taxa in total, representing 1,096 species, 18 subspecies, 84 varieties, 2 forms, and 2 hybrids in 530 genera and 133 families. Among them, 55 taxa were endemic plants to Korea, and 38 taxa were red data plants. The floristic target plants amounted to 102 taxa, specifically 27 taxa of grade V and 75 taxa of grade IV. In all, 121 alien plants were recorded in the investigated area. Calciphilous plants amounted to 102 taxa, specifically 14 taxa of calciphilous indicator plants, 30 taxa of superlative most calciphilous plants, and 58 taxa of comparative more calciphilous plants. A cluster analysis showed a high degree of similarity between sites that are geographically adjacent with similar habitat environments. Limestone areas also supported groups distinct from those in non-limestone areas, demonstrating the specificity of limestone flora. Plant geography approaches therefore appear to be crucial to gain a better understanding of the level of biodiversity in limestone areas, not only at the interspecific but also at the intraspecific level. These results highlight the importance of protecting limestone habitats to preserve not only their interspecific but also the intraspecific diversity, which is highly threatened.
\end{abstract}

Keywords: limestone, calciphilous, checklist, biodiversity

탄산염 기반의 퇴적암(이하 석회암)은 중량 $50 \%$ 이상이 탄산염 광물로 이루어진 퇴적암을 가리키며(Bates and Jackson, 1987), 크게 석회암(limestone)과 돌로스톤(dolostone) 으로 분류된다. 석회암은 주로 탄산칼슘 $\left(\mathrm{CaCO}_{3}\right)$ 성분의 방해석(calcite) 또는 아라고나이트(aragonite)로, 돌로스톤 은 주로 돌로마이트 $\left(\mathrm{CaMg}\left(\mathrm{CO}_{3}\right)_{2}\right)$ 로 구성된다. $50 \%$ 이상 의 탄산칼슘과 현저한 양의 돌로마이트를 함유한 탄산염 암을 돌로마이트질 석회암(dolomitic limestone), $50 \%$ 이상 의 돌로마이트와 현저한 양의 탄산칼슘을 함유한 탄산염 암을 석회질 돌로스톤(calcareous dolostone)이라 부른다. 탄 산칼슘은 광물 격자 내에 흔히 마그네슘, 철, 망간 등을 소 량 포함한다(Blatt et al., 1980; Dromgoole and Walter, 1990).
한반도의 석회암은 후기 고생대 또는 중생대 백악기 지 층 내에도 존재하나 지층의 두께가 얇고 연장성이 불량하 여 넓은 면적을 차지하지 않는다. 그에 비해 전기 고생대 동안(약 5억 2,000만 년 전부터 4억 6,000만 년 전까지) 퇴 적된 지층의 다발인 조선누층군 내에 석회암 지층이 우세 하게 발달하였다. 특히 충청북도 제천시, 단양군, 강원도 영월군, 정선군, 평창군, 태백시, 삼척시, 강릉시 지역과 경 상북도 문경시 일대에 석회암이 널리 분포한다(Fig. 1). 석 회암을 자세히 세분할 때, 지역별로 암상(lithology)과 암상 조합(lithologic succession)에 차이가 있어 이 넓은 지역의 조선누층군을 태백층군, 영월층군, 용탄층군, 평창층군, 문경층군으로 구분한다(Choi, 1998).

\footnotetext{
*Author for correspondence: webdogam@naver.com
} 


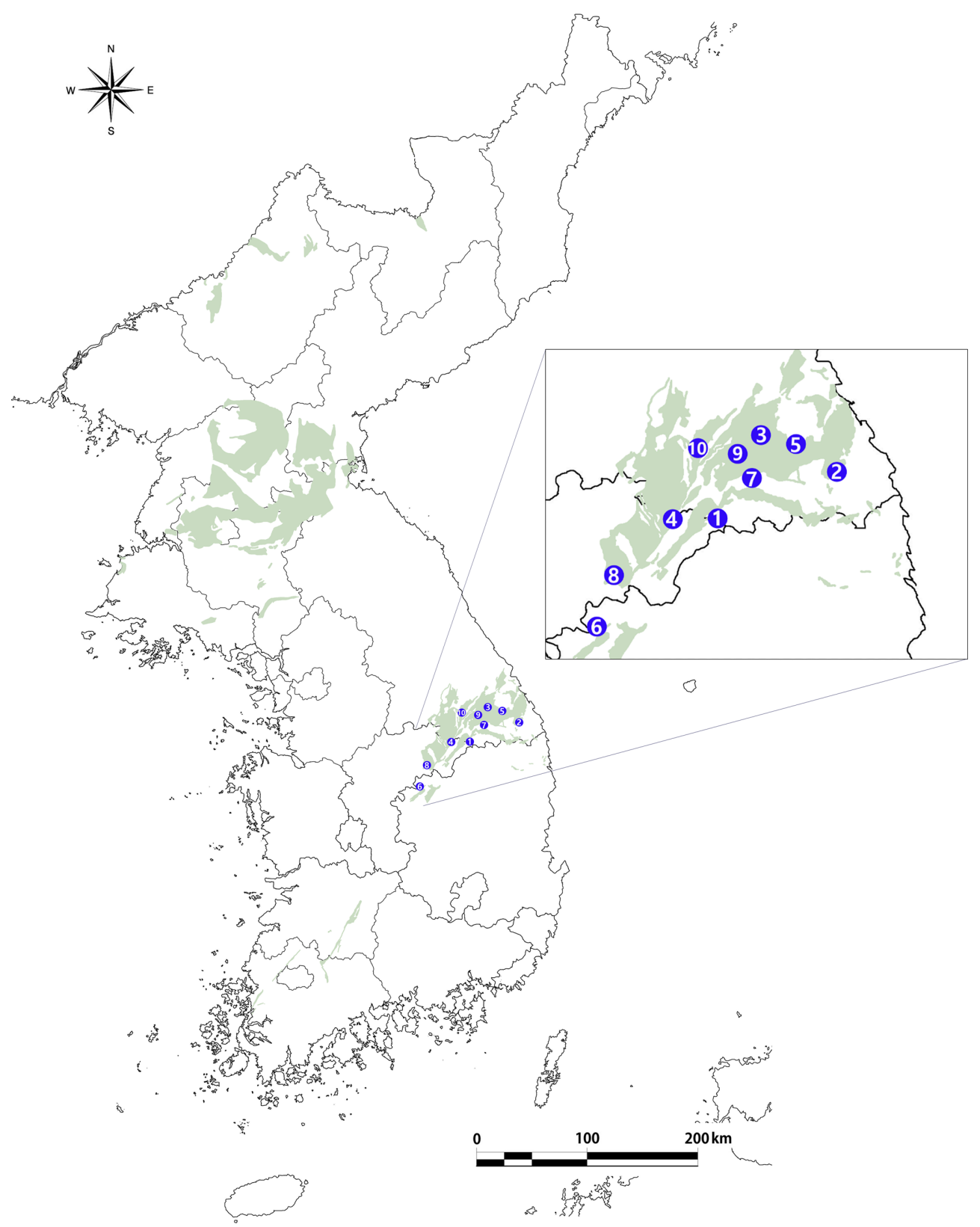

Fig. 1. The distribution map of limestone areas and investigated areas in Korea. 1, Taehwa mountain; 2, Osip stream; 3, Goyang mountain; 4, Samtae mountain; 5, Golji stream; 6, Wonpung stream; 7, Jungnyeom mountain; 8, Dumu mountain; 9, Baeki mountain; 10, Nambyeong mountain.

우리나라에 분포하는 석회암지대는 생성 시기에 따라 크게 4가지 유형으로 구분된다. 첫째, 충청북도 및 강원 도 일대에 광범위하게 분포하는 캄브로-오르도비스기 (Cambrian-Ordovician) 대석회암통의 석회암층(조선계 대 석회암통), 둘째, 전라남북도 및 충정남도 일대의 옥천계 변성 퇴적암류 내에서 맥상 또는 층상으로 나타나는 시대 미상의 석회암층(옥천계 시대 미상의 석회암층), 셋째, 주 로 경기도, 강원도, 경상북도에서 선캄브리아기 편마암체 내에서 소규모 렌즈상으로 분산 분포하는 고기 석회암층 (선캄브리아기 석회암), 그리고 대석회암통의 상부에 부정
합으로 피복하며, 주로 대석회암통 분포지역의 연변부에 집중적으로 분포하는 석탄기의 홍점 석회암층(평안계 홍점통) 등이다(Lee and Sunwoo, 2010; Korea National Arboretum, 2012). 이 가운데 우리나라 조선계 대석회암통 으로 불리는 석회암 지층이 충청북도와 강원도에 걸쳐 광 범위한 지역에 걸쳐 분포하고 전체 석회암지대 면적의 $80 \%$ 이상을 차지한다(Fig. 1).

석회암지대는 다량의 탄산칼슘을 함유하고 있어 $\mathrm{pH}$ 가 높고 단립구조가 발달하여 다른 토양보다 쉽게 건조해지 는 토양의 물리적, 화학적 특징으로 인해 비석회암지대와 
는 다른 생태계 구조를 갖는 것으로 알려져 있다(Kim et al., 2005). 이러한 생태계 구조의 특이성으로 한반도를 포 함하여 동남아시아, 중국, 뉴질랜드, 유럽 등지의 석회암 지대는 비석회암지대에 비해 생물종 다양성이 높은 지역 으로 알려져 있으며, 특히 고유종 및 희귀식물의 구성비 율이 높은 것으로 평가하고 있다(Karim et al., 2004; Latinne et al., 2011; Zhang et al., 2017; Liu et al., 2018; Rogers et al., 2018; Kiew and Rafidah, 2021). 동남아시아 말레이반도의 석회암지대는 말레이시아 전체 식물상의 약 $14 \%$ 가 이 지 역에 분포하며, 석회암과 관련된 식물 가운데 말레이반도 의 고유종이 $21 \%$ 이고 이 석회암지대에서만 발견되는 고 유종이 $11 \%$ 를 차지한다(Clements et al., 2006). 중국 구이저 우성의 석회암지대는 우리나라의 면적과 비슷한 105,230 $\mathrm{km}^{2}$ 에 불과하지만, 이 지역에 분포하는 식물은 총 7,505 분 류군이며, 그 가운데 고유종이 171분류군에 달해 생물다 양성이 높은 지역으로 꼽힌다(Liu et al., 2018). 또한 뉴질 랜드 전체 식물상의 약 $5.6 \%$ (152분류군)가 석회암지대에 분포하는 호석회성 식물이며, 그 식물의 $95 \%$ 가 고유종이 고 $29 \%$ (43분류군)는 희귀식물에 포함된다(Rogers et al., 2018).

식물의 생리생태학 적응 및 분포학적 출현 여부 등 석회 암 환경의 선호성을 근거로 석회암지대에 출현하는 식물 을 호석회성 식물과 혐석회성 식물로 분류하는 것은 현재 까지도 식물학자들에게 관심을 끌고 있는 난제이다(Kim et al., 1992; Choo and Song, 1998; Kim and Oh, 2000; Ewald, 2003; Kim et al., 2005). 전 세계적으로 나타나는 석회암지대 의 고유한 식물상적 특이성으로 인해 석회암과 관련한 식 물지리학적 연구는 활발히 진행되어 왔다. Shimizu (1963) 와 Chin (1977)은 석회암지대와 비석회암지대의 분포 여 부 및 출현 빈도를 기준으로 종 특성에 따라 출현하는 식 물의 그룹화를 시도하였다. Shimizu (1963)는 일본과 대만 에 분포하는 석회암지대의 식물상적 연구 결과를 바탕으 로 5개 그룹: (1) 한정종(限定種, 석회암지대에서만 나타 나는 종), (2) 선택종(選擇種, 주로 석회암지대에서 분포하 지만 비석회암지대에서도 일부 분포하는 종), (3) 기호종 (咾好種, 비석회암지대에서 분포하지만 석회암지대에 비 교적 더 많이 분포하는 종), (4) 비관련종(非關聯種, 석회 암지대와 연관성 없이 분포하는 종), (5) 혐오종(嫌惡種, 석회암지대에 전혀 분포하지 않거나 드물게 출현하는 종) 으로 구분하였다. 또한 Chin (1977)은 말레이시아에 분포 하는 석회암지대의 식물상적 연구 결과를 바탕으로 4 개 그룹: (1) 절대종(exclusives, 석회암지대에서만 분포하는 지표종), (2) 선호종(preferents, 비석회암지대에도 분포하 지만 석회암지대에서 더 많이 분포하는 종), (3) 비관련종 (indifferents, 석회암지대와 비석회암지대에 모두 분포하 는 종), (4) 우연종(strangers, 비석회암지대에 흔히 분포하 지만 석회암지대에서는 드물게 분포하는 종)으로 세분하 였다.
전 세계적으로 석회암지대의 식생은 지역적 또는 국지 적 분포 양상에서 전형적인 비대상 분포(azonal distribution) 을 보이며, 그 지역에 발달하는 식물종 역시 지역 고유성 과 특이성이 잘 나타난다(Ryu, 2016). 우리나라의 석회암 지대에서도 비석회암지대와 다른 식생뿐만 아니라 고산 식물의 격리 또는 북방계 희귀식물들의 분포, 그리고 석 회암이라는 특수한 생육환경에 고립 및 적응하여 새로운 종분화가 일어나는 등의 특성이 이를 뒷받침한다(Kim et al., 2005; Korea National Arboretum, 2012; Nam et al., 2012). 이러한 식물지리학적 특이성으로 인해 여러 생태분류학 자들에게 연구중심의 대상지가 되었으며(Chung, 1994; Hong and Im, 1997; Kim et al., 2005; Korea Teacher's Plant Research Association, 2011; Moon et al., 2013; Oh, 2013; Nam et al., 2014; Song et al., 2016; Chae et al., 2019; Park et al., 2020), 최근까지도 신종 및 미기록종 등의 식물이 지속적으 로 발견되고 있다(National Institute of Biological Resources, $2011,2017)$. 그러나 생태계 다양성의 중요한 지역임에도 불구하고 석회석 생산이라는 명분아래 일부 석회암지대 의 산지 대부분은 소실되어 그 원형을 알아보기 힘들고 생태학적 기능은 상실된 상태이다.

본 연구는 우리나라의 주요 석회암지대 10 개 지역에 대 한 식물상적 조사를 종합하여 종조성 특징과 식물지리학 적 중요성을 밝히고 특이식물의 분포, 호석회성 식물의 구 분, 유사도 분석을 토대로 석회암지대의 체계적인 보전 방안 수립을 위한 기초자료를 제시하고자 한다.

\section{재료 및 방법}

우리나라 석회암지대의 식물다양성 조사는 2010년부 터 2016년까지, 총 7년간 석회암 대표 산지 7개 지역, 대표 하천 3 개 지역 등 10 개 지역(Fig. 1, Table 1)을 중심으로 153 회 229일간 현지조사를 수행하였다(Table 2). 조사지역 내 에 생육하는 모든 관속식물은 건조 또는 액침표본으로 제 작하여 국립생물자원관 표본수장고 $(\mathrm{KB})$ 에 보관하였다. 조사경로는 등산로를 중심으로 산지, 능선, 평지, 계곡, 사 면, 하천 등의 주요 생태학적 생육지를 포함하였으며, 일 부는 등산로를 벗어나 무작위로 채집하였다. 채집된 식물 의 동정은 Lee (1980), Lee (1996), Park (2009), Cho et al. (2016), Lee and Lee (2018), Kim and Kim (2018), Kim et al. (2018) 등의 식물도감을 이용하였다.

관속식물의 목록은 증거표본을 바탕으로 작성하고 속 이하의 계급은 알파벳순으로 정리하였으며(Appendix 1), 중복 채집품은 목록 간소화를 위해 대표 번호를 부여하였 다. 식물목록의 학명과 배열은 국가생물종목록집(National Institute of Biological Resources, 2019a)을 따랐으며, 주요 식물의 선별은 한반도 고유식물(특산식물) (Chung et al. 2017), 적색목록(National Institute of Biological Resources, 2021), 식물구계학적 특정식물(National Institute of Ecology, 
Table 1. Investigated localities and sites of limestone areas in Korea.

\begin{tabular}{cll}
\hline \hline No. & \multicolumn{1}{c}{ Survey site } & \multicolumn{1}{c}{ Localities } \\
\hline 1 & Taehwa mountain & Gangwon-do, Youngwol-gun and Chungcheongbuk-do, Danyang-gun \\
2 & Osip stream & Gangwon-do, Samcheok-si and Taebaek-si \\
3 & Goyang mountain & Gangwon-do, Jeongseon-gun \\
4 & Samtae mountain & Chungcheongbuk-do, Danyang-gun \\
5 & Golji stream & Gangwon-do, Jeongseon-gun, Samcheok-si and Taebaek-si \\
6 & Wonpung stream & Chungcheongbuk-do, Goesan-gun \\
7 & Jungnyeom mountain & Gangwon-do, Jeongseon-gun \\
8 & Dumu mountain & Chungcheongbuk-do, Jecheon-si \\
9 & Baeki mountain & Gangwon-do, Jeongseon-gun \\
10 & Nambyeong mountain & Gangwon-do, Pyeongchung-gun \\
\hline
\end{tabular}

Table 2. Investigation dates and sites of limestone areas in Korea.

\begin{tabular}{|c|c|c|}
\hline No. & Survey site & Dates \\
\hline 1 & Taehwa mountain & $\begin{array}{l}1 \text { Apr 2010; } 2 \text { Apr 2010; } 6 \text { May 2010; } 7 \text { May 2010; } 26 \text { May 2010; } 27 \text { May 2010; } 3 \text { Jun 2010; } 14 \text { Jun 2010; } 15 \\
\text { Jun 2010; } 14 \text { Jul 2010; } 15 \text { Jul 2010; } 16 \text { Jul 2010; } 27 \text { Jul 2010; } 28 \text { Jul 2010; } 6 \text { Aug 2010; } 1 \text { Sep 2010; } 2 \text { Sep } \\
\text { 2010; } 10 \text { Sep 2010; } 5 \text { Oct 2010; } 11 \text { Oct 2010; } 12 \text { Oct 2010; } 13 \text { Oct 2010; } 14 \text { Oct 2010; } 22 \text { Oct } 2010\end{array}$ \\
\hline 2 & Osip stream & $\begin{array}{l}29 \text { Mar 2011; } 25 \text { Apr 2011; } 26 \text { Apr 2011; } 27 \text { Apr 2011; } 7 \text { Jun 2011; } 8 \text { Jun 2011; } 21 \text { Jun 2011; } 22 \text { Jun 2011; } 20 \\
\text { Jul 2011; } 21 \text { Jul 2011; } 24 \text { Aug 2011; 25 Aug 2011; } 5 \text { Oct 2011; } 6 \text { Oct 2011; } 7 \text { Oct } 2011\end{array}$ \\
\hline 3 & Goyang mountain & $\begin{array}{l}17 \text { Apr 2012; } 18 \text { Apr 2012; } 16 \text { May 2012; } 17 \text { May 2012; } 18 \text { May 2012; } 12 \text { Jun 2012; } 13 \text { Jun 2012; } 14 \text { Jun } \\
\text { 2012; } 16 \text { Jul 2012; } 17 \text { Jul 2012; } 18 \text { Jul 2012; } 19 \text { Jul 2012; } 20 \text { Aug 2012; } 21 \text { Aug 2012; } 22 \text { Aug 2012; } 6 \text { Sep } \\
\text { 2012; } 7 \text { Sep 2012; } 25 \text { Sep 2012; } 26 \text { Sep 2012; } 10 \text { Oct 2012; } 11 \text { Oct 2012; } 12 \text { Oct } 2012\end{array}$ \\
\hline 4 & Samtae mountain & $\begin{array}{l}24 \text { Mar 2012; } 14 \text { Apr 2012; } 15 \text { Apr 2012; } 28 \text { Apr 2012; } 12 \text { May 2012; } 13 \text { May 2012; } 26 \text { May 2012; } 9 \text { Jun } \\
\text { 2012; } 16 \text { Jun 2012; } 23 \text { Jun 2012; } 14 \text { Jul 2012; } 23 \text { Jul 2012; } 10 \text { Aug 2012; } 11 \text { Aug 2012; } 22 \text { Sep 2012; } 6 \text { Oct } \\
\text { 2012; } 21 \text { Oct } 2012\end{array}$ \\
\hline 5 & Golji stream & $\begin{array}{l}22 \text { Apr 2013; } 23 \text { Apr 2013; } 24 \text { Apr 2013; } 10 \text { Jun 2013; } 11 \text { Jun 2013; } 12 \text { Jun 2013; } 13 \text { Jun 2013; } 15 \text { Jul 2013; } \\
\text { 16 Jul 2013; } 17 \text { Jul 2013; } 18 \text { Jul 2013; } 19 \text { Aug 2013; } 20 \text { Aug 2013; } 21 \text { Aug 2013; } 22 \text { Aug 2013; } 10 \text { Sep 2013; } \\
\text { 11 Sep 2013; } 12 \text { Sep 2013; } 14 \text { Oct 2013; } 15 \text { Oct 2013; } 16 \text { Oct 213; } 17 \text { Oct 2013 }\end{array}$ \\
\hline 6 & Wonpung stream & $\begin{array}{l}2 \text { Apr 2014; } 1 \text { May 2014; } 12 \text { May 2014; } 13 \text { May 2014; } 14 \text { May 2014; } 15 \text { May 2014; } 4 \text { Jun 2014; } 5 \text { Jun 2014; } \\
6 \text { Jun 2014; } 7 \text { Jun 2014; } 17 \text { Jun 2014; } 19 \text { Jun 2014; } 16 \text { Jul 2014; } 17 \text { Jul 2014; } 5 \text { Aug 2014; } 15 \text { Aug 2014; } 18 \\
\text { Aug 2014; } 20 \text { Aug 2014; } 21 \text { Aug 2014; } 1 \text { Sep 2014; } 13 \text { Sep 2014; } 14 \text { Sep 2014; } 17 \text { Sep 2014; } 22 \text { Sep 2014; } 24 \\
\text { Sep 2014; } 25 \text { Sep 2014; } 18 \text { Oct 2014; } 30 \text { Oct 2014; } 31 \text { Oct } 2014\end{array}$ \\
\hline 7 & Jungnyeom mountain & $\begin{array}{l}4 \text { Apr 2015; } 25 \text { Apr 2015; } 9 \text { May 2015; } 10 \text { May 2015; } 13 \text { May 2015; } 14 \text { May 2015; } 16 \text { May 2015; } 26 \text { May } \\
\text { 2015; } 27 \text { May 2015; } 28 \text { May 2015; } 6 \text { Jun 2015; } 14 \text { Jun 2015; } 15 \text { Jun 2015; } 16 \text { Jun 2015; } 20 \text { Jun 2015; } 23 \text { Jun } \\
\text { 2015; } 24 \text { Jun 2015; } 25 \text { Jun 2015; } 28 \text { Jun 2015; } 15 \text { Jul 2015; } 16 \text { Jul 2015; } 17 \text { Jul 2015; } 18 \text { Jul 2015; } 20 \text { Jul } \\
\text { 2015; } 25 \text { Jul 2015; } 27 \text { Jul 2015; } 2 \text { Aug 2015; } 3 \text { Aug 2015; } 10 \text { Aug 2015; } 12 \text { Aug 2015; } 15 \text { Aug 2015; } 19 \text { Aug } \\
\text { 2015; } 20 \text { Aug 2015; } 22 \text { Aug 2015; } 23 \text { Aug 2015; } 29 \text { Aug 2015; } 2 \text { Sep 2015; } 3 \text { Sep 2015; } 4 \text { Sep 2015; } 16 \text { Sep } \\
\text { 2015; } 17 \text { Sep 2015; } 19 \text { Sep 2015; } 9 \text { Oct 2015 }\end{array}$ \\
\hline 8 & Dumu mountain & $\begin{array}{l}31 \text { Mar 2015; } 27 \text { Apr 2015; } 28 \text { Apr 2015; } 26 \text { May 2015; } 27 \text { May 2015; } 29 \text { Jun 2015; } 30 \text { Jun 2015; } 27 \text { Jul } \\
\text { 2015; } 28 \text { Jul 2015; } 24 \text { Aug 2015; 25Aug 2015; } 21 \text { Sep 2015; } 22 \text { Sep 2015; } 19 \text { Oct 2015; } 20 \text { Oct } 2015\end{array}$ \\
\hline 9 & Baeki mountain & $\begin{array}{l}19 \text { Apr 2016; } 20 \text { Apr 2016; } 12 \text { May 2016; } 13 \text { May 2016; } 30 \text { May 2016; } 31 \text { May 2016; } 1 \text { Jun 2016; } 18 \text { Jul } \\
\text { 2016; } 19 \text { Jul 2016; } 31 \text { Aug 2016; } 1 \text { Sep 2016; } 12 \text { Oct 2016; } 13 \text { Oct 2016 }\end{array}$ \\
\hline 10 & Nambyeong mountain & $\begin{array}{l}9 \text { Apr 2016; } 13 \text { Apr 2016; } 23 \text { Apr 2016; } 24 \text { Apr 2016; } 25 \text { Apr 2016; } 26 \text { Apr 2016; } 27 \text { Apr 2016; } 29 \text { Apr 2016; } \\
\text { 5 May 2016; } 16 \text { May 2016; } 17 \text { May 2016; } 18 \text { May 2016; } 21 \text { May 2016; } 23 \text { May 2016; } 4 \text { Jun 2016; } 18 \text { Jun } \\
\text { 2016; } 26 \text { Jun 2016; } 27 \text { Jun 2016; Jul 2016; } 14 \text { Jul 2016; } 23 \text { Jul 2016; } 24 \text { Jul 2016; } 11 \text { Aug 2016; } 13 \text { Aug } \\
\text { 2016; } 15 \text { Aug 2016; } 3 \text { Sep 2016; } 11 \text { Sep 2016; } 24 \text { Sep 2016; } 15 \text { Oct 2016 }\end{array}$ \\
\hline
\end{tabular}

2018), 외래식물(Kang et al., 2020)을 참조하여 제시하였다. 일부 자료가 부족하거나 최근 보고되어 누락된 종은 논문 과 문헌을 참고하여 추가하였다.

호석회성 식물의 그룹은 Shimizu (1963)와 Chin (1977)이
제시한 기준을 일부 수정하여(Table 3), 우리나라 석회암 지대에서 확인된 호석회성 식물을 3 가지 그룹(지표종, 극 선호종, 선호종)으로 구분하였다. 석회암지대 호석회성 식 물의 선정 기준은 다음과 같다. 첫째, 지표종(calciphilous 
Table 3. Groups of calciphilous plants on limestone areas in Korea.

\begin{tabular}{ll}
\hline \hline \multicolumn{1}{c}{ Groups of calciphious plants } & Criteria \\
\hline Calciphious indicator plants (석회암 지표종) & Plants which occur only on limestone areas in the World \\
Superlative most calciphilous plants (석회암 극선호종) & $\begin{array}{l}\text { Plants restricted to limestone areas in the South Korea, but occur on } \\
\text { non-limestone areas in another country }\end{array}$ \\
Comparative more claciphilous plants (석회암 선호종) & $\begin{array}{l}\text { Plants dominant on limestone, which have a preference for limestone } \\
\text { areas, appearing in both limestone and non-limestone in the South Korea }\end{array}$ \\
\hline
\end{tabular}

indicator plants)은 전 세계적으로 석회암지대에만 분포하 는 분류군과 국내의 석회암지대에만 분포하는 고유식물 (특산식물), 둘째, 극선호종(superlative most calciphilous plants)은 전 세계적인 분포에서는 석회암지대와 비석회 암지대에 분포하지만 국내에서는 석회암지대에만 분포 하는 식물, 셋째, 선호종(comparative more calciphilous plants)은 국내 남부지역(경상누층군) 또는 아고산지대, 풍 혈지 등의 비석회암지대에도 일부 분포하지만 석회암지 대에서 개체수 및 개체군이 더 많은 식물이다. 이상의 기준 들을 바탕으로 현지조사, $\mathrm{KB}$ 표본관에 보관중인 소장표본, 그리고 국립수목원의 분포도(Korea National Arboretum, 2016)를 참조하여 호석회성 식물을 제시하였다.

석회암지대 간 종조성의 유사도 분석은 MVSP (Multi Variate Statistical Package) ver. 3.1. software (Kovach, 2007) 를 활용하였다. 분석 대상지는 자체 조사지역 10 개 지역 (Table 1), 석회암지대 10개 지역(도담삼봉(Chung, 1994), 자병산(Hong and Im, 1997), 덕항산(Kim et al., 2005), 각희 산(Korea Teacher's Plant Research Association, 2011), 응봉 산(Moon et al., 2013), 석문봉(Oh, 2013), 면산·묘봉(Nam et al., 2014), 석병산(Song et al., 2016), 동강(Chae et al., 2019), 대덕산·금대봉(Park et al., 2020)), 인근의 비석회암지대 10 개 지역(공덕산(Chung et al., 2008), 갈라산(Chung et al., 2010), 청태산(Ji et al., 2011), 흥정산(Han et al., 2012), 청량
산(Nam et al., 2015), 백암산(Cheon et al., 2016), 자암산(Kim et al., 2019), 부용봉(National Institute of Biological Resources, 2019b), 무이산(National Institute of Biological Resources, 2020), 구룡산(Sung et al., 2019))이다. UPGMA (Unweighted Pair-Group Method using Arithmetic averages) 방법으로 군 집분석을 수행하였고, Sørensen의 유사도 지수(similarity index)를 기반으로 dendrogram을 작성하였다.

\section{결 과}

\section{관속식물 분포}

한반도 석회암지대에 분포하는 관속식물을 조사 및 종 합한 결과, 133 과 530 속 1,096 종 18 아종 84 변종 2품종 2교 잡종, 총 1,202 분류군으로 구성되었다(Table 4, Appendix 1). 이는 우리나라 관속식물 4,552 분류군의 $26.4 \%$ 에 해당 된다. 종 다양성이 높은 지역은 태화산(773분류군), 남병 산(768분류군), 골지천(731분류군), 고양산(705분류군), 원 풍천(685분류군)의 순으로 나타났으며, 주로 강원권역의 석회암지대가 상위에 포함되었다(Table 4). 석회암지대에 서 확인된 관속식물의 분포는 지형, 토양 및 지질의 특성 이 잘 반영돼 있다. 특히 바위종덩굴(Clematis calcicola J. S. Kim) (Fig. 2C), 동강할미꽃(Pulsatilla tongkangensis Y. N. Lee \& T. C. Lee) (Fig. 2D), 긴털댕강나무(Zabelia densipila

Table 4. The number of vascular palnts investigated on limestone areas in Korea.

\begin{tabular}{|c|c|c|c|c|c|c|c|c|}
\hline Limestones & Fam. & Gen. & Sp. & Ssp. & Var. & For. & Hybr. & Total \\
\hline Taehwa mountain & 125 & 412 & 702 & 15 & 54 & 2 & - & 773 \\
\hline Osip stream & 114 & 353 & 538 & 9 & 41 & 1 & - & 589 \\
\hline Goyang mountain & 109 & 379 & 647 & 12 & 46 & - & - & 705 \\
\hline Samtae mountain & 100 & 250 & 327 & 7 & 33 & - & 1 & 368 \\
\hline Golji stream & 116 & 390 & 665 & 12 & 53 & 1 & - & 731 \\
\hline Wonpung stream & 119 & 378 & 622 & 11 & 51 & 1 & - & 685 \\
\hline Jungnyeom mountain & 108 & 345 & 552 & 10 & 41 & 1 & 1 & 605 \\
\hline Dumu mountain & 102 & 300 & 435 & 8 & 38 & 1 & - & 482 \\
\hline Baeki mountain & 107 & 337 & 522 & 13 & 46 & 1 & - & 582 \\
\hline Nambyeong mountain & 119 & 409 & 687 & 14 & 65 & 1 & 1 & 768 \\
\hline Total & 133 & 530 & 1,096 & 18 & 84 & 2 & 2 & 1,202 \\
\hline
\end{tabular}



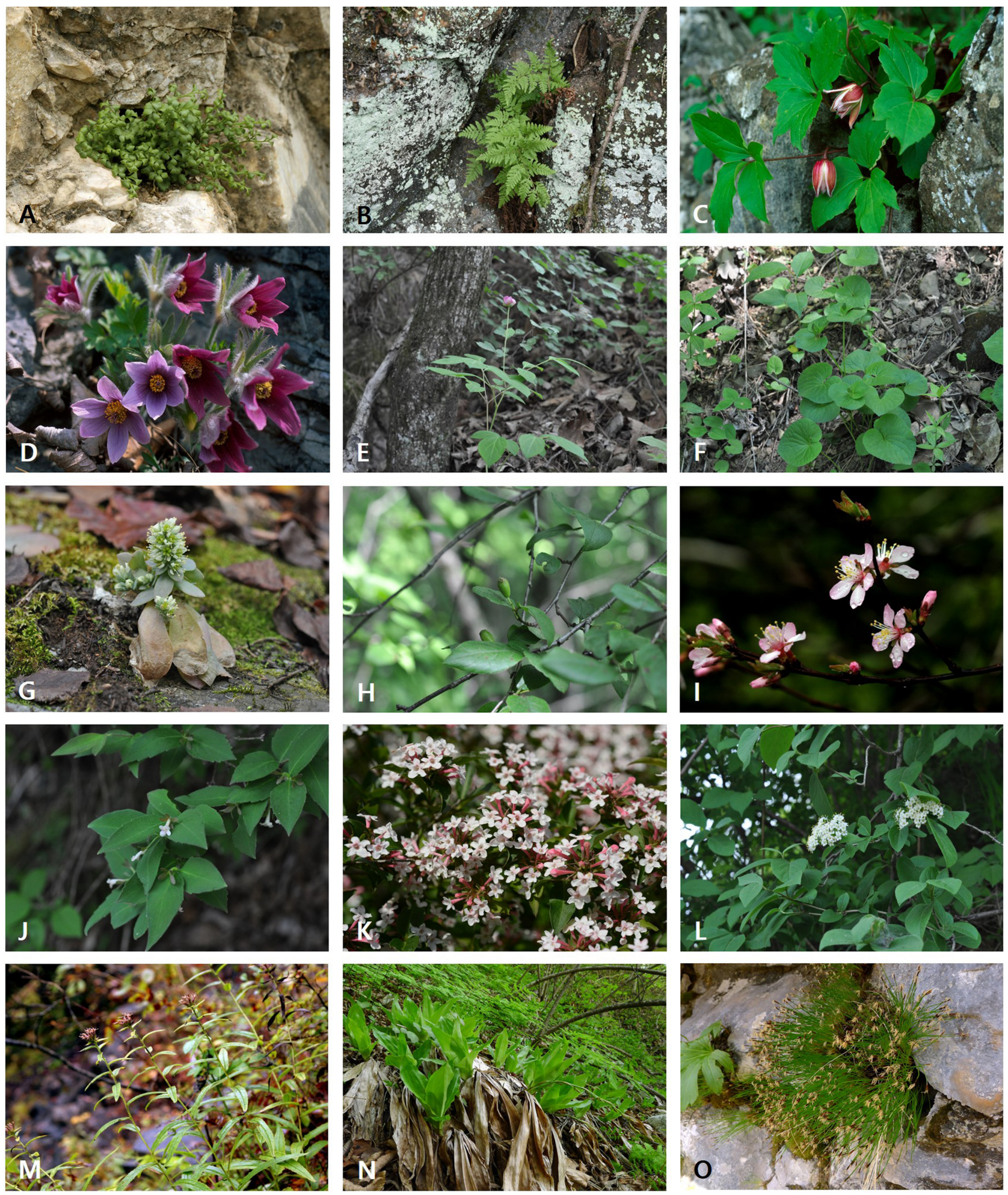

Fig. 2. The photograph of calciphilous plants in Korea. A. Asplenium tura-muraria L. B. Hypodematium glanduloso-pilosum (Tagawa) Ohwi. C. Clematis calcicola J. S. Kim. D. Pulsatilla tongkangensis Y. N. Lee \& T. C. Lee. E. Paeonia obovata Maxim. F. Viola mirabilis L. G. Orostachys chongsunensis Y. N. Lee. H. Cotoneaster integrrimus Medik. I. Prunus choreiana Nakai ex H. T. Im. J. Zabelia densipila M. P. Hong, Y. C. Kim \& B. Y. Lee. K. Zabelia tyaihyonii (Nakai) Hisauti \& H. Hara. L. Viburnum burejaeticum Regel \& Herd. M. Saussurea chabyoungsanica H. T. Im. N. Carex splendentissima U. Kang \& J. M. Chung. O. Trichophorum polygamum D. C. Son \& K. S. Chang. 
M. P. Hong, Y. C. Kim \& B. Y. Lee) (Fig. 2J), 반들대사초(Carex splendentissima U. Kang \& J. M. Chung) (Fig. $2 \mathrm{~N}$ ), 동강고랭이 (Trichophorum polygamum D. C. Son \& K. S. Chang) (Fig. 2O) 등 고유식물이 석회암이라는 특수한 환경에서 새로운 종 분화가 일어난 것, 가래고사리(Phegopteris connectilis (Michx.) Watt), 산겨릅나무(Acer tegmentosum Maxim.), 산가 막살나무(Viburnum wrightii Miq.), 개쑥부쟁이(Aster meyendorffii (Regel \& Maack) Voss) 등 북방계 고산식물이 저지대에 분포 하는 것, 소사나무(Carpinus turczaninowii Hance), 병아리꽃나 무(Rhodotypos scandens (Thunb.) Makino), 등대풀(Euphorbia helioscopia L.), 반디지치(Lithospermum zollingeri A. DC.) 등 해안성 식물이 본 지역에 격리 분포하는 것이 석회암지대 의 식물분포학적인 특징이다(Kim et al., 2005; Korea National Arboretum, 2012; Nam et al., 2012).

\section{한반도 고유식물}

한반도 고유식물은 총 55 분류군(Table 5)으로 무늬족도 리풀(Asarum chungbuensis (C. S. Yook \& J. G. Kim) B. U. $\mathrm{Oh}$ ), 홀아비바람꽃(Anemone koraiensis Nakai), 연잎꾱의다리 (Thalictrum coreanum H. Lév.), 덕우기름나물(Sillaphyton podagraria (H. Boissieu) Pimenov), 한국앉은부채(Symplocarpus koreanus J. S. Lee, S. H. Kim \& S. C. Kim), 한라사초(Carex erythrobasis H. Lév. \& Vaniot), 푸른마(Dioscorea coreana (Prain \& Burkill) R. Knuth) 등이며, 한반도 고유식물 360분 류군의 $15 \%$ 에 해당된다. 이 가운데 바위종덩굴, 동강할미 꽃, 방울제비꽃(Viola breviflora J. Lee \& M. Kim), 정선바위 솔(Orostachys chongsunensis Y. N. Lee) (Fig. 2G), 복사앵도 (Prunus choreiana Nakai ex H. T. Im) (Fig. 2I), 긴털댕강나 무, 줄댕강나무(Zabelia tyaihyonii (Nakai) Hisauti \& H. Hara)

Table 5. The list of the endemic plants investigated on limestone areas in Korea.

\begin{tabular}{|c|c|}
\hline Family & Taxa \\
\hline Aristolochiaceae & Asarum chungbuensis (C. S. Yook \& J. G. Kim) B. U. Oh 무늬족도리풀 \\
\hline Aristolochiaceae & Asarum koreanum J. Kim \& C. Yook ex B. U. Oh 자주족도리풀 \\
\hline Ranunculaceae & Aconitum pseudolaeve Nakai 진범 \\
\hline Ranunculaceae & Anemone koraiensis Nakai 홀아비바람꽃 \\
\hline Ranunculaceae & Cimicifuga heracleifolia var. bifida Nakai 세잎승마 \\
\hline Ranunculaceae & Clematis brachyura Maxim. 외대으아리 \\
\hline Ranunculaceae & Clematis calcicola J. S. Kim 바위종덩굴 \\
\hline Ranunculaceae & Clematis fusca var. flabellata (Nakai) J. S. Kim 요강나물 \\
\hline Ranunculaceae & Clematis trichotoma Nakai 할미밀 망 \\
\hline Ranunculaceae & Pulsatilla tongkangensis Y. N. Lee \& T. C. Lee 동강할미꽃 \\
\hline Ranunculaceae & Thalictrum coreanum H. Lév. 연잎뀡의다리 \\
\hline Berberidaceae & Berberis koreana Palib. 매자나무 \\
\hline Fumariaceae & Corydalis grandicalyx B. U. Oh \& Y. S. Kim 갈퀴현호색 \\
\hline Fumariaceae & Corydalis hirtipes B. U. Oh \& J. G. Kim 털현호색 \\
\hline Fumariaceae & Corydalis maculata B. U. Oh \& Y. S. Kim 점현호색 \\
\hline Fumariaceae & Corydalis ohii Lidén 선현호색 \\
\hline Caryophyllaceae & Pseudostellaria setulosa Ohwi 숲개별꽃 \\
\hline Polygonaceae & Aconogonon microcarpum (Kitag.) H. Hara 참개싱아 \\
\hline Violaceae & Viola breviflora J. Lee \& M. Kim 방울제비꽃 \\
\hline Violaceae & Viola seoulensis Nakai 서울제비꽃 \\
\hline Salicaceae & Salix koriyanagi Kimura ex Goerz 키버들 \\
\hline Primulaceae & Lysimachia coreana Nakai 참좁쌀풀 \\
\hline Crassulaceae & Orostachys chongsunensis Y. N. Lee 정선바위솔 \\
\hline Crassulaceae & Sedum latiovalifolium Y. N. Lee 태백기린초 \\
\hline Saxifragaceae & Chrysosplenium barbatum Nakai 흰털 괭이눈 \\
\hline Rosaceae & Potentilla squamosa Soják 털양지꽃 \\
\hline Rosaceae & Prunus choreiana Nakai ex H. T. Im 복사앵도 \\
\hline Fabaceae & Vicia chosenensis Ohwi 노랑갈퀴 \\
\hline Apiaceae & Angelica reflexa B. Y. Lee 강활 \\
\hline Apiaceae & Sillaphyton podagraria (H. Boissieu) Pimenov 덕우기름나물 \\
\hline Lamiaceae & Ajuga spectabilis Nakai 자란초 \\
\hline Lamiaceae & Salvia chanryoenica Nakai 참배암차즈기 \\
\hline Oleaceae & Forsythia ovata Nakai 만리화 \\
\hline Oleaceae & Forsythia saxatilis (Nakai) Nakai 산개나리 \\
\hline Scrophulariaceae & Melampyrum setaceum var. nakaianum (Tuyama) T. Yamaz. 새며느리밥풀 \\
\hline Linnaeaceae & Zabelia tyaihyonii (Nakai) Hisauti \& H. Hara 줄댕 강나무 \\
\hline Linnaeaceae & Zabelia densipila M. P. Hong, Y. C. Kim \& B. Y. Lee 긴털댕강나무 \\
\hline Diervillaceae & Weigela subsessilis (Nakai) L. H. Bailey 병꽃나무 \\
\hline Caprifoliaceae & Lonicera subsessilis Rehder 청괴불나무 \\
\hline
\end{tabular}


Table 5. Continued.

\begin{tabular}{|c|c|}
\hline Family & Taxa \\
\hline Asteraceae & Cirsium setidens (Dunn) Nakai 고려엉겅퀴 \\
\hline Asteraceae & Dendranthema jeongseonensis M. Kim \& H. Jo 정선국화 \\
\hline Asteraceae & Leontopodium coreanum Nakai 솜다리 \\
\hline Asteraceae & Saussurea calcicola Nakai 사창분취 \\
\hline Asteraceae & Saussurea chabyoungsanica H. T. Im 자병취 \\
\hline Asteraceae & Saussurea eriophylla Nakai 솜분취 \\
\hline Asteraceae & Saussurea macrolepis (Nakai) Kitam. 각시서덜취 \\
\hline Araceae & Symplocarpus koreanus J. S. Lee, S. H. Kim \& S. C. Kim 한국앉은부채 \\
\hline Cyperaceae & Carex erythrobasis H. Lév. \& Vaniot 한라사초 \\
\hline Cyperaceae & Carex splendentissima U. Kang \& J. M. Chung 반들대사초 \\
\hline Cyperaceae & Trichophorum polygamum D. C. Son \& K. S. Chang 동강고랭이 \\
\hline Liliaceae & Heloniopsis koreana S. Fuse, N. S. Lee \& M. N. Tamura 처녀치마 \\
\hline Liliaceae & Hemerocallis hakuunensis Nakai 백 운산원추리 \\
\hline Liliaceae & Hosta minor (Baker) Nakai 좀비비추 \\
\hline Iridaceae & Iris odaesanensis Y. N. Lee 노랑무늬붓꽃 \\
\hline Dioscoreaceae & Dioscorea coreana (Prain \& Burkill) R. Knuth 푸른마 \\
\hline
\end{tabular}

(Fig. 2K), 정선국화(Dendranthema jeongseonensis M. Kim \& H. Jo), 자병취(Saussurea chabyoungsanica H. T. Im) (Fig. $2 \mathrm{M})$, 반들대사초, 동강고랭이 11 분류군은 우리나라의 석 회암지대에서만 관찰되는 지표식물이다. 이들의 공통된 특징은 석회암의 노두가 노출된 바위틈이나 그 주변 언저 리에 분포하는 점으로 미루어 석회암이라는 특수한 생육 환경에 적응 진화하여 발생한 것으로 판단된다.

외대으아리(Clematis brachyura Maxim.), 서울제비꽃 (Viola seoulensis Nakai), 키버들(Salix koriyanagi Kimura ex Goerz) 3분류군은 모든 조사지역에 분포하고 할미밀망 (Clematis trichotoma Nakai), 노랑갈퀴(Vicia chosenensis Ohwi), 청괴불나무(Lonicera subsessilis Rehder), 백운산원 추리(Hemerocallis hakuunensis Nakai) 4분류군은 9개 지역 에서 확인되었으며, 이들은 분포역이 넓고 개체수 및 개 체군도 많은 편이다. 반면에 무늬족도리풀, 자주족도리풀 (Asarum koreanum J. Kim \& C. Yook ex B. U. Oh), 바위종 덩굴, 요강나물(Clematis fusca var. flabellata (Nakai) J. S. $\mathrm{Kim}$ ), 연잎뀡의다리, 매자나무(Berberis koreana Palib), 방 울제비꽃, 강활(Angelica reflexa $\mathrm{B}$. Y. Lee), 자란초(Ajuga spectabilis Nakai), 솜다리(Leontopodium coreanum Nakai), 솜분취(Saussurea eriophylla Nakai), 한국앉은부채 등의 9 분류군은 1 개 지역에서만 분포가 확인되었으며, 이들은 분포역이 좁고 개체수 및 개체군도 적은 편이다(Korea National Arboretum, 2016).

\section{멸종위기 I급 및 적색목록}

멸종위기 II급에 해당하는 식물은 백부자(Aconitum coreanum (H. Lév.) Rapaics), 연잎뀡의다리, 분홍장구채 (Silene capitata Kom.), 산작약(Paeonia obovata Maxim.) (Fig. 2E), 넓은잎제비꽃(Viola mirabilis L.) (Fig. 2F), 왕제비 꽃(Viola websteri Hemsl.), 개병풍(Astilboides tabularis (Hemsl.) Engl.), 큰바늘꽃(Epilobium hirsutum L.), 가시오갈
피나무(Eleutherococcus senticosus (Rupr. \& Maxim.) Maxim.), 대성쓴풀(Anagallidium dichotomum (L.) Griseb.), 산분꽃나 무(Viburnum burejaeticum Regel \& Herd.) (Fig. 2L), 대흥란 (Cymbidium macrorhizon Lindl.), 복주머니란(Cypripedium macranthos Sw.), 구름병아리난초(Neottianthe cucullata (L.) Schltr.) 등 14 분류군이 확인되었다(Table 6). 또한 석회암지 대에서 생육이 확인된 관속식물 가운데 멸종우려 범주 (threatened categories)에 속하는 위급(critically endangered, $\mathrm{CR}$ ), 위기(endangered, EN), 취약(vulnerable, $\mathrm{VU}$ )으로 평가 된 분류군은 암공작고사리(Adiantum capillus-junonis Rupr.), 애기가물고사리(Woodsia hancockii Baker), 산국수나무 (Physocarpus amurensis (Maxim.) Maxim.), 나도여로(Zigadenus sibiricus (L.) A. Gray) 등 총 18분류군이다(Table 6, Appendix 1). 한편 준위협(near threatened, NT)은 향나무(Juniperus chinensis L.), 꽃꿩의다리(Thalictrum petaloideum L.), 좁은 잎덩굴용담(Pterygocalyx volubilis Maxim.), 검은도루박이 (Scirpus orientalis Ohwi) 등 20분류군이다(Table 6, Appendix 1).

지역적색목록 평가는 IUCN의 세계적색목록 기준에 따 라 예비범주를 획득한 뒤 지역 개체군의 상대적인 절멸위 험을 판단하기 위해 고유종 여부, 인근 지역 동일 분류군 의 개체군에 미치는 영향 등을 고려하여 예비범주를 상향 또는 하향 조정하여 최종범주를 도출한다. 이러한 평가 기준으로 멸종위기 II에 속하는 대다수의 분류군과 분포 역이 좁은 고유식물들은 적색목록에서도 취약 이상의 멸 종위기 범주에 포함된다. 근래 우리나라에서 신종 발표된 바위종덩굴, 방울제비꽃, 정선바위솔, 긴털댕강나무, 정 선국화, 자병취, 반들대사초, 동강고랭이는 전 세계적으 로 국내의 석회암지대에서만 자라는 고유식물임과 동시 에 지표식물들로 적색목록 범주에 등재되도록 평가할 필 요가 있다. 최근 개정된 적색목록에서 이들을 다루고 있 지 않는 만큼, 추후 예비범주에 포함시켜 더 많은 자생지 
Table 6. The list of the endangered plants (grade II) and red data vascular plants investigated on limestone areas in Korea.

\begin{tabular}{|c|c|c|c|}
\hline Family & Taxa & Grade & Criteria \\
\hline Adiantaceae & Adiantum capillus-junonis Rupr. 암공작고사리 & & EN \\
\hline Woodsiaceae & Woodsia hancockii Baker 애기가물고사리 & & VU \\
\hline Cupressaceae & Juniperus chinensis L. 향나무 & & NT \\
\hline Ranunculaceae & Aconitum barbatum var. hispidum (DC.) Ser. 넓은잎노랑투구꽃 & & NT \\
\hline Ranunculaceae & Aconitum coreanum (H. Lév.) Rapaics 백부자 & II & VU \\
\hline Ranunculaceae & Pulsatilla tongkangensis Y. N. Lee \& T. C. Lee 동강할미꽃 & & VU \\
\hline Ranunculaceae & Thalictrum coreanum H. Lév. 연잎뀡의다리 & II & VU \\
\hline Ranunculaceae & Thalictrum petaloideum L. 꽃뀡의다리 & & NT \\
\hline Berberidaceae & Jeffersonia dubia (Maxim.) Benth. \& Hook. f. ex Baker \& S. Moore 깽깽이풀 & & NT \\
\hline Chenopodiaceae & Chenopodium aristatum L. 바늘명아주 & & NT \\
\hline Caryophyllaceae & Gypsophila pacifica Kom. 가는대나물 & & NT \\
\hline Caryophyllaceae & Silene capitata Kom. 분홍장구채 & II & VU \\
\hline Paeoniaceae & Paeonia lactiflora var. trichocarpa (Bunge) Stern 참작약 & & NT \\
\hline Paeoniaceae & Paeonia obovata Maxim. 산작약 & II & $\mathrm{EN}$ \\
\hline Violaceae & Viola mirabilis L. 넓은잎제비꽃 & II & $\mathrm{EN}$ \\
\hline Violaceae & Viola websteri Hemsl. 왕제비꽃 & II & VU \\
\hline Saxifragaceae & Astilboides tabularis (Hemsl.) Engl. 개병풍 & II & NT \\
\hline Rosaceae & Physocarpus amurensis (Maxim.) Maxim. 산국수나무 & & VU \\
\hline Rosaceae & Prunus choreiana Nakai ex H. T. Im 복사앵도 & & NT \\
\hline Thymelaeaceae & Daphne pseudomezereum var. koreana (Nakai) Hamaya 두메 닥나무 & & NT \\
\hline Thymelaeaceae & Diarthron linifolium Turcz. 아마풀 & & NT \\
\hline Onagraceae & Epilobium hirsutum L. 큰바늘꽃 & II & NT \\
\hline Araliaceae & Eleutherococcus senticosus (Rupr. \& Maxim.) Maxim. 가시오갈피나무 & II & VU \\
\hline Gentianaceae & Anagallidium dichotomum (L.) Griseb. 대성쓴풀 & II & EN \\
\hline Gentianaceae & Pterygocalyx volubilis Maxim. 좁은잎덩굴용담 & & NT \\
\hline Lamiaceae & Dracocephalum rupestre Hance 벌깨풀 & & NT \\
\hline Oleaceae & Forsythia ovata Nakai 만리화 & & \\
\hline Oleaceae & Forsythia saxatilis (Nakai) Nakai 산개나리 & & \\
\hline Linnaeaceae & Zabelia tyaihyonii (Nakai) Hisauti \& H. Hara 줄댕강나무 & & VU \\
\hline Viburnaceae & Viburnum burejaeticum Regel \& Herd. 산분꽃나무 & II & NT \\
\hline Potamogetonaceae & Potamogeton perfoliatus L. 넓은잎말 & & VU \\
\hline Cyperaceae & Scirpus orientalis Ohwi 검은도루박이 & & NT \\
\hline Liliaceae & Zigadenus sibiricus (L.) A. Gray 나도여로 & & $\mathrm{CR}$ \\
\hline Orchidaceae & Cymbidium macrorhizon Lindl. 대흥란 & II & VU \\
\hline Orchidaceae & Cypripedium macranthos Sw. 복주머니란 & II & VU \\
\hline Orchidaceae & Epipactis papillosa Franch. \& Sav. 청닭의난초 & & NT \\
\hline Orchidaceae & Herminium monorchis (L.) R. Br. 나도씨눈란 & & NT \\
\hline Orchidaceae & Neottianthe cucullata (L.) Schltr. 구름병아리난초 & II & $\mathrm{EN}$ \\
\hline Orchidaceae & Platanthera japonica (Thunb.) Lindl. 갈매기란 & & NT \\
\hline Orchidaceae & Pogonia minor (Makino) Makino 방울새란 & & NT \\
\hline
\end{tabular}

및 개체군 조사를 통해 범주를 평가하고 적용할 필요가 있다.

\section{식물구계학적 특정식물}

국내에서 일부 지역에만 제한적으로 분포하는 특성으 로 식물지리학적 가치가 높게 평가되는 식물구계학적 특 정식물 $\mathrm{IV}$ 등급과 $\mathrm{V}$ 등급은 총 102 분류군이 조사되었다 (Table 7, Appendix 1). V등급은 백부자, 동강할미꽃, 분홍 장구채, 왕제비꽃, 큰바늘꽃 등 27 분류군이며, IV등급은 돌좀고사리(Asplenium ruta-muraria L.) (Fig. 2A), 개버무리 (Clematis serratifolia Rehder), 몽고뽕나무(Morus mongolica (Bureau) C. K. Schneid), 꼬리진달래(Rhododendron micranthum Turcz.), 층실사초(Carex remotiuscula Wahlenb.), 나도씨눈
란(Herminium monorchis (L.) R. Br) 등 75분류군이다. 그 외 III등급은 개부처손(Selaginella stauntoniana Spring), 주저 리고사리(Dryopteris fragrans (L.) Schott), 만주바람꽃 (Isopyrum manshuricum Kom.), 돌뽕나무(Morus tiliaefolia Makino) 등 101분류군, II등급은 고비고사리(Coniogramme intermedia Hieron.), 퍼진고사리(Dryopteris expansa (C. Presl) Fraser-Jenk. \& Jermy), 등칡(Aristolochia manshuriensis Kom.), 채고추나물(Hypericum attenuatum Fisch. ex Choisy), 가지더부살이(Phacellanthus tubiflorus Siebold \& Zucc.) 등 84분류군, I등급은 금족제비고사리(Dryopteris gymnophylla (Baker) C. Chr.), 개비자나무(Cephalotaxus harringtonia (Knight ex Forbes) K. Koch), 터리풀(Filipendula glaberrima Nakai), 뻐꾹나리(Tricyrtis macropoda Miq.), 범부채(Iris domestica 
Table 7. The list of the floristic target plants (grade IV-V) investigated on limestone areas in Korea.

\begin{tabular}{|c|c|c|}
\hline Family & Taxa & Grade \\
\hline Aspleniaceae & Asplenium pekinense Hance 사철고사리 & IV \\
\hline Aspleniaceae & Asplenium ruta-muraria $\mathrm{L}$. 돌좀고사리 & IV \\
\hline Woodsiaceae & Woodsia macrochlaena Mett. ex Kuhn 참우드풀 & IV \\
\hline Dryopteridaceae & Dryopteris goeringiana (Kunze) Koidz. 바위틈고사리 & IV \\
\hline Cupressaceae & Platycladus orientalis (L.) Franco 측백나무 & IV \\
\hline Ranunculaceae & Aconitum coreanum (H. Lév.) Rapaics 백부자 & $\mathrm{V}$ \\
\hline Ranunculaceae & Anemone koraiensis Nakai 홀아비바람꽃 & IV \\
\hline Ranunculaceae & Anemone reflexa Stephan 회리바람꽃 & IV \\
\hline Ranunculaceae & Cimicifuga heracleifolia var. bifida Nakai 세잎승마 & IV \\
\hline Ranunculaceae & Clematis calcicola J. S. Kim 바위종덩굴 & IV \\
\hline Ranunculaceae & Clematis serratifolia Rehder 개버무리 & IV \\
\hline Ranunculaceae & Delphinium maackianum Regel 큰제비고깔 & IV \\
\hline Ranunculaceae & Pulsatilla tongkangensis Y. N. Lee \& T. C. Lee 동강할미꽃 & $\mathrm{V}$ \\
\hline Ranunculaceae & Thalictrum coreanum H. Lév. 연 잎뀡의다리 & $\mathrm{V}$ \\
\hline Ranunculaceae & Thalictrum ichangense Lecoy. ex Oliv. 꼭지연잎뀡의다리 & IV \\
\hline Ranunculaceae & Thalictrum petaloideum $\mathrm{L}$. 꽃뀡의다리 & IV \\
\hline Berberidaceae & Berberis koreana Palib. 매자나무 & IV \\
\hline Berberidaceae & Jeffersonia dubia (Maxim.) Benth. \& Hook. f. ex Baker \& S. Moore 깽깽이풀 & IV \\
\hline Ulmaceae & Ulmus macrocarpa Hance 왕느릅나무 & IV \\
\hline Ulmaceae & Ulmus pumila L. 비술나무 & IV \\
\hline Moraceae & Morus mongolica (Bureau) C. K. Schneid 몽고뽕나무 & IV \\
\hline Urticaceae & Girardinia diversifolia subsp. suborbiculata (C. J. Chen) C. J. Chen \& Friis 큰쐐기풀 & IV \\
\hline Phytolaccaceae & Phytolacca acinosa Roxb. 자리공 & IV \\
\hline Chenopodiaceae & Chenopodium aristatum L. 바늘명아주 & IV \\
\hline Caryophyllaceae & Moehringia lateriflora (L.) Fenzl 개벼룩 & IV \\
\hline Caryophyllaceae & Pseudostellaria setulosa Ohwi 숲개별꽃 & IV \\
\hline Caryophyllaceae & Silene capitata Kom. 분홍장구채 & $\mathrm{V}$ \\
\hline Polygonaceae & Aconogonon microcarpum (Kitag.) H. Hara 참개싱아 & IV \\
\hline Paeoniaceae & Paeonia lactiflora var. trichocarpa (Bunge) Stern 참작약 & IV \\
\hline Paeoniaceae & Paeonia obovata Maxim. 산작약 & $\mathrm{V}$ \\
\hline Violaceae & Viola mirabilis L. 넓은잎제비꽃 & $\mathrm{V}$ \\
\hline Violaceae & Viola websteri Hemsl. 왕제비꽃 & $\mathrm{V}$ \\
\hline Cucurbitaceae & Schizopepon bryoniifolius Maxim. 산외 & IV \\
\hline Ericaceae & Rhododendron micranthum Turcz. 꼬리진 달래 & IV \\
\hline Monotropaceae & Monotropa hypopitys L. 구상난풀 & $\mathrm{V}$ \\
\hline Primulaceae & Lysimachia coreana Nakai 참좁쌀풀 & IV \\
\hline Crassulaceae & Sedum latiovalifolium Y. N. Lee 태백기린초 & IV \\
\hline Saxifragaceae & Astilboides tabularis (Hemsl.) Engl. 개병풍 & $\mathrm{V}$ \\
\hline Saxifragaceae & Chrysosplenium ramosum Maxim. 가지괭이눈 & IV \\
\hline Saxifragaceae & Rodgersia podophylla A. Gray 도깨비부채 & IV \\
\hline Rosaceae & Cotoneaster integerrimus Medik. 개야광나무 & $\mathrm{V}$ \\
\hline Rosaceae & Prunus choreiana Nakai ex H. T. Im 복사앵도 & IV \\
\hline Rosaceae & Prunus sibirica L. 시베리아살구나무 & IV \\
\hline Rosaceae & Rosa davurica Pall. 생 열 귀나무 & IV \\
\hline Rosaceae & Rosa spinosissima L. 둥근인가목 & IV \\
\hline Rosaceae & Spiraea trichocarpa Nakai 갈기조팝나무 & IV \\
\hline Rosaceae & Waldsteinia ternata (Stephan) Fritsch 나도양지꽃 & IV \\
\hline Fabaceae & Caragana fruticosa (Pall.) Besser 참골담초 & IV \\
\hline Fabaceae & Vicia bungei Ohwi 들완두 & IV \\
\hline Thymelaeaceae & Daphne pseudomezereum var. koreana (Nakai) Hamaya 두메 닥나무 & IV \\
\hline Thymelaeaceae & Diarthron linifolium Turcz. 아마풀 & $\mathrm{V}$ \\
\hline Onagraceae & Epilobium hirsutum L. 큰바늘꽃 & $\mathrm{V}$ \\
\hline Rhamnaceae & Rhamnus parvifolia Bunge 돌갈매나무 & IV \\
\hline Linaceae & Linum stelleroides Planch. 개아마 & IV \\
\hline Polygalaceae & Polygala sibirica L. 두메애기풀 & IV \\
\hline Polygalaceae & Polygala tatarinowii Regel 병아리풀 & IV \\
\hline Aceraceae & Acer tegmentosum Maxim. 산겨릅나무 & IV \\
\hline Araliaceae & Eleutherococcus divaricatus (Siebold \& Zucc.) S. Y. Hu 개가시오갈피나무 & $\mathrm{V}$ \\
\hline
\end{tabular}


Table 7. Continued.

\begin{tabular}{|c|c|c|}
\hline Family & Taxa & Grade \\
\hline Araliaceae & Eleutherococcus senticosus (Rupr. \& Maxim.) Maxim. 가시오갈피나무 & $\mathrm{V}$ \\
\hline Araliaceae & Panax ginseng C. A. Mey. 인삼 & $\mathrm{V}$ \\
\hline Apiaceae & Aegopodium alpestre Ledeb. 왜방풍 & IV \\
\hline Apiaceae & Libanotis seseloides (Fisch. \& C. A. Mey. ex Turcz.) Turcz. 가는잎방풍 & IV \\
\hline Apiaceae & Sillaphyton podagraria (H. Boissieu) Pimenov 덕우기름나물 & IV \\
\hline Gentianaceae & Anagallidium dichotomum (L.) Griseb. 대성쓴풀 & $\mathrm{V}$ \\
\hline Gentianaceae & Pterygocalyx volubilis Maxim. 좁은잎덩굴용담 & $\mathrm{V}$ \\
\hline Lamiaceae & Dracocephalum rupestre Hance 벌깨풀 & $\mathrm{V}$ \\
\hline Lamiaceae & Salvia chanryoenica Nakai 참배암차즈기 & IV \\
\hline Oleaceae & Forsythia ovata Nakai 만리화 & $\mathrm{V}$ \\
\hline Oleaceae & Forsythia saxatilis (Nakai) Nakai 산개나리 & IV \\
\hline Oleaceae & Syringa fauriei H. Lév. 버들개회나무 & IV \\
\hline Oleaceae & Syringa wolfii C. K. Schneid. 꽃개회나무 & IV \\
\hline Rubiaceae & Galium boreale L. 긴잎갈퀴 & IV \\
\hline Linnaeaceae & Zabelia tyaihyonii (Nakai) Hisauti \& H. Hara 줄댕강나무 & $\mathrm{V}$ \\
\hline Caprifoliaceae & Lonicera tatarinowii Maxilm. 흰괴불나무 & IV \\
\hline Viburnaceae & Viburnum burejaeticum Regel \& Herd. 산분꽃나무 & $\mathrm{V}$ \\
\hline Valerianaceae & Patrinia rupestris (Pall.) Juss. 돌마타리 & IV \\
\hline Asteraceae & Artemisia sieversiana Ehrh. ex Willd. 산흰쑥 & IV \\
\hline Asteraceae & Leontopodium coreanum Nakai 솜다리 & $\mathrm{V}$ \\
\hline Asteraceae & Saussurea calcicola Nakai 사창분취 & IV \\
\hline Asteraceae & Saussurea chabyoungsanica H. T. Im 자병취 & IV \\
\hline Asteraceae & Tephroseris phaeantha (Nakai) C. Jeffrey \& Y. L. Chen 바위솜나물 & $\mathrm{V}$ \\
\hline Cyperaceae & Carex longirostrata var. pallida (Kitag.) Ohwi 실피사초 & IV \\
\hline Cyperaceae & Carex remotiuscula Wahlenb. 층실사초 & IV \\
\hline Cyperaceae & Carex stipata Muhl. ex Willd. 양덕사초 & IV \\
\hline Cyperaceae & Scirpus orientalis Ohwi 검은도루박이 & IV \\
\hline Cyperaceae & Trichophorum polygamum D. C. Son \& K. S. Chang 동강고랭이 & IV \\
\hline Poaceae & Festuca japonica Makino 산묵새 & IV \\
\hline Poaceae & Festuca rubra L. 왕김의털 & IV \\
\hline Poaceae & Poa nemoralis L. 선포아풀 & IV \\
\hline Liliaceae & Hemerocallis middendorffii Trautv. \& C. A. Mey. 큰원추리 & IV \\
\hline Liliaceae & Lilium cernuum Kom. 솔나리 & IV \\
\hline Liliaceae & Lilium leichtlinii var. maximowiczii (Regel) Baker 중나리 & IV \\
\hline Liliaceae & Polygonatum stenophyllum Maxim. 층층둥굴레 & IV \\
\hline Liliaceae & Trillium camschatcense Ker Gawl. 연영초 & IV \\
\hline Liliaceae & Veratrum maackii var. parviflorum (Maxim. ex Miq.) H. Hara 파란여로 & IV \\
\hline Liliaceae & Zigadenus sibiricus (L.) A. Gray 나도여로 & $\mathrm{V}$ \\
\hline Iridaceae & Iris odaesanensis Y. N. Lee 노랑무늬붓꽃 & IV \\
\hline Orchidaceae & Cymbidium macrorhizon Lindl. 대흥란 & $\mathrm{V}$ \\
\hline Orchidaceae & Cypripedium macranthos $\mathrm{Sw}$. 복주머니란 & $\mathrm{V}$ \\
\hline Orchidaceae & Epipactis papillosa Franch. \& Sav. 청닭의난초 & IV \\
\hline Orchidaceae & Herminium monorchis (L.) R. Br. 나도씨눈란 & IV \\
\hline Orchidaceae & Neottianthe cucullata (L.) Schltr. 구름병아리난초 & $\mathrm{V}$ \\
\hline
\end{tabular}

(L.) Goldblatt \& Mabb.) 등 72분류군이다(Appendix 1). 결과 적으로 식물구계적학적 특성식물은 총 359 분류군으로 한 반도 전체 특정식물 1,476 분류군의 $24.3 \%$, 석회암지대 전 체 출현식물 1,202 분류군의 $29.9 \%$ 에 해당하는 높은 수치 로 나타남에 따라 우리나라 석회암지대가 한반도 식물상 을 구성하는 식물지리학적 주요지역 가운데 하나로 확인 되었다.

백부자는 강원도 및 경상북도에 걸쳐 석회암지대 산지 에 집중적으로 분포하고 경기도 및 충청북도 일부 지역에
도 출현한다. 전 세계적으로 북한, 중국, 러시아 등지에 분 포한다. 강원도 석회암지대에서는 비교적 많은 개체가 확 인되지만 다른 지역에서는 매우 드물다. 영월군 태화산, 제천시 두무산 2 개 산지의 능선부에서 10 여 개체가 산발 적으로 생육하고 있다. 약용이나 상업을 목적으로 한 무 분별한 채취로 인해 개체가 급감한 것으로 추정된다. 동 강할미꽃은 전 세계적으로 강원도와 충청북도 석회암지 대에만 제한적으로 분포하는 한반도 고유식물이며, 현재 까지 확인된 자생지는 10 여 개 지역에 불과하다 $(\mathrm{Oh}$ et al., 
2014). 삼척시 오십천, 정선군 덕산기계곡의 석회암지대 바위틈에서 소수 개체가 확인되었다. 관상 및 상업을 목 적으로 한 무분별한 채취와 자생지 교란이 개체 감소로 어이지고 있다. 연잎뀡의다리는 강원도 깊은 솦 속에 불 연속적으로 분포하는 한반도 고유식물이며, 자생지 및 개 체수도 극히 드물다. 기존에 알려진 자생지 외의 범위에 서 확인된 출현정보는 꼭지연잎뀡의다리와 혼동되었을 가능성이 많다. 평창군 대덕사의 바위틈 또는 근처의 양 지바른 풀밭에서 10 여 개체가 확인되었다. 나도씨눈란은 강원도 및 경상도 일대 고산지대의 숲 속이나 나무그늘에 서 자란다. 정선군 반론산, 제천시 두무산 2 개 지역에서 10 여 개체가 산발적으로 생육하고 있다. 주분포역과 떨어진 제천시 두무산(해발고도 $400 \mathrm{~m}$ )에서 발견된 것은 수직분 포적 측면에서도 특이하다.

그 외 국내에서는 드물게 분포하는 바위종덩굴, 꽃뀡의 다리, 바늘명아주(Chenopodium aristatum L.), 참작약(Paeonia lactiflora var. trichocarpa (Bunge) Stern), 개병풍, 개야광나 무(Cotoneaster integerrimus Medik.) (Fig. 2H), 둥근인가목 (Rosa spinosissima L.), 대성쓴풀, 벌깨풀(Dracocephalum rupestre Hance), 바위솜나물(Tephroseris phaeantha (Nakai) C. Jeffrey \& Y. L. Chen), 구름병아리난초 등이 석회암지대 에서 생육하고 있다.

\section{외래식물}

석회암지대에서 확인된 외래식물은 애기수영(Rumex acetosella L.), 가시박(Sicyos angulatus L.), 돼지풀(Ambrosia artemisiifolia L.), 단풍잎돼지풀(Ambrosia trifida L.) 등을 포 함하여 총 121 분류군이 확인되었으며(Table 8, Appendix $1)$, 한반도 전체 외래식물 619 분류군의 $19.5 \%$, 석회암지대 전체 출현식물 1,202 분류군의 $10.1 \%$ 에 해당하였다. 말냉 이(Thlaspi arvense L.), 아까시나무(Robinia pseudoacacia L.), 달맞이꽃(Oenothera biennis L.), 미국쑥부쟁이(Aster pilosus Willd.), 지느러미엉겅퀴(Carduus crispus L.), 개망초(Erigeron annuus (L.) Pers.), 서양민들레(Taraxacum officinale F. H. Wigg.)는 10 개 지역에서 모두 관찰되었으며, 명아주 (Chenopodium album L.), 긴털비름(Amaranthus hybridus L.), 수박풀(Hibiscus trionum L.), 복사나무(Prunus persica (L.) Batsch.), 족제비싸리(Amorpha fruticosa L.), 흰전동싸리 (Melilotus albus Medik.), 전동싸리(Melilotus suaveolens Ledeb.), 큰땅빈대(Euphorbia hypericifolia L.), 망초(Conyza canadensis (L.) Cronquist), 개싹갓(Senecio vulgaris L.), 털빕 새귀리(Bromus tectorum L.), 오리새(Dactylis glomerata L.), 구주개밀(Elymus repens (L.) Gould), 큰김의털(Festuca arundinacea Schreb.), 왕포아풀(Poa pratensis L.)은 9개 지 역에서 확인되었다. 반면에 털비름(Amaranthus retroflexus L.), 털여뀌(Persicaria orientalis (L.) Spach), 들다닥냉이 (Lepidium campestre (L.) R. Br.), 길다닥냉이(Lepidium densiflorum Schrad.), 가새잎개갓냉이(Rorippa sylvestris (L.)
Table 8. The list of the alien plants investigated on limestone areas in Korea.

\begin{tabular}{|c|c|}
\hline Family & Taxa \\
\hline Moraceae & Morus alba L. 뽕나무 \\
\hline Phytolaccaceae & Phytolacca acinosa Roxb. 자리공 \\
\hline Phytolaccaceae & Phytolacca americana L. 미국자리공 \\
\hline Chenopodiaceae & Chenopodium album L. 명아주 \\
\hline Chenopodiaceae & Chenopodium ficifolium $\mathrm{Sm}$. 좀명아주 \\
\hline Amaranthaceae & Amaranthus hybridus L. 긴털비름 \\
\hline Amaranthaceae & Amaranthus lividus L. 개비름 \\
\hline Amaranthaceae & Amaranthus retroflexus L. 털비름 \\
\hline Caryophyllaceae & Cerastium glomeratum Thuill. 유럽점나도나물 \\
\hline Caryophyllaceae & Silene alba (Mill.) E. H. L. Krause 달맞이장구채 \\
\hline Caryophyllaceae & Silene armeria L. 끈근이대나물 \\
\hline Caryophyllaceae & Stellaria media (L.) Vill. 별꽃 \\
\hline Polygonaceae & Persicaria orientalis (L.) Spach 털여뀌 \\
\hline Polygonaceae & Rumex acetosella L. 애기수영 \\
\hline Polygonaceae & Rumex crispus L. 소리쟁이 \\
\hline Polygonaceae & Rumex obtusifolius L. 돌소리쟁이 \\
\hline Polygonaceae & Rumex patientia L. 부령소리쟁이 \\
\hline Malvaceae & Abutilon theophrasti Medik. 어저귀 \\
\hline Malvaceae & Hibiscus trionum L. 수박풀 \\
\hline Cucurbitaceae & Sicyos angulatus L. 가시박 \\
\hline Brassicaceae & Barbarea vulgaris R. Br. 유럽나도냉이 \\
\hline Brassicaceae & Descurainia sophia (L.) Webb ex Prantl 재쑥 \\
\hline Brassicaceae & Lepidium campestre (L.) R. Br. 들다닥냉이 \\
\hline Brassicaceae & Lepidium densiflorum Schrad. 길다닥냉이 \\
\hline Brassicaceae & Lepidium virginicum L. 콩다닥냉이 \\
\hline Brassicaceae & Nasturtium officinale W. T. Aiton 물냉이 \\
\hline Brassicaceae & Rorippa sylvestris (L.) Besser 가새잎개갓냉이 \\
\hline Brassicaceae & Thlaspi arvense L. 말냉이 \\
\hline Rosaceae & Potentilla supina L. 개소시랑개비 \\
\hline Rosaceae & Prunus persica (L.) Batsch. 복사나무 \\
\hline Rosaceae & Prunus tomentosa Thunb. 앵도나무 \\
\hline Fabaceae & Amorpha fruticosa L. 족제비싸리 \\
\hline Fabaceae & Astragalus sinicus L. 자운영 \\
\hline Fabaceae & Indigofera bungeana Walp. 큰낭아초 \\
\hline Fabaceae & $\begin{array}{l}\text { Lespedeza lichiyuniae T. Nemoto, H. Ohashi \& T. } \\
\text { Itoh 자주비수리 }\end{array}$ \\
\hline Fabaceae & Lotus corniculatus L. 서양벌노랑이 \\
\hline Fabaceae & Medicago lupulina L. 잔개자리 \\
\hline Fabaceae & Medicago polymorpha L. 개자리 \\
\hline Fabaceae & Medicago sativa L. 자주개자리 \\
\hline Fabaceae & Melilotus albus Medik. 흰전동싸리 \\
\hline Fabaceae & Melilotus suaveolens Ledeb. 전동싸리 \\
\hline Fabaceae & Robinia pseudoacacia L. 아까시나무 \\
\hline Fabaceae & Trifolium pratense L. 붉은토끼풀 \\
\hline Fabaceae & Trifolium repens L. 토끼풀 \\
\hline Fabaceae & Vicia villosa Roth 벳지 \\
\hline Onagraceae & Oenothera biennis L. 달맞이꽃 \\
\hline Euphorbiaceae & Euphorbia hypericifolia L. 큰땅빈대 \\
\hline Euphorbiaceae & Euphorbia maculata L. 애기땅빈대 \\
\hline Simaroubaceae & Ailanthus altissima (Mill.) Swingle 가중나무 \\
\hline Oxalidaceae & Oxalis dillenii Jacq. 들괭이밥 \\
\hline Solanaceae & Datura stramonium L. 독말풀 \\
\hline Solanaceae & Nicandra physalodes (L.) Gaertn. 페루꽈리 \\
\hline Solanaceae & Physalis angulata $\mathrm{L}$. 땅꽈리 \\
\hline Solanaceae & Solanum americanum Mill. 미국까마중 \\
\hline Convolvulaceae & Cuscuta campestris Yunck. 미국실새삼 \\
\hline Convolvulaceae & Ipomoea hederacea Jacq. 미국나팔꽃 \\
\hline
\end{tabular}


Table 8. Continued.

\begin{tabular}{|c|c|}
\hline Family & Taxa \\
\hline Convolvulaceae & Ipomoea lacunosa L. 애기나팔꽃 \\
\hline Convolvulaceae & Ipomoea purpurea (L.) Roth 둥근잎나팔꽃 \\
\hline Convolvulaceae & Ipomoea rubriflora O'Donell 둥근잎유홍초 \\
\hline Boraginaceae & Symphytum officinale L. 컴프리 \\
\hline Plantaginaceae & Plantago lanceolata L. 창질경이 \\
\hline Scrophulariaceae & Lindernia dubia (L.) Pennell 미국외풀 \\
\hline Scrophulariaceae & $\begin{array}{l}\text { Paulownia tomentosa (Thunb.) Steud. 참오동 } \\
\text { 나무 }\end{array}$ \\
\hline Scrophulariaceae & Verbascum thapsus L. 우단담배풀 \\
\hline Scrophulariaceae & Veronica anagallis-aquatica L. 큰물칭개나물 \\
\hline Scrophulariaceae & Veronica arvensis L. 선개불알풀 \\
\hline Scrophulariaceae & Veronica peregrina L. 문모초 \\
\hline Scrophulariaceae & Veronica persica Poir. 큰개불알풀 \\
\hline Asteraceae & Achillea millefolium L. 서양톱풀 \\
\hline Asteraceae & Ambrosia artemisiifolia L. 돼지풀 \\
\hline Asteraceae & Ambrosia trifida L. 단풍잎돼지풀 \\
\hline Asteraceae & Aster pilosus Willd. 미국쑥부쟁이 \\
\hline Asteraceae & Aster subulatus Michx. 비짜루국화 \\
\hline Asteraceae & Bidens frondosa L. 미국가막사리 \\
\hline Asteraceae & Bidens pilosa L. 울산도깨비바늘 \\
\hline Asteraceae & Carduus crispus L. 지느러미엉겅퀴 \\
\hline Asteraceae & Conyza canadensis (L.) Cronquist 망초 \\
\hline Asteraceae & Coreopsis lanceolata L. 큰금계국 \\
\hline Asteraceae & Coreopsis tinctoria Nutt. 기생초 \\
\hline Asteraceae & $\begin{array}{l}\text { Erechtites hieracifolia (L.) Raf. ex DC. 붉은서 } \\
\text { 나물 }\end{array}$ \\
\hline Asteraceae & Erigeron annuus (L.) Pers. 개망초 \\
\hline Asteraceae & Erigeron philadelphicus L. 봄망초 \\
\hline Asteraceae & Galinsoga parviflora Cav. 별꽃아재비 \\
\hline Asteraceae & $\begin{array}{l}\text { Galinsoga quadriradiata Ruiz \& Pav. 털별꽃아 } \\
\text { 재비 }\end{array}$ \\
\hline Asteraceae & Helianthus tuberosus L. 뚱딴지 \\
\hline Asteraceae & Lactuca scariola L. 가시상추 \\
\hline Asteraceae & Leucanthemum vulgare Lam. 불란서국화 \\
\hline Asteraceae & $\begin{array}{l}\text { Matricaria matricarioides (Less.) Porter ex } \\
\text { Britton 족제비쑥 }\end{array}$ \\
\hline Asteraceae & Senecio vulgaris L. 개쑥갓 \\
\hline Asteraceae & Sonchus asper (L.) Hill 큰방가지똥 \\
\hline Asteraceae & Sonchus oleraceus L. 방가지똥 \\
\hline Asteraceae & Tagetes minuta L. 만수국아재비 \\
\hline Asteraceae & $\begin{array}{l}\text { Taraxacum laevigatum (Willd.) DC. 붉은씨서 } \\
\text { 양민들레 }\end{array}$ \\
\hline Asteraceae & Taraxacum officinale F. H. Wigg. 서양민들레 \\
\hline Asteraceae & Tragopogon dubis Scop. 쇠채아재비 \\
\hline Asteraceae & $\begin{array}{l}\text { Verbesina alternifolia (L.) Britton ex Kearney 나 } \\
\text { 래가막사리 }\end{array}$ \\
\hline Asteraceae & Xanthium orientale L. 큰도꼬마리 \\
\hline Asteraceae & Xanthium strumarium L. 도꼬마리 \\
\hline Poaceae & Agrostis gigantea Roth 흰겨이삭 \\
\hline Poaceae & Alopecurus aequalis Sobol. 뚝새풀 \\
\hline Poaceae & Alopecurus japonicus Steud. 털뚝새풀 \\
\hline Poaceae & Alopecurus pratensis L. 큰뚝새풀 \\
\hline Poaceae & Bromus catharticus Vahl 큰이삭풀 \\
\hline Poaceae & Bromus inermis Leyss. 좀참새귀리 \\
\hline Poaceae & Bromus mollis L. 털참새귀리 \\
\hline Poaceae & Bromus rigidus Roth 긴까락빕새귀리 \\
\hline Poaceae & Bromus sterilis L. 까락빕새귀리 \\
\hline Poaceae & Bromus tectorum L. 털빕새귀리 \\
\hline
\end{tabular}

Table 8. Continued.

\begin{tabular}{ll}
\hline \hline \multicolumn{1}{c}{ Family } & \multicolumn{1}{c}{ Taxa } \\
\hline Poaceae & Chloris virgata Sw. 나도바랭이 \\
Poaceae & Dactylis glomerata L. 오리새 \\
Poaceae & Elymus repens (L.) Gould 구주개밀 \\
Poaceae & Eragrostis curvula (Schrad.) Nees 능수참새그령 \\
Poaceae & Festuca arundinacea Schreb. 큰김의털 \\
Poaceae & Festuca heterophylla Lam. 사방김의털 \\
Poaceae & Lolium multiflorum Lam. 쥐보리 \\
Poaceae & Lolium perenne L. 호밀풀 \\
Poaceae & Panicum dichotomiflorum Michx. 미국개기장 \\
Poaceae & Phleum pratense L. 큰조아재비 \\
Poaceae & Poa pratensis L. 왕포아풀 \\
Poaceae & Vulpia myuros (L.) C. C. Gmel. 들묵새 \\
Liliaceae & Allium tuberosum Rottler ex Spreng. 부추 \\
\hline
\end{tabular}

Besser), 자운영(Astragalus sinicus L.), 자주비수리(Lespedeza lichiyuniae T. Nemoto, H. Ohashi \& T. Itoh), 개자리 (Medicago polymorpha L.), 벳지(Vicia villosa Roth), 독말풀 (Datura stramonium L.), 페루꽈리(Nicandra physalodes (L.) Gaertn.), 땅꽈리(Physalis angulata L.), 미국외풀(Lindernia dubia (L.) Pennell), 우단담배풀(Verbascum thapsus L.), 문모 초(Veronica peregrina L.), 서양톱풀(Achillea millefolium L.), 단풍잎돼지풀, 봄망초(Erigeron philadelphicus L.), 족제비쑥 (Matricaria matricarioides (Less.) Porter ex Britton), 쇠채아재 비(Tragopogon dubis Scop.), 털뚝새풀(Alopecurus japonicus Steud.), 큰이삭풀(Bromus catharticus Vahl), 좀참새귀리 (Bromus inermis Leyss.), 털참새귀리(Bromus mollis L.), 긴 까락빕새귀리(Bromus rigidus Roth), 나도바랭이(Chloris virgata Sw.), 능수참새그령(Eragrostis curvula (Schrad.) Nees), 들묵새(Vulpia myuros (L.) C. C. Gmel.)는 1개 지역에 서만 조사되었다. 외래식물들은 주로 비의도적으로 유입 되고 교란된 지역에서 발생되며, 대부분 자생종의 생육지 파괴, 생태계 교란 및 생물다양성 감소 등 부정적인 영향 을 미친다(Kang et al., 2020). 석회암지대에서도 도로 주변, 하천변과 인접한 숲 가장자리, 고랭지밭 경작지 부근의 교란된 지역에서 출현빈도가 높게 나타났으며, 일부 광역 분포종은 산지 숲에서도 관찰되었다.

\section{호석회성 식물}

석회암지대에 분포하는 식물들의 분포 특성을 분석하 여 호석회성 식물을 지표종, 극선호종, 선호종으로 구분 하였다. 석회암지대 지표종은 전 세계적으로 석회암지대 에만 분포하는 분류군과 국내의 석회암지대에만 분포하 는 한반도 고유식물이 포함된다(Table 9). 지표종의 범주 에는 돌좀고사리, 바위종덩굴, 동강할미꽃, 줄댕강나무, 자병취, 반들대사초 등 14 분류군이 속한다. 극선호종은 전 세계적인 분포에서는 석회암지대와 비석회암지대에 분포하지만 국내에서는 석회암지대에서만 분포하는 식 물이 포함된다(Table 10). 극선호종의 범주에는 개부처손, 
Table 9. The list of the calciphilous indicator plants investigated on limestone areas in Korea.

\begin{tabular}{ll}
\hline \hline \multicolumn{1}{c}{ Family } & \multicolumn{1}{c}{ Taxa } \\
\hline Aspleniaceae & Asplenium tura-muraria L. 돌좀고사리 \\
Hypodematiaceae & Hypodematium glanduloso-pilosum (Tagawa) Ohwi 금털고사리 \\
Hypodematiaceae & Hypodematium squamuloso-pilosum Ching 흰금털고사리 \\
Ranunculaceae & Clematis calcicola J. S. Kim 바위종덩굴 \\
Ranunculaceae & Pulsatilla tongkangensis Y. N. Lee \& T. C. Lee 동강할미꽃 \\
Violaceae & Viola breviflora J. Lee \& M. Kim 방울제비꽃 \\
Crassulaceae & Orostachys chongsunensis Y. N. Lee 정선바위솔 \\
Rosaceae & Prunus choreiana Nakai ex H. T. Im 복사앵도 \\
Linnaeaceae & Zabelia densipila M. P. Hong, Y. C. Kim \& B. Y. Lee 긴털댕강나무 \\
Linnaeaceae & Zabelia tyaihyonii (Nakai) Hisauti \& H. Hara 줄댕강나무 \\
Asteraceae & Dendranthema jeongseonensis M. Kim \& H. Jo 정선국화 \\
Asteraceae & Saussurea chabyoungsanica H. T. Im 자병취 \\
Cyperaceae & Carex splendentissima U. Kang \& J. M. Chung 반들대사초 \\
Cyperaceae & Trichophorum polygamum D. C. Son \& K. S. Chang 동강고랭이 \\
\hline
\end{tabular}

Table 10. The list of the superlative most calciphilous plants investigated on limestone areas in Korea.

\begin{tabular}{|c|c|}
\hline Family & Taxa \\
\hline Selaginellaceae & Selaginella stauntoniana Spring 개부처손 \\
\hline Adiantaceae & Adiantum capillus-junonis Rupr. 암공작고사리 \\
\hline Athyriaceae & Gymnocarpium jessoense (Koidz.) Koidz. 산토끼고사리 \\
\hline Woodsiaceae & Woodsia hancockii Baker 애기가물고사리 \\
\hline Ranunculaceae & Aconitum barbatum var. hispidum (DC.) Ser. 넓은잎노랑투구꽃 \\
\hline Ranunculaceae & Clematis brevicaudata DC. 좀사위질 빵 \\
\hline Moraceae & Morus mongolica (Bureau) C. K. Schneid. 몽고뽕나무 \\
\hline Urticaceae & Pilea oligantha Nakai 강계큰물통이 \\
\hline Chenopodicaceae & Chenopodium aristatum L. 바늘명아주 \\
\hline Caryophyllaceae & Gypsophila pacifica Kom. 가는대나물 \\
\hline Caryophyllaceae & Minuartia verna var. leptophylla (Rchb.) Nakai 삼수개미자리 \\
\hline Violaceae & Viola mirabilis L. 넓은잎제비꽃 \\
\hline Rosaceae & Cotoneaster integrrimus Medik. 개야광나무 \\
\hline Rosaceae & Potentilla rugulosa Kitag. 당양지꽃 \\
\hline Rosaceae & Rosa spinosissima L. 둥근인가목 \\
\hline Rosaceae & Physocarpus amurensis (Maxim.) Maxim. 산국수나무 \\
\hline Fabaceae & Astragalus penduliflorus var. dahuricus (DC.) X. Y. Zhu 황기 \\
\hline Fabaceae & Caragana fruticose (Pall.) Besser 참골담초 \\
\hline Euphorbiaceae & Euphorbia fischeriana Steud. 낭독 \\
\hline Rhamnaceae & Rhamnus parvifolia Bunge 돌갈매나무 \\
\hline Polygalaceae & Polygala sibirica L. 두메애기풀 \\
\hline Apiaceae & Angelica czernaevia (Fisch. \& C. A. Mey.) Kitag. 잔잎바디 \\
\hline Apiaceae & Libanotis seseloides (Fisch. \& C. A. Mey. ex Turcz.) Turcz. 가는잎방풍 \\
\hline Gentianaceae & Anagallidium dichotomum (L.) Griseb. 대성쓴풀 \\
\hline Lamiaceae & Dracocephalum rupestre Hance 벌깨풀 \\
\hline Rubiaceae & Galium kinuta Nakai \& H. Hara 민둥갈퀴 \\
\hline Asteraceae & Saussurea mongolica (Franch.) Franch. 북분취 \\
\hline Cyperaceae & Carex ussuriensis Kom. 싸래기사초 \\
\hline Haemodoraceae & Anemarrhena asphodeloides Bunge 지모 \\
\hline Liliaceae & Zigadenus sibiricus (L.) A. Gray 나도여로 \\
\hline
\end{tabular}

산토끼고사리(Gymnocarpium jessoense (Koidz.) Koidz.), 넓 은잎노랑투구꽃(Aconitum barbatum var. hispidum (DC.) Ser.), 개야광나무, 낭독, 가는잎방풍(Libanotis seseloides (Fisch. \& C. A. Mey. ex Turcz.) Turcz.) 등 30분류군이 속한 다. 선호종은 국내 남부지역(경상누층군) 또는 아고산지대 및 풍혈지 등의 비석회암지대에도 일부 분포하지만 석회 암지대에서 개체수 및 개체군이 더 많은 식물이 포함된다
(Table 11). 선호종의 범주에는 왜구실사리(Selaginella helvetica (L.) Link), 바위틈고사리(Dryopteris goeringiana (Kunze) Koidz.), 강화황기(Astragalus sikokianus Nakai), 덕우 기름나물, 만리화(Forsythia ovata Nakai), 사창분취 (Saussurea calcicola Nakai), 장군대사초(Carex poculisquama Kük.) 등 58 분류군이 속한다. 이상의 기준들을 통하여 호 석회성 식물은 총 102 분류군이며, 석회암지대 전체 출현 
Table 11. The list of the comparative more calciphilous plants investigated on limestone areas in Korea.

\begin{tabular}{|c|c|}
\hline Family & Taxa \\
\hline Selaginellaceae & Selaginella helvetica (L.) Link 왜구실사리 \\
\hline Ophioglossaceae & Botrychium strictum Underw. 긴꽃고사리삼 \\
\hline Aspleniaceae & $\begin{array}{l}\text { Asplenium varians Wall. ex Hook. \& Grev. 애기 } \\
\text { 꼬리고사리 }\end{array}$ \\
\hline Dryopteridaceae & $\begin{array}{l}\text { Dryopteris goeringiana (Kunze) Koidz. 바위틈 } \\
\text { 고사리 }\end{array}$ \\
\hline Dryopteridaceae & $\begin{array}{l}\text { Polystichum craspedosorum (Maxim.) Diels 낚 } \\
\text { 시고사리 }\end{array}$ \\
\hline Cupressaceae & Platycladus orientalis (L.) Franco 측백나무 \\
\hline Ranunculaceae & Aconitum coreanum (H. Lév.) Rapaics 백부자 \\
\hline Ranunculaceae & $\begin{array}{l}\text { Cimicifuga heracleifolia var. bifida Nakai 세잎 } \\
\text { 승마 }\end{array}$ \\
\hline Ranunculaceae & Thalictrum coreanum H. Lév. 연잎꿩의다리 \\
\hline Ranunculaceae & $\begin{array}{l}\text { Thalictrum ichangense Lecoy. ex Oliv. 꼭지연 잎 } \\
\text { 꿩의다리 }\end{array}$ \\
\hline Ranunculaceae & Thalictrum petaloideum L. 꽃꿩의다리 \\
\hline Ulmaceae & Ulmus macrocarpa Hance 왕느릅나무 \\
\hline Celtidaceae & Celtis koraiensis Nakai 왕팽나무 \\
\hline Urticaceae & Parietaria micrantha Ledeb. 개물통이 \\
\hline Paeoniaceae & Paeonia lactiflora var. trichocarpa (Bunge) \\
\hline Paeoniaceae & Stern 참작약 \\
\hline Crassulaceae & Paeonia obovata Maxim. 산작약 \\
\hline Saxifragaceae & Sedum latiovalifolium Y. N. Lee 태백기린초 \\
\hline Rosaceae & Astilboides tabularis (Hemsl.) Engl. 개병풍 \\
\hline Rosaceae & Exochorda serratifolia S. Moore 가침박달 \\
\hline Rosaceae & Neillia uyekii Nakai 나도국수나무 \\
\hline Rosaceae & Spiraea chinensis Maxim. 당조팝나무 \\
\hline Fabaceae & Spiraea trichocarpa Nakai 갈기조팝나무 \\
\hline Fabaceae & Astragalus sikokianus Nakai 강화황기 \\
\hline Fabaceae & Lathyrus vaniotii H. Lév. 산새콩 \\
\hline Thymelaeaceae & Vicia bungei Ohwi 들완두 \\
\hline Thymelaeaceae & Daphne pseudomezereum var. koreana (Nakai) \\
\hline Buxaceae & Hamaya 두메 닥나무 \\
\hline Euphorbiaceae & Diarthron linifolium Turcz. 아마풀 \\
\hline Linaceae & $\begin{array}{l}\text { Buxus microphylla var. koreana Nakai ex Rehder } \\
\text { 회양목 }\end{array}$ \\
\hline Polygalaceae & Euphorbia ebracteolata Hayata 붉은대극 \\
\hline Apiaceae & Linum stelleroides Planch. 개아마 \\
\hline Gentianaceae & Polygala tatarinowii Regel 병아리풀 \\
\hline Asclepiadaceae & $\begin{array}{l}\text { Sillaphyton podagraria (H. Boissieu) Pimenov } \\
\text { 덕우기름나물 }\end{array}$ \\
\hline Boraginaceae & Pterygocalyx volubilis Maxim. 좁은잎덩굴용담 \\
\hline Lamiaceae & Cynanchum inamoenum (Maxim.) Loes. 선백미꽃 \\
\hline Lamiaceae & Lithospermum erythrorhizon Siebold \& Zucc. 지치 \\
\hline Oleaceae & Nepeta cataria L. 개박하 \\
\hline Oleaceae & Teucrium veronicoides Maxim. 곽향 \\
\hline Rubiaceae & Forsythia ovata Nakai 만리화 \\
\hline Linnaeaceae & Forsythia saxatilis (Nakai) Nakai 산개나리 \\
\hline Caprifoliaceae & Galium boreale L. 긴잎갈퀴 \\
\hline Viburnaceae & Zabelia biflora (Turcz.) Makino 털댕강나무 \\
\hline Valerianaceae & Lonicera tatarinowii Maxilm. 흰괴불나무 \\
\hline Dipsacaceae & Viburnum burejaeticum Regel \& Herd. 산분꽃나무 \\
\hline Asteraceae & Patrinia rupestris (Pall.) Juss. 돌마타리 \\
\hline Asteraceae & Dipsacus japonicus Miq. 산토끼꽃 \\
\hline Asteraceae & Aster maackii Regel 좀개미취 \\
\hline Asteraceae & $\begin{array}{l}\text { Aster meyendorffii (Regel \& Maack) Voss 개쑥 } \\
\text { 부쟁이 }\end{array}$ \\
\hline
\end{tabular}

Table 11. Continued.

\begin{tabular}{|c|c|}
\hline Family & Taxa \\
\hline Asteraceae & Saussurea calcicola Nakai 사창분취 \\
\hline Asteraceae & $\begin{array}{l}\text { Saussurea odontolepis Sch. Bip. ex Herder 빗살 } \\
\text { 서덜취 }\end{array}$ \\
\hline Asteraceae & $\begin{array}{l}\text { Tephroseris phaeantha (Nakai) C. Jeffrey \& Y. } \\
\text { L. Chen 바위솜나물 }\end{array}$ \\
\hline Cyperaceae & $\begin{array}{l}\text { Carex longirostrata var. pallida (Kitag.) Ohwi 실 } \\
\text { 피사초 }\end{array}$ \\
\hline Cyperaceae & Carex poculisquama Kük. 장군대사초 \\
\hline Cyperaceae & Carex remotiuscula Wahlenb. 층실사초 \\
\hline Liliaceae & $\begin{array}{l}\text { Hemerocallis middendorffii Trautv. \& C. A. } \\
\text { Mey. 큰원추리 }\end{array}$ \\
\hline Liliaceae & Veratrum nigrum L. 참여로 \\
\hline Orchidaceae & Epipactis papillosa Franch. \& Sav. 청 닭의난초 \\
\hline Orchidaceae & Herminium monorchis (L.) R. Br. 나도씨눈란 \\
\hline Orchidaceae & Neottianthe cucullata (L.) Schltr. 구름병아리난초 \\
\hline
\end{tabular}

식물의 $8.5 \%$ 에 해당되었다. 기존 Korea National Arboretum (2012)에서 제시한 호석회성 식물 목록 109분류군과 비교 하여, 돌좀고사리, 금털고사리(Hypodematium glandulosopilosum (Tagawa) Ohwi) (Fig. 2B), 동강할미꽃, 동강고랭이, 삼수개미자리(Minuartia verna var. leptophylla (Rchb.) Nakai), 나도여로 등 58 분류군은 공통적으로 적용한 종들이다. 이 와 별개로 문헌(Korea National Arboretum, 2012)에서 제시한 51 분류군, 그리고 본 연구에서 제시한 44 분류군을 서로 다 르게 적용시켜 총 95 분류군이 차이나는 것으로 나타났다. 문헌의 목록에서는 부싯깃고사리(Cheilanthes argentea (S. G. Gmel.) Kunze), 거미고사리(Asplenium ruprechtii Sa. Kurata), 노간주나무(Juniperus rigida Siebold \& Zucc.), 굴참 나무(Quercus variabilis Blume), 화살나무(Euonymus alatus (Thunb.) Siebold), 회목나무(Euonymus pauciflorus Maxim.), 부추(Allium tuberosum Rottler ex Spreng.), 방울비짜루 (Asparagus oligoclonos Maxim.), 청가시덩굴(Smilax sieboldii $\mathrm{Miq}$ ) 등 전국적으로 분포하는 식물들이 포함되어 이들을 제 외시켰다. 본 연구에서 제시한 흰금털고사리(Hypodematium squamuloso-pilosum Ching), 방울제비꽃, 긴털댕강나무, 정 선국화, 반들대사초는 문헌 발표 이후, 최근 석회암지대에 서 보고된 신종 또는 미기록종들이며, 좀사위질빵(Clematis brevicaudata DC.), 몽고뽕나무, 개야광나무, 둥근인가목, 낭 독, 가는잎방풍, 지모(Anemarrhena asphodeloides Bunge), 개 물통이(Parietaria micrantha Ledeb.), 장군대사초 등은 비교 적 최근에 국내 분포가 확인된 분류군(National Institute of Biological Resources, 2017)으로써 이들을 목록에 포함시켜 처리한 결과에서 차이가 나는 것으로 판단된다.

\section{유사도}

본 연구에서 조사한 석회암지대 10 개 지역 간 종조성의 유사도를 분석한 결과(Fig. 3), 3번 지역(고양산)과 5번 지 역(골지천)의 유사도가 $77.6 \%$ 로 가장 높게 나타났다(node 


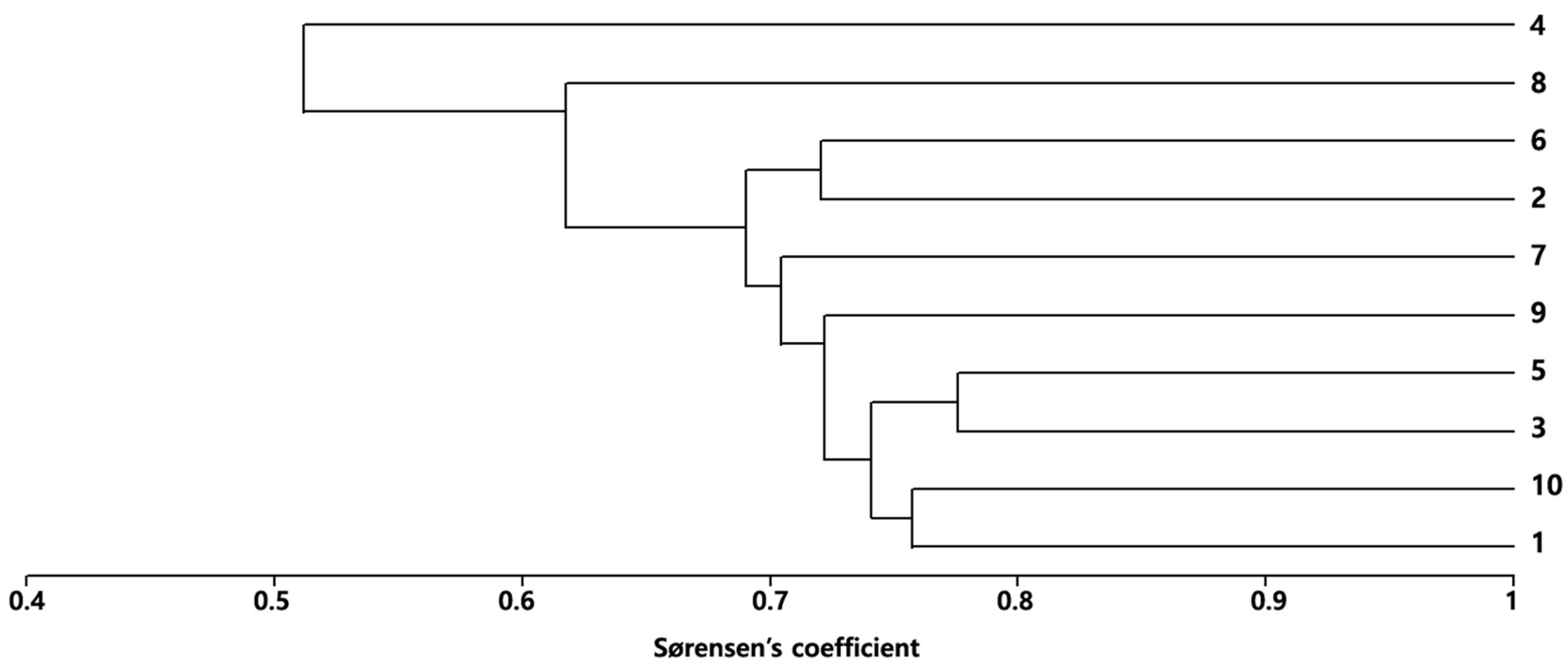

Fig. 3. UPGMA (Unweighted Pair-Group Method using Arithmetic averages) dendrogram of plant species composition on the 10 survey sites of limestone areas in Korea based on Sørensen's similarity index. 1, Taehwa mountain; 2, Osip stream; 3, Goyang mountain; 4, Samtae mountain; 5, Golji stream; 6, Wonpung stream; 7, Jungnyeom mountain; 8, Dumu mountain; 9, Baeki mountain; 10, Nambyeong mountain.

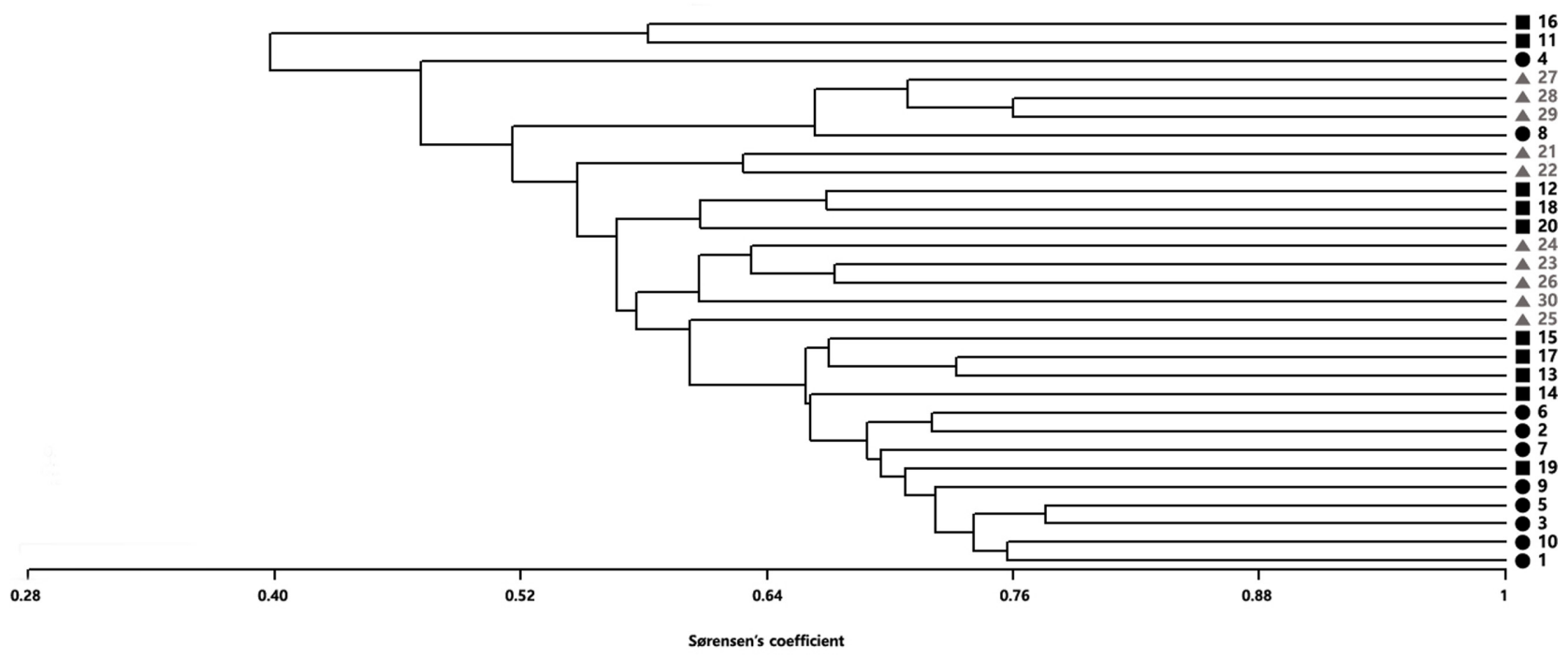

Fig. 4. UPGMA (Unweighted Pair-Group Method using Arithmetic averages) dendrogram of plant species composition on limestone areas including our survey sites (black circle, 1-10) and literature sites (black square, 11-20), and non-limestone areas (grey triangle, 21-30) in Korea based on Sørensen's similarity index. 1, Taehwa mountain; 2, Osip stream; 3, Goyang mountain; 4, Samtae mountain; 5, Golji stream; 6, Wonpung stream; 7, Jungnyeom mountain; 8, Dumu mountain; 9, Baeki mountain; 10, Nambyeong mountain; 11, Todam Sambong; 12, Chabyong mountain; 13, Deokhang mountain; 14, Gakhui mountain; 15, Eungbong mountain; 16, Seokmunbong; 17, Myeon mountain-Myobong; 18, Seokbyeong mountain; 19, Donggang; 20, Daedeok mountain Geumdaebong; 21, Gongdeok mountain; 22, Galla mountain; 23, Cheongtae mountain; 24, Heungjeong mountain; 25, Cheongnyang mountain; 26, Baegam mountain; 27, Jaam mountain; 28, Buyongbong; 29, Mui mountain; 30, Guryong mountain.

1). 1 번 지역(태화산)과 10 번 지역(남병산)은 $75.7 \%$ (node 2), node 1 과 node 2 는 $74.1 \%$ (node 3 ), node 3 과 9 번 지역(백 이산)은 $72.2 \%$ 로 그 뒤를 이었다. 2 번 지역(오십천)과 6 번 지역(원풍천)의 종조성은 $72.1 \%$ 유사한 것으로 나타났다.

자체 조사지역 외 문헌을 통해 수집한 석회암지대(11-
20번 지역)와 비석회암지대(21-30번 지역)의 종목록을 통 합하여 유사도 분석을 수행한 결과(Fig. 4), 석회암지대인 3 번 지역(고양산)과 5번 지역(골지천)의 유사도가 $77.6 \%$ (node 1), 비석회암지대인 28번 지역(부용산)과 29번 지 역(무이산)이 $76.0 \%$ (node 2)로 유사도가 높게 나타났다. 1 
번 지역(태화산)과 10 번 지역(남병산)이 $75.7 \%$ (node 3), node 1 과 node 3 가 $74.1 \%$ (node 4), 13번 지역(덕항산)과 17 번 지역(면산.묘봉)이 $73.2 \%$, node 4 와 9번 지역(백이산)이 $72.2 \%$ (node 6)로 그 뒤를 이어 석회암지대 내 지역끼리 높 은 유사도를 보여주었다. 27번 지역(자암산)은 비석회암 지대 그룹인 node 2 와 $70.9 \%$ 유사한 것으로 나타나 주요 node들은 석회암지대와 비석회암지대의 지역들을 다른 군집으로 구분하였다.

\section{고 찰}

본 연구의 조사결과, 한반도 석회암지대에서 확인된 관 속식물은 133 과 530 속 1,096 종 18 아종 84 변종 2품종 2교잡 종, 총 1,202 분류군이 확인되었다. 무늬족도리풀, 홀아비 바람꽃, 덕우기름나물, 한국앉은부채, 푸른마 등 한반도 고유식물이 55 분류군이고, 백부자, 연잎뀡의다리, 넓은잎 제비꽃, 개병풍, 큰바늘꽃 등 멸종위기 II급 및 적색목록 멸종우려에 해당되는 식물이 40 분류군이다. 분홍장구채, 왕제비꽃, 개병풍, 좁은잎덩굴용담, 바위솜나물, 꽃꿩의 다리, 참작약, 가는잎방풍, 검은도루박이 등 식물지리학 적 주요종으로 평가되는 식물구계학적 특정식물 $\mathrm{IV}-\mathrm{V}$ 등 급 식물이 102 분류군이다. 외래식물은 생태계 교란식물 인 애기수영, 가시박, 돼지풀, 단풍잎돼지풀 등을 포함하 여 121 분류군이 확인되었다. 호석회성 식물 범주에 포함 되는 지표종 가운데 바위종덩굴, 동강할미꽃, 복사앵도, 긴 털댕강나무, 자병취, 반들대사초 등 11 분류군은 전 세계적 으로 우리나라 석회암지대에서만 관찰되는 희귀식물이다. 또한 개부처손, 암공작고사리, 좀사위질빵, 개야광나무, 낭독, 나도여로 등 30 분류군은 국내에서 석회암지대에만 관찰되는 극선호종이며, 바위틈고사리, 백부자, 강화황기, 산새콩(Lathyrus vaniotii H. Lév.), 아마풀(Diarthron linifolium Turcz.), 덕우기름나물 등 58분류군은 국내 남부지역(경상 누층군), 아고산지대 및 풍혈지 등의 비석회암지대에도 분포하지만, 석회암지대에서 분포역이 넓은 선호종이다. 특히 지표종과 극선호종에 범주에 속하는 종들은 자생지 가 알려져 있지 않거나 2-3곳에 불과해 분포지 보호 및 모 니터링이 필요한 분류군이다. 석회암지대 내 군집분석은 지리적으로 인접한 지역 간 높은 유사도를 보여주었다 (Fig. 3). 2번 지역(오십천, 강원도 삼척시)과 6번 지역(원풍 천, 충청북도 괴산군)은 지리적 거리에도 불구하고 높은 유사도(72.1\%)로 유집되었다. 지리적 인접성 뿐만 아니라 자생지 특성(산지 또는 하천)이 석회암지대 내에서도 지 역 간 종조성에 영향을 미치는 것으로 나타난 만큼 이러 한 결과는 추후 석회암지대 관리 및 보전전략 수립에 고 려되어야 할 것이다. 지리적으로 인접한 지역이더라도 석 회암지대와 비석회암지대는 서로 다른 군집을 이루는 것 으로 나타났다(Fig. 4). 비석회암지대의 23번(청태산), 24 번(흥정산), 26번(백암산) 지역들은 모두 강원도에 위치하
지만 동일지역의 석회암지대와는 다른 군집을 형성하였 다. 이러한 결과는 석회암지대 식물상의 고유성과 특이성 (Kim et al., 2005; Ryu, 2016)을 보여준다.

한반도 석회암지대의 대부분은 탄산칼슘 성분을 갖는 퇴적암으로 우리나라의 화산암지대, 화강암지대, 변성암 지대와 다른 식생의 분포유형을 가지고 있는 생태적으로 매우 중요한 지역이다(Kim et al., 2005; Korea National Arboretum, 2012). 석회암지대의 식물상적 특징으로 수직 적 분포면에서 주로 아고산대 산지 능선 또는 정상부에 분포하는 가래고사리, 산겨릅나무, 산가막살나무, 개쑥부 쟁이 등의 북방계 고산식물들이 해발고도가 낮은 하천변( 해발고도 200-500 m)에서 생육하고 있다. 또한 정선군 백 이산 능선(해발고도 $900 \mathrm{~m}$ )에서는 둥근인가목, 선백미꽃 (Cynanchum inamoenum (Maxim.) Loes.), 참여로(Veratrum nigrum L.) 등 북방계 식물들의 상층에서 남방계 식물인 소사나무가 생육하는 독특한 식물군락 구조를 보이고 있 다. 수평적 분포면에서도 병아리꽃나무, 등대풀, 반디지 치, 대흥란 등 해안성 또는 남방계 식물이 내륙지역에 격 리 분포한다. 이러한 식물지리학적 분포유형이 석회암지 대의 특성이다(Kim et al., 2005; Korea National Arboretum, 2012; Nam et al., 2012). 또한 석회암지대는 지역 고유성과 특이성이 잘 나타날 뿐만 아니라 희귀식물들의 분포 비율 이 매우 높은 한반도 생태계의 핵심축 가운데 하나이다. 석회암지대는 식물지리학적으로 중요한 지역임에도 불 구하고 일부 지역은 석회석 채굴로 인해 산지 정상부가 소실되어 생태학적 기능이 상실되었으며, 현재에도 채굴 이 진행되고 있어 보존대책과 방안마련이 시급하다.

본 연구에서는 한반도 석회암지대의 식물상적 현황 조 사를 통하여 석회암이라는 특수성을 지닌 식물지리적 가 치를 밝히고 석회암지대의 보전의 중요성과 시급성을 강 조하고자 하였다. 석회암지대의 생물학적인 가치와 함께 경관 보전에 대한 시급성을 인식하여 체계적인 관리방안 이 마련되어야 할 것으로 생각된다.

ORCID: Jung-Hyun KIM https://orcid.org/0000-0003-2699-5635; Gi-Heum NAM https://orcid.org/0000-0002-3497-8870; Seungbae LEE https://orcid.org/0000-0003-3368-2506; Sookyung SHIN https://orcid.org/0000-0002-8076-438X; Jin-Seok KIM https://orcid.org/0000-0002-4474-1244

\section{Acknowledgments}

This work was supported by a grant from the National Institute of Biological Resources (NIBR), funded by the Ministry of Environment (MOE) of the Republic of Korea (NIBR201701109, NIBR202102103) and also supported by a basic research project of the Korea Institute of Geoscience and Mineral Resources (GP2020-008). 


\section{Conflict of Interest}

The authors declare that there are no conflicts of interest.

\section{Literature Cited}

Bates, R. L. and J. A. Jackson. 1987. Glossary of Geology. American Geological Institute, Alexandria, 788 pp.

Blatt, H., G. V. Middleton and R. C. Murray. 1980. Origin of Sedimentary Rocks. 2nd ed. Prentice-Hall, Englewood Cliffs, NJ, $634 \mathrm{pp}$.

Chae, H.-H., Y.-C. Kim, K.-S. Lee, G.-H. Nam, S.-R. Lee, Y.-J. Lee and Y.-K. Lee. 2019. Floristic characteristics of vascular plants in the Dong-gang river basin ecological and scenery conservation area. Korean Journal of Environment and Ecology 33: 131-167. (in Korean)

Cheon, K.-S., K.-A. Kim and K.-O. Yoo. 2016. Floristic study of Mt. Baegam (Hongcheon-gun, Gangwon-do). Korean Journal of Plant Resources 29: 171-188. (in Korean)

Chin, S.-C. 1977. The limestone hill flora of Malaya I. Gardens' Bulletin Singapore 30: 165-219.

Cho, Y. H., J. H. Kim and S. H. Park. 2016. Grasses and Sedges in South Korea. Geobook, Seoul, 527 pp. (in Korean)

Choi, D. K. 1998. The Yongwol group (Cambrian-Ordovician) redefined: A proposal for the stratigraphic nomenclayure of the Choson supergroup. Geosciences Journal 2: 220-234.

Choo, Y.-S. and S.-D. Song. 1998. Ecophysiological characteristcs of plant taxon-specific calcium metabolism. Korean Journal of Ecology 21: 47-63. (in Korean)

Chung, G. Y. 1994. A study on the flora of vascular plants and conservation in Todam Sambong area, limestone region. Bulletin of the Korean Association for Conservation of Nature 13: 99119. (in Korean)

Chung, G. Y., K. S. Chang, J.-M. Chung, H. J. Choi, W.-K. Paik and J.-O. Hyun. 2017. A checklist of endemic plants on the Korean peninsula. Korean Journal of Plant Taxonomy 47: 264-288. (in Korean)

Chung, G. Y., M. S. Park, S. Y. Jung, S. H. Lee, H. N. Choi, B. M. Nam, Y. M. Lee and H. J. Choi. 2008. Distribution of vascular plants in Gongdeoksan (Mungyeong, Gyeongbuk). Korean Journal of Plant Resources 21: 270-280. (in Korean)

Chung, G. Y., M. S. Park, B. M. Nam, K. N. Hong, J. Jang, H. J. Jeong and K. O. Yoo. 2010. Distribution of vascular plants in Gallasan (Andong-si · Uiseong-gun, Gyeongbuk). Korean Journal of Plant Resources 23: 99-114. (in Korean)

Clements, R., N. S. Sodhi, M. Schilthuizen and P. K. L. Ng. 2006. Limestone karsts of Southeast Asia: Imperiled arks of biodiversity. BioScience 56: 733-742.
Dromgoole, E. L. and L. M. Walter. 1990. Iron and manganese incorporation into calcite: Effects of growth kinetics, temperature and solution chemistry. Chemical Geology 81: 311-336.

Ewald, J. 2003. The calcareous riddle: Why are there so many calciphilous species in the Central European flora?. Folia Geobotanica 38: 357-366.

Han, J.-S., K.-S. Cheon, K.-A. Kim and K.-O. Yoo. 2012. Distribution and characteristics of plant resources in Mt. Heungjeong (Pyeongchang-gun, Gangwon-do). Korean Journal of Plant Resources 25: 416-432. (in Korean)

Hong, H.-H. and H.-T. Im. 1997. A floristic and conservational study on Mt. Chabyong. Bulletin of the Korean Association for Conservation of Nature 16: 1-19. (in Korean)

Ji, S.-J., S.-Y. Jung, C. Chang, J.-W. Jang, C.-H. Lee, J.-C. Yang, M.-S. Park and G. Y. Chung. 2011. Floristic study of Mt. Cheongtae area (Pyeongchang-gun, Gangwon-do). Korean Journal of Plant Taxonomy 41: 415-428. (in Korean)

Kang, E. S., S.-R. Lee, S. H. Oh, D.-K. Kim, S.-Y. Jung and D. C. Son. 2020. Comprehensive review about alien plants in Korea. Korean Journal of Plant Taxonomy 50: 89-119. (in Korean)

Karim, C., A. A. Tuen and M. T. Abdullah. 2004. Mammals. Sarawak Bau limestone biodiversity. Sarawak Museum Journal 59: 221-234.

Kiew, R. and A. R. Rafidah. 2021. Plant diversity assessment of karst limestone, a case study of Malaysia's Batu caves. Nature Conservation 44: 21-49.

Kim, B.-W. and Y.-J. Oh. 2000. Classification of calcicoles and calcifuges in Mt. Jabyeong. Journal of the Speleological Society of Korea 61: 17-46. (in Korean)

Kim, J.-H., Y.-S. Kwak and H.-T. Mun. 1992. Classification of calcicoles and calcifuges on the basis of the ratio of soluble to insoluble $\mathrm{Ca}^{2+}$ and $\mathrm{Mg}^{2+}$ in the leaves. Korean Journal of Ecology 15: 311-328.

Kim, J.-H., H.-J. Park, G.-H. Nam, K.-U. Lee and J.-S. Kim. 2019. Floristic study of Mt. Jaamsan in the Gyeongsang supergroup, Korea. Korean Journal of Environmental Biology 37: 229248. (in Korean)

Kim, J. S., J. H. Kim and J. H. Kim. 2018. Herbaceous Plants of Korean PeninsulaI. Plants Living in Seasides, Rivers, Wetlands and Cities. Dolbegae, Paju, 657 pp. (in Korean)

Kim, J.-S., B.-C. Lee, J.-M. Chung and J.-H. Pak. 2005. Flora and phytogeography on Mt. Deokhang (Gangwon-do), limestone area in Korea. Korean Journal of Plant Taxonomy 35: 337364. (in Korean)

Kim, T. Y. and J. S. Kim. 2018. Woody Plants of Korean Peninsula. Dolbegae, Paju, 715 pp. (in Korean)

Korea National Arboretum. 2012. The Plants in Limestone Areas. Geobook, Seoul, 141 pp. (in Korean) 
Korea National Arboretum. 2016. Distribution Maps of Vascular Plants in Korea. Korea National Arboretum, Pocheon, 1530 pp. (in Korean)

Korea Teacher's Plant Research Association. 2011. The Flora of Mt. Gakhui, Mt. Mulrae, and Mt. Jahu. Korea Teacher's Plant Research Association, Seoul, 130 pp. (in Korean)

Kovach, W. L. 2007. MVSP - A MultiVariate Statistical Package for Windows, ver. 3.1. Kovach Computing Services, Pentraeth, Wales, $145 \mathrm{pp}$.

Latinne, A., S. Waengsothorn, V. Herbreteau and J. R. Michaux. 2011. Thai limestone karsts: An impending biodiversity crisis. In The 1st Environment Asia International Conference on Environmental Supporting in Food Energy Security: Crisis Opportunity. Bangkok. Pp. 176-187.

Lee, B. J. and C. Sunwoo. 2010. Petrology and Geological Structure in Korea. CIR, Seoul, 322 pp. (in Korean)

Lee, C. S. and K. H. Lee. 2018. Pteridophytes of Korea: Lycophytes \& Ferns. 2nd ed. Geobook, Seoul, 491 pp. (in Korean)

Lee, T. B. 1980. Illustrayed Flora of Korea. Hyangmunsa, Seoul, 990 pp. (in Korean)

Lee, W. T. 1996. Coloured Standard Illustrations of Korean Plants. Academy Publishing Co., Seoul, 624 pp. (in Korean)

Liu, B., M. Zhang, W. R. Bussmann, H.-M. Liu, Y.-Y. Liu, Y.-D. Peng, K.-L. Zu, Y.-M. Zhao, Z.-B. Liu and S.-X. Yu. 2018. Species richness and conservation gap analysis of karst areas: A case study of vascular plants from Guizhou, China. Global Ecology and Conservation 16: e00460.

Moon, A.-R., J.-W. Han, J.-M. Park and C.-G. Jang. 2013. The flora of Mt. Eungbongsan (Prov. Gangwon, Youngwol). Korean Journal of Plant Resources 26: 234-247. (in Korean)

Nam, B. M., S. Jeong, M. G. Kim and G. Y. Chung. 2014. A floristic study of Mt. Myeonsan - Myobong (Taebaek-si, Samcheok-si, Bonghwa-gun) in Korea. Korean Journal of Plant Resources 27: 501-517. (in Korean)

Nam, B. M., J. Y. Kim, S. Jeong, J.-H. Lee, M. J. Nam, B.-U. Oh and G. Y. Chung. 2015. A flora of vascular plants in Mt. Cheongnyangsan (Bonghwa-gun, Andong-si). Korean Journal of Plant Resources 28: 616-634. (in Korean)

Nam, G.-H., J.-H. Kim, Y.-C. Kim, J.-S. Kim and B.-Y. Lee. 2012. Floristic study of county Pyeong-chang and Yeong-wol including limestone regions (Prov. Gangwon-do) from Korea. Korean Journal of Environment and Ecology 26: 11-38. (in Korean)

National Institute of Biological Resources. 2011. Survey on Species Diversity of Strategic Regions. National Institute of Biological Resources, Incheon, 283 pp. (in Korean)

National Institute of Biological Resources. 2017. Plant Diversity Research by the Regional Parataxonomust (II). National Institute of Biological Resources, Incheon, 162 pp. (in Korean)
National Institute of Biological Resources. 2019a. National Species List of Korea. I. Plants, Fungi, Algae, Prokaryotes. Designzip, Seoul. Pp. 51-206. (in Korean)

National Institute of Biological Resources. 2019b. Plant Diversity Research by the Regional Parataxonomust (IV). National Institute of Biological Resources, Incheon, 81 pp. (in Korean)

National Institute of Biological Resources. 2020. Plant Diversity Research by the Regional Parataxonomust (V). National Institute of Biological Resources, Incheon, 93 pp. (in Korean)

National Institute of Biological Resources. 2021. Red Data Book of Republic of Korea. 2nd ed. Vol. 5. Vascular Plants. National Institute of Biological Resources, Incheon, 523 pp. (in Korean)

National Institute of Ecology. 2018. Floristic Target Species in Korea. Geobook, Seoul, 728 pp. (in Korean)

Oh, H.-K. 2013. Conservation methods and vascular plants of Thuja orientalis community in Seokmun-bong, Danyang. Journal of the Korean Society of Environmental Restoration Technology 16: 75-92. (in Korean)

Oh, H.-K., K. Lee, Y. Lee and Y. Choung. 2014. Geographical distribution and ecology in microhabitats of the rare species, Pulsatilla tongkangensis Y. N. Lee et T. C. Lee. Korean Journal of Ecology and Environment 47: 74-82. (in Korean)

Park, S., Y. Son, D. Lee and H. Son. 2020. Flora and medical plant resources of natural ecosystem conservation area at Mt. Daedeoksan-Geumdaebong. Korean Journal of Plant Resources 33: 501-515. (in Korean)

Park, S. H. 2009. New Illustrations and Photographs of Naturalized Plants of Korea. Ilchokak, Seoul, 575 pp. (in Korean)

Rogers, G. M., S. P. Courtney and P. B. Heenan. 2018. The calcicolous vascular flora on New Zealand: Life forms, taxonomy, biogeography and conservation status. Science for Conservation 331: 1-37.

Ryu, T. B. 2016. Vegetation on limestone in South Korea. PhD dissertation, Keimyung University, Daegu, 160 pp. (in Korean)

Shimizu, T. 1963. Studies on the limestone flora of Japan and Taiwan, part II. Journal of the Faculty of Textile Science and Technology, Shinshu University, Ser. A, Biology 12: 1-86.

Song, J.-M., H.-J. Son, Y.-S. Kim, S.-C. Kim, D.-H. Lee, W.-G. Park and S.-J. Kwon. 2016. The flora of limestone area, Mt. Seokbyeong. Korean Journal of Plant Resources 29: 241-263. (in Korean)

Sung, J. W., J. W. Yoon, H. T. Shin, J. K. Bae, S. G. Kang and M. H. Yi. 2019. The vascular plants in Mt. Guryong, Korea. Korean Journal of Plant Resources 32: 589-614. (in Korean)

Zhang, R., X. Qin, H. Chen, B. P. L. Chan, F. Xing and Z. Xu. 2017. Phytogeography and floristic affinities of the limestone flora of Mt. Exianling, Hainan Island, China. Botanical Review 83: 38-58. 


\section{한반도 석회암지대의 관속식물 목록}

\section{김중현 · 남기흠 ${ }^{1}$ 이승배 ${ }^{2} \cdot$ 신수경 ${ }^{3}$ - 김진석 $4 *$}

국립생물자원관 식물자원과, ${ }^{1}$ 국립생물자원관 전략기획과, 2한국지질자원연구원 지질박물관, ${ }^{3}$ 국립생물자원관 전시교육과, ${ }^{4}$ 금수강산

적 요: 석회암지대는 수억만년 전 칼슘 분비 해양 생물에 의해 생성되고 탄산칼슘으로 구성된 퇴적암 노두 이며, 지각 운동에 의해 해수면 위로 상승하였다. 석회암지대는 고유식물의 비율이 매우 높고 생물학적 정보 가 많은 생물다양성 지역으로 알려져 있다. 본 연구는 10 개 지역의 석회암지대에 대한 식물상과 식물 종조성 의 조사를 통하여 석회암 식생에 안정적인 보전계획 수립을 위한 기초자료를 제시하고자 한다. 2010년 4월 부터 2016년 10월까지 153회에 걸쳐 조사한 결과, 관속식물은 133과 530속 1,096종 18 아종 84 변종 2품종 2 교잡종으로 총 1,202 분류군이 확인되었다. 이 가운데 한반도 고유식물은 55 분류군, 적색목록식물은 38 분류군 이었다. 식물구계학적 특정식물은 총 102 분류군으로 $\mathrm{V}$ 등급에 27 분류군, $\mathrm{IV}$ 등급에 75 분류군이 포함되었다. 외래식물은 121 분류군이었다. 호석회성 식물은 총 102 분류군으로 지표종에 14 분류군, 극선호종에 30 분류군, 그리고 선호종에 58 분류군이 포함되었다. 군집분석은 석회암지대 내에서 지리적으로 인접하고, 자생지 환경 (하천지역)이 유사한 지역 간에 높은 유사도를 보여주었다. 또한 석회암지대는 인근지역의 비석회암지대와 구별되는 종조성을 갖는 것으로 나타나 석회암지대 식물상의 고유성과 특이성을 보여주었다. 식물지리학적 접근은 석회암지대 생물다양성의 수준을 잘 이해하기 위해 매우 중요하다. 이러한 결과는 석회암 생육지를 보호 하고 그 상호 특이적 생물다양성뿐만 아니라 고도로 위협받는 종내 생물다양성 보존의 중요성을 강조한다.

주요어: 석회암, 호석회, 목록, 생물다양성 
Appendix 1. The list of vascular plants investigated on limestone areas in Korea.

\section{Selaginellaceae 부처손과}

Selaginella helvetica (L.) Link 왜구실사리(II, LC); 245240, 359468, 433134, 528487, 590728 (1, 3, 4, 6, 7)

Selaginella rossii (Baker) Warb. 구실사리; 305767, 451851, 487952, 574438, 599744 (2, 4, 5, 9, 10)

Selaginella stauntoniana Spring 개부처손(III); 234893, 520300, 568257, $552179(1,6,7,8)$

Selaginella tamariscina (P. Beauv.) Spring 바위손; 468835 (5)

Ophioglossaceae 고사리삼과

Botrychium nipponicum Makino 단풍고사리삼; 599126 (10)

Botrychium strictum Underw. 긴꽃고사리삼(II, LC); 235515, 385513, 441346, 553167, 576435, 579005, 585363 (1, 3, 4, 7, 8, 9, 10)

Botrychium ternatum (Thunb.) Sw. 고사리삼; 324013, 388063, 482681, $551762(2,3,5,9)$

Equisetaceae 속새과

Equisetum arvense L. 쇠뜨기; 234950, 284278, 354989, 433262, 488070, 552117, 577118, 577791, 585712 (1, 2, 3, 4, 5, 7, 8, 9, 10)

Equisetum hyemale L. 속새(III); 433284 (4)

Equisetum ramosissimum Desf. 개속새(II); 234941, 305294, 385336, 446439, 487858, 523989, 552917, 580459 (1, 2, 3, 4, 5, 6, 7, 8, 9)

Osmundaceae 고비과

Osmunda cinnamomea L. 꿩고비(II); 235332, 359093, 569628, 578527 (1, 3, 9, 10)

Osmunda japonica Thunb. 고비; 235362, $469084(1,5)$

Dennstaedtiaceae 잔고사리과

Dennstaedtia hirsuta (Sw.) Mett. ex Miq. 잔고사리; 243197, 387747, 433330, 472719, 552645, 576451, $578810(1,3,4,5,8,9,10)$

Dennstaedtia wilfordii (T. Moore) H. Christ 황고사리; 235505, 305362, 387588, 446768, 472752, 528470, 575698, 578864, 585752 (1, 2, 3, 4, 5, 6, 7, 9, 10)

Pteridium aquilinum var. latiusculum (Desv.) Underw. ex A. Heller 고사리; 236969, 284567, 385670, 441284, 472613, 524567, 585345, 599778 (1, 2, 3, 4, $5,6,7,10)$

\section{Pteridaceae 봉의꼬리과}

Cheilanthes argentea (S. G. Gmel.) Kunze 부싯깃고사리(I); 245121, 323896, 441608, 463980, 520294, 553120, 576427, 580390, 354930 (1, 2, 3, 4, 5, 6, 8, 9) Coniogramme intermedia Hieron. 고비고사리(II); 243410, 309900, 385421, 451556, 576462, 585745, 599314 (1, 2, 3, 4, 7, 9, 10)

Adiantaceae 공작고사리과

Adiantum capillus-junonis Rupr. 암공작고사리(EN); 575651, $645879(1,9)$

Aspleniaceae 꼬리고사리과

Asplenium incisum Thunb. 꼬리고사리; 235119, 385712, 433183, 487913, 520318, 576437, 577555 (1, 3, 4, 5, 6, 9, 10)

Asplenium pekinense Hance 사철고사리(IV); 552176,566119 (7, 8)

Asplenium ruprechtii Sa. Kurata 거미고사리; 234900, 284439, 354911, 433117, 487940, 520278, 552007, 565981, 577109, 577695 (1, 2, 3, 4, $5,6,7,8,9,10)$

Asplenium ruta-muraria L. 돌좀고사리(IV, LC); 236834, 305526, 394133, 433137, 520937, 552175, 566102, 599633 (1, 2, 3, 4, 6, 7, 8, 10) Asplenium scolopendrium L. 골고사리(II, LC); 385437, 433229, $569735(3,4,9)$

Asplenium varians Wall. ex Hook. \& Grev. 애기꼬리고사리; 245120, 305561, 433273, 551896, 577692, $580491(1,2,4,7,9,10)$

Asplenium $\times$ castaneoviride Baker 거미꼬리고사리(II); 553535 (8)

Thelypteridaceae 처녀고사리과

Macrothelypteris oligophlebia var. elegans (Koidz.) Ching 각시고사리; 536240 (6)

Phegopteris connectilis (Michx.) Watt 가래고사리(II); 451863 (4)

Thelypteris palustris (A. Gray) Schott 처녀고사리; 243255, 395842, 536436, 574428, 591158, $599264(1,3,6,7,9,10)$

Woodsiaceae 우드풀과

Woodsia hancockii Baker 애기가물고사리(VU); 441436 (4)

Woodsia macrochlaena Mett. ex Kuhn 참우드풀(IV); 553062, $574441(8,9)$

Woodsia manchuriensis Hook. 만주우드풀; 243833, 387746, 446742, 481373, 551891, 599144 (1, 3, 4, 5, 9, 10)

Woodsia polystichoides D. C. Eaton 우드풀; 235600, 284648, 446781, 482130, 552643, 575937, 578856 (1, 2, 4, 5, 8, 9, 10)

Woodsia subcordata Turcz. 산우드풀(II); 243819, 446426, 552495, $574803(1,4,8,9)$

Athyriaceae 개고사리과

Athyrium niponicum (Mett.) Hance 개고사리; 235797, 305460, 387580, 449804, 487848, 528482, 551959, 590112, 599141 (1, 2, 3, 4, 5, 6, 7, 9, 10) Athyrium sinense Rupr. 참새발고사리; 235474, 305510, 359064, 446761, 495751, 576441, 578836, $585393(1,2,3,4,5,7,9,10)$

Athyrium yokoscense (Franch. \& Sav.) H. Christ 뱀고사리; 243830, 305570, 387572, 451110, 482635, 530462, 578827, 590816 (1, 2, 3, 4, 5, 6, 7, 10) Cornopteris crenulatoserrulata (Makino) Nakai 응달고사리; 578826, 309902, 385733, 495460 (2, 3, 5, 10)

Deparia coreana (H. Christ) M. Kato 곱새고사리; 235745, 305519, 385419, 451555, 524007, 552493, 575529, 585899 (1, 2, 3, 4, 6, 7, 8, 9) Deparia pycnosora (H. Christ) M. Kato 털고사리; 243829, 309901, 385436, 451583, 487994, 551895, 552660, 591989, 598961 (1, 2, 3, 4, 5, 7, 8, 9, 10) Deparia pycnosora var. albosquamata M. Kato 흰털고사리; 599854 (10)

Deparia $\times$ angustata Nakaike 개좀진고사리; 575642, $599072(9,10)$

Gymnocarpium jessoense (Koidz.) Koidz. 산토끼고사리; 244446, 385594, 441197, 552496, 576467, 579006, 585391 (1, 3, 4, 8, 9, 10)

Onocleaceae 야산고비과

Matteuccia struthiopteris (L.) Tod. 청나래고사리(II); 244395, 324030, 390501, 441203, 585143, 599273 (1, 2, 3, 4, 7, 10)

Onoclea sensibilis L. 야산고비(I); 235409, 395838, $446452(1,3,4)$

Pentarhizidium orientale (Hook.) Hayata 개면마; 243681, 310127, 385752, 441469, 574979, 585351, 599074 (1, 2, 3, 4, 7, 9, 10) 
Appendix 1. Continued.

\section{Dryopteridaceae 관중과}

Cyrtomium fortunei J. Sm. 쇠고비; 244125, 284256, 385659, 520339, 576439, 578577 (1, 2, 3, 6, 9, 10)

Dryopteris bissetiana (Baker) C. Chr. 산족제비고사리; 242396, $552184(1,8)$

Dryopteris chinensis (Baker) Koidz. 가는잎족제비고사리; 243317, 284636, 385668, 433238, 472741, 524500, 553058, 569453,578811 (1, $2,3,4,5,6,8,9,10)$

Dryopteris crassirhizoma Nakai 관중; 235208, 284667, 359156, 441191, 495768, 575929, 580488, 599556 (1, 2, 3, 4, 5, 7, 9, 10)

Dryopteris expansa (C. Presl) Fraser-Jenk. \& Jermy 퍼진고사리(II); 385415, 578834 (3, 10)

Dryopteris fragrans (L.) Schott 주저리고사리(III); 243827, 387752, 552494, $599858(1,3,8,10)$

Dryopteris goeringiana (Kunze) Koidz. 바위틈고사리(IV, LC); 235726, 385461, 441266, 524519, 575930, $585440(1,3,4,6,7,9)$

Dryopteris gymnophylla (Baker) C. Chr. 금족제비고사리(I); 577954, $591988(7,10)$

Dryopteris lacera (Thunb.) Kuntze 비늘고사리; 244098, 305478, 451883, 482823, 524496, 574544, 579156, 585529 (1, 2, 4, 5, 6, 7, 9, 10)

Dryopteris monticola (Makino) C. Chr. 왕지네고사리; 385734, $578831(3,10)$

Dryopteris sacrosancta Koidz. 애기족제비고사리; 243300, $576452(1,9)$

Dryopteris saxifraga H. Itô 바위족제비고사리; 451715, 495860, $577707(4,5,10)$

Leptorumohra borealis Shmakov 왁살고사리; 235684, 585450, $599863(1,7,10)$

Polystichum braunii (Spenn.) Fée 좀나도히초미(II); 235215, 433180, 359071, 551894, 585383, 599065 (1, 3, 4, 7, 9, 10)

Polystichum craspedosorum (Maxim.) Diels 낚시고사리; 234903, 305528, 354956, 433243, 488048, 520336, 565939, 575859, 577829 (1, 2 , $3,4,5,6,7,9,10)$

Polystichum ovato-paleaceum var. coraiense (H. Christ) Sa. Kurata 참나도히초미(I); 385499, 433166, 575827, 578804, 580489 (3, 4, 7, 9, 10)

Polystichum tripteron (Kunze) C. Presl 십자고사리; 235313, 305509, 385420, 451707, 495304, 569627, 578470, 580487 (1, 2, 3, 4, 5, 7, 9, 10)

Hypodematiaceae 금털고사리과

Hypodematium glanduloso-pilosum (Tagawa) Ohwi 금털고사리(II, LC); 552644, 590693, 599634, 242133, 441723, 472831, 520320 (1, 4, 5, $6,7,8,10)$

Hypodematium squamuloso-pilosum Ching 흰금털고사리; 555435 (1)

Davalliaceae 넉줄고사리과

Davallia mariesii T. Moore ex Baker 넉줄고사리; 242146, 481377, 530421, $574821(1,5,6,9)$

Polypodiaceae 고란초과

Lepisorus ussuriensis (Regel \& Maack) Ching 산일엽초; 235613, 387554, 433356, 468978, 575839, 577747 (1, 3, 4, 5, 9, 10)

Pleurosoriopsis makinoi (Maxim. ex Makino) Fomin 좀고사리(II); 242170, 359147, 577731 (1, 3, 10)

Pyrrosia linearifolia (Hook.) Ching 우단일엽; 243818, 309886, 433300, 495854, 520936, 553060, 574917, 577780, 585431 (1, 2, 4, 5, 6, 7, $8,9,10)$

Pyrrosia petiolosa (H. Christ) Ching 애기석 위(II); 235242, 463969, 524529, 552154, 566113, 598868 (1, 5, 6, 7, 8, 10)

Pinaceae 소나무과

Abies holophylla Maxim. 전나무(II); 324123, 387629, 433247 (2, 3, 4)

Pinus densiflora Siebold \& Zucc. 소나무; 235371, 324116, 359402, 441540, 468928, 520854, 554083, 585458, 599780 (1, 2, 3, 4, 5, 6, 7, 8, 10)

Pinus koraiensis Siebold \& Zucc. 잣나무(II); 244393, 305458, 385508, 433381, 468893, 585129 (1, 2, 3, 4, 5, 7)

Pinus thunbergii Parl. 곰솔; 235034, $433357(1,4)$

Cupressaceae 측백나무과

Juniperus chinensis L. 향나무(III, NT); 242082, 284581, 394093, 433370, 577072, 599651 (1, 2, 3, 4, 9, 10)

Juniperus rigida Siebold \& Zucc. 노간주나무; 235492, 324138, 395915, 433355, 488046, 520306, 552000, 585475, 599163 (1, 2, 3, 4, 5, 6, $7,8,10)$

Platycladus orientalis (L.) Franco 측백나무(IV, LC); 243782, 305643, 495356, 520357, 552973, 579184 (1, 2, 5, 6, 8, 10)

Cephalotaxaceae 개비자나무과

Cephalotaxus harringtonia (Knight ex Forbes) K. Koch 개비자나무(I); 488045 (5)

Magnoliaceae 목련과

Magnolia sieboldii K. Koch 함박꽃나무(II); 235261, 284525, 385384, 441538, 469059, 553028, 575636, 578373, 586032 (1, 2, 3, 4, 5, 8, 9, 10)

Lauraceae 녹나무과

Lindera erythrocarpa Makino 비목나무(I); 472547 (5)

Lindera glauca (Siebold \& Zucc.) Blume 감태나무(I); 284545, 481410, $523972(2,5,6)$

Lindera obtusiloba Blume 생강나무; 243209, 305452, 354919, 433140, 463986, 520280, 552021, 565935, 577699, 583016 (1, 2, 3, 4, 5, 6, 7, 8, 9, 10)

Chloranthaceae 흘아비꽃대과

Chloranthus japonicus Siebold 홀아비꽃대(I); 235025, 284325, 359090, 441582, 488066, 520975, 553531, 566008, 569610, 577813 (1, 2, 3 , $4,5,6,7,8,9,10)$

\section{Aristolochiaceae 쥐방울덩굴과}

Aristolochia contorta Bunge 쥐방울덩굴(I); 243448, 395909, 472875, 552413, 590960, 599754 (1, 3, 5, 7, 8, 10)

Aristolochia manshuriensis Kom. 등칡(II); 284549, 359151, 441459, 495271, 591113 (2, 3, 4, 5, 7)

Asarum chungbuensis (C. S. Yook \& J. G. Kim) B. U. Oh 무늬족도리풀(E); 583050 (9)

Asarum koreanum J. Kim \& C. Yook ex B. U. Oh 자주족도리풀(E); 469070 (5)

Asarum mandshuricum (Maxim.) M. Kim \& S. So 털족도리풀(III); 359095, 441366, 578023, 585434 (3, 4, 7, 10) 
Appendix 1. Continued.

Asarum sieboldii Miq. 족도리풀; 235305, 354993, 433186, 469033, 569675, 577786 (1, 3, 4, 5, 9, 10)

Schisandraceae 오미자과

Schisandra chinensis (Turcz.) Baill. 오미자(II); 235226, 359084, 441472, 524019, 575934, 578035, 580370 (1, 3, 4, 6, 7, 9, 10)

Ranunculaceae 미나리아재비과

Aconitum barbatum var. hispidum (DC.) Ser. 넓은잎노랑투구꽃(NT); 243717, 388029, 449617, 551802, $598939(1,3,4,9,10)$

Aconitum ciliare DC. 놋젓가락나물; 449828, $583277,590187(4,7,9)$

Aconitum coreanum (H. Lév.) Rapaics 백부자(V, VU); 243722, photo15001 $(1,6)$

Aconitum jaluense Kom. 투구꽃(I); 244072, 395928, 449770, 488064, 536423, 591672, 599056 (1, 3, 4, 5, 6, 7, 10)

Aconitum longecassidatum Nakai 흰진범(I); 591153, $599192(7,10)$

Aconitum pseudolaeve Nakai 진범(E); 242288, 323898, 390231, 449608, 495874, 590499, 599054 (1, 2, 3, 4, 5, 7, 10)

Actaea asiatica H. Hara 노루삼(III); 305520, 359086, 441444, 495423, 553169, 575643, 577785, 585451 (2, 3, 4, 5, 7, 8, 9, 10)

Adonis amurensis Regel \& Radde 복수초; 354990, 433207, $577726(3,4,10)$

Anemone koraiensis Nakai 홀아비바람꽃(E, IV, LC); 433286, 569725, $577710(4,9,10)$

Anemone raddeana Regel 꿩의 바람꽃; 354983, 433191, 577688, 583032 (3, 4, 9, 10)

Anemone reflexa Stephan 회리바람꽃(IV); 235315, 359456, 433159, 566175, 577157, $577689(1,3,4,7,9,10)$

Aquilegia buergeriana var. oxysepala (Trautv. \& C. A. Mey.) Kitam. 매발톱(III); 235388, 441764, $578382(1,4,10)$

Caltha palustris L. 동의나물(II); $578020,583012(9,10)$

Cimicifuga dahurica (Turcz. ex Fisch. \& C. A. Mey.) Maxim. 눈빛승마; 242153, 309899, 388028, 449648, 590136, 599061 (1, 2, 3, 4, 7, 10)

Cimicifuga heracleifolia var. bifida Nakai 세잎승마(E, IV); 243691, 324129, 387528, 449615, 495677, 536489, 551731, 591649, 599802 (1, 2, 3, 4, 5, 6, 7, 9, 10)

Cimicifuga simplex (DC.) Wormsk. ex Turcz. 촛대승마(I); 449771 (4)

Clematis apiifolia DC. 사위질빵; 242208, 310091, 387994, 449385, 481807, 528361, 551899, 556080, $598967(1,2,3,4,5,6,8,9,10)$

Clematis brachyura Maxim. 외대으아리(E, III); 235420, 284603, 385730, 446800, 468817, 523770, 552969, 575707, 578256, 585468 (1, 2 , $3,4,5,6,7,8,9,10)$

Clematis brevicaudata DC. 좀사위질빵; 590776 (7)

Clematis calcicola J. S. Kim 바위종덩굴(E, V); 218724

Clematis fusca var. flabellata (Nakai) J. S. Kim 요강나물(E, III); $578416(10)$

Clematis fusca var. violacea Maxim. 종덩굴(III); 235743, 387577, 446925, 553258, 576411, 585979, 599329 (1, 3, 4, 7, 8, 9, 10)

Clematis heracleifolia var. urticifolia (Nakai ex Kitag.) U. C. La 병조희풀(III); 244479, 305433, 387507, 446770, 495756, 552636, 576683 , $585970,599399(1,2,3,4,5,7,8,9,10)$

Clematis koreana Kom. 세잎종덩굴(III, LC); 576464 (9)

Clematis patens C. Morren \& Decne. 큰꽃으아리(I); 235204, 284672, 387648, 446549, 468808, 553831, 578381, 580457 (1, 2, 3, 4, 5, 7, 8, 10)

Clematis serratifolia Rehder 개버무리(IV); 244433, 323855, 390270, 451193, 552411, 590051 (1, 2, 3, 4, 7, 8)

Clematis terniflora var. mandshurica (Rupr.) Ohwi 으아리; 245210, 305347, 387598, 446739, 472835, 524355, 552975, 575593, 585830, 599497

$(1,2,3,4,5,6,7,8,9,10)$

Clematis trichotoma Nakai 할미밀 망(E); 235399, 284645, 385390, 441322, 469060, 523985, 575865, 578371, 580367 (1, 2, 3, 4, 5, 6, 7, 9, 10)

Delphinium maackianum Regel 큰제비고깔(IV, LC); 236887, 495668, 528420, 574978, $599147(1,5,6,9,10)$

Eranthis stellata Maxim. 너도바람꽃(III); 235589, 354985, 433217, 577681, $583046(1,3,4,9,10)$

Hepatica asiatica Nakai 노루귀(I); 235109, 284261, 354955, 433194, 495294, 565927, 577112, 577728 (1, 2, 3, 4, 5, 7, 9, 10)

Isopyrum manshuricum Kom. 만주바람꽃(III, LC); 568247 (7)

Isopyrum raddeanum (Regel) Maxim. 나도바람꽃(III); 359437, 433161, $577600(3,4,10)$

Pulsatilla cernua (Thunb.) Bercht. \& J. Presl 할미꽃; 245164, 284418, 359247, 433345, 496005, 520291, 552181, 566072, 577713, 583023

$(1,2,3,4,5,6,7,8,9,10)$

Pulsatilla tongkangensis Y. N. Lee \& T. C. Lee 동강할미꽃(E, V, VU); 359487, Photo001 (2, 3)

Ranunculus cantoniensis DC. 털개구리미나리; $575814,585791(7,9)$

Ranunculus chinensis Bunge 젓가락나물; 235464, 385572, 441751, 468900, 523826, 556087, 569655, 578846, 585372 (1, 3, 4, 5, 6, 8, 9, 10) Ranunculus japonicus Thunb. 미나리아재비; 245165, 359069, 441491, 468855, 520917, 575900, 577755, 580356 (1, 3, 4, 5, 6, 7, 9, 10)

Ranunculus sceleratus L. 개구리자리; 553861, $578422(8,10)$

Ranunculus tachiroei Franch. \& Sav. 개구리미나리; 305501, $553863(2,8)$

Thalictrum coreanum H. Lév. 연잎뀡의다리(E, V, VU); 244466 (1)

Thalictrum filamentosum Maxim. 산꿩의다리; 385507, 441565, 495422, $578830(3,4,5,10)$

Thalictrum ichangense Lecoy. ex Oliv. 꼭지연잎뀡의다리(IV, LC); 235390, 394165, 523967, 553158, 575907, 578105, 591143 (1, 3, 6, 7, 8, 9, 10)

Thalictrum minus var. hypoleucum (Siebold \& Zucc.) Miq. 좀꿩의다리; 245291, 309904, 388045, 446798, 472818, 528311, 552615, 574966,

$585848,599217(1,2,3,4,5,6,7,8,9,10)$

Thalictrum petaloideum L. 꽃뀡의다리(IV, NT); 552971 (8)

Thalictrum rochebrunnianum Franch. \& Sav. 금꿩의다리(III); 388097, $599245(4,10)$

Berberidaceae 매자나무과

Berberis amurensis Rupr. 매 발톱나무(II); 385442, 449830, 583044 (3, 4, 9)

Berberis koreana Palib. 매자나무(E, IV); 359479 (3)

Caulophyllum robustum Maxim. 뀡의다리아재비(II); 237014, 385441, 495443, 569722, 591114, 599343 (1, 3, 5, 7, 9, 10) 
Appendix 1. Continued.

Jeffersonia dubia (Maxim.) Benth. \& Hook. f. ex Baker \& S. Moore 깽깽이풀(IV, NT); 569648 (9)

Lardizabalaceae 으름덩굴과

Akebia quinata (Houtt.) Decne. 으름덩굴; 578095, 234965, 284398, 481845, 520837 (1, 2, 5, 6, 10)

Menispermaceae 새모래덩굴과

Cocculus trilobus (Thunb.) DC. 댕댕이덩굴; 235755, 305648, 472832, 523993, 552563, 590165, $599504(1,2,5,6,7,8,10)$

Menispermum dauricum DC. 새모래덩굴; 235456, 284650, 385496, 441662, 468796, 523970, 578192, 579205, 583045 (1, 2, 3, 4, 5, 6, 7, 9, 10)

Papaveraceae 양귀비과

Chelidonium majus var. asiaticum (H. Hara) Ohwi 애기똥풀; 234912, 284387, 359171, 433094, 463977, 520809, 552220, 569635, 577762, $566044(1,2,3,4,5,6,7,8,9,10)$

Hylomecon vernalis Maxim. 피나물(II); 235132, 284354, 359370, 495320, 577834 (1, 2, 3, 5, 10)

Fumariaceae 현호색과

Corydalis grandicalyx B. U. Oh \& Y. S. Kim 갈퀴현호색(E, III); 433209, 577727 (4, 10)

Corydalis hirtipes B. U. Oh \& J. G. Kim 털현호색(E); 284352, $433177(2,4)$

Corydalis maculata B. U. Oh \& Y. S. Kim 점현호색(E, III); 245127, 284419, 354909, 433110, 552087, 565920, 577113, 577680 (1, 2, 3, 4, 7, 8, 9, 10)

Corydalis ohii Lidén 선현호색(E); $566182,577549(7,10)$

Corydalis pauciovulata Ohwi 선괴불주머니; 244006, 305461, 387998, 449680, 481795, 528495, 551882, 591978, 599016 (1, 2, 3, 4, 5, 6, 7, 9, 10)

Corydalis remota Fisch. ex Maxim. 현호색; 235133, 284280, 354987, 433160, 464004, 520285, 552098, 577647 (1, 2, 3, 4, 5, 6, 8, 10)

Corydalis speciosa Maxim. 산괴불주머니; 235175, 284297, 354907, 433197, 463975, 520928, 552026, 565993, 569630, 577703 (1, 2, 3, 4, $5,6,7,8,9,10)$

Corydalis turtschaninovii Besser 조선현호색; 234984, 520895, $577809(1,6,10)$

Ulmaceae 느릅나무과

Hemiptelea davidii (Hance) Planch. 시무나무(I); 244505, 284706, 359296, 441226, 468756, 520840, 553843, 566038, 569456,577827 (1, 2 , $3,4,5,6,7,8,9,10)$

Ulmus davidiana Planch. 당느릅나무(I);234979, $359200(1,3)$

Ulmus davidiana var. japonica (Rehder) Nakai 느릅나무(I); 235264, 284310, 387350, 441314, 481109, 524032, 552030, 568261, 577729 (1, $2,3,4,5,6,7,8,10)$

Ulmus laciniata (Trautv.) Mayr 난티나무(III); 385440, 446749, 495368 (3, 4, 5)

Ulmus macrocarpa Hance 왕느릅나무(IV); 245217, 284339, 396065, 446910, 468758, 523929, 578030, 579196 (1, 2, 3, 4, 5, 6, 7, 10)

Ulmus parvifolia Jacq. 참느릅나무(I); 481774 (5)

Ulmus pumila L. 비술나무(IV); 284476, 359074, 433385, 566041, 577583, $583118(2,3,4,7,9,10)$

Celtidaceae 팽나무과

Celtis koraiensis Nakai 왕팽나무(III); 235573, 284626, 385521, 446615, 463967, 523941, 578052, $591537(1,2,3,4,5,6,7,10)$

Celtis sinensis Pers. 팽나무; 237023, $482229(1,5)$

Cannabaceae 삼과

Humulus japonicus Siebold \& Zucc. 환삼덩굴; 242083, 305597, 387793, 449358, 481786, 530348, 552586, 574528, 590171, 599146 (1, 2, 3 , $4,5,6,7,8,9,10)$

Moraceae 뽕나무과

Broussonetia papyrifera (L.) L'Hér. ex Vent 꾸지나무; 235352, 284649, 359339, 481121, 523911, 575918, $579210(1,2,3,5,6,7,9)$

Fatoua villosa (Thunb.) Nakai 뽕모시풀; 242085, 324102, 395959, 482311, 530418, 590091 (1, 2, 3, 5, 6, 7)

Morus alba L. 뽕나무(A); 235462, 284613, 385409, 472819, 523867, 553899, 578537, 585374 (1, 2, 3, 5, 6, 7, 8, 10)

Morus bombycis Koidz. 산뽕나무; 235190, 284566, 359070, 441120, 468709, 575939, 578060, 580339 (1, 2, 3, 4, 5, 9, 10)

Morus mongolica (Bureau) C. K. Schneid 몽고뽕나무(IV); 578056, 585340, 394402, 441879, 495344, $523903(3,4,5,6,7,10)$

Morus tiliaefolia Makino 돌뽕나무(III); 284853 (2)

Urticaceae 쐐기풀과

Boehmeria gracilis C. H. Wright 풀거북꼬리; 387564, 449792, 524520, 553155, 575539, 599547 (3, 4, 6, 8, 9, 10)

Boehmeria japonica (L. f.) Miq. 왜모시풀; 235714, 305493, 387477, 472529, 537618, 552657, 598957 (1, 2, 3, 5, 6, 8, 10)

Boehmeria spicata (Thunb.) Thunb. 좀깨잎나무; 235631, 309945, 387647, 446369, 472754, 528397, 553267, 585878 (1, 2, 3, 4, 5, 6, 7, 8)

Girardinia diversifolia subsp. suborbiculata (C. J. Chen) C. J. Chen \& Friis 큰쐐기풀(IV); 309971, 537671 (2, 6)

Laportea bulbifera (Siebold \& Zucc.) Wedd. 혹쐐기풀; 244138, 387584, 451789, 574797, 585845, $599017(1,3,4,7,9,10)$

Parietaria micrantha Ledeb. 개물통이; 236876 (1)

Pilea japonica (Maxim.) Hand.-Mazz. 산물통이(I); 242142, 309975, 390375, 451324, 495894, 530401, 552662, 574486, 590190, 599070 (1, $2,3,4,5,6,7,8,9,10)$

Pilea mongolica Wedd. 모시물통이; 242440, 323879, 395905, 449401, 482820, 536243, 574536, 590542, 599078 (1, 2, 3, 4, 5, 6, 7, 9, 10)

Pilea oligantha Nakai 강계큰물통이; 642882 (4)

Pilea peploides (Gaudich.) Hook. \& Arn. 물통이; 242189 (1)

Urtica angustifolia Fisch. ex Hornem. 가는잎쐐기풀(III); 235637, 309980, 387533, 446666, 552502, 576445, 599005 (1, 2, 3, 4, 8, 9, 10)

Urtica laetevirens Maxim. 애기쐐기풀; 244117, 310068, 449498, $585893(1,2,4,7)$

Juglandaceae 가래나무과

Juglans mandshurica Maxim. 가래나무(I); 243182, 305356, 359201, 441605, 566043, 577842 (1, 2, 3, 4, 7, 10) 
Appendix 1. Continued.

Platycarya strobilacea Siebold \& Zucc. 굴피나무; 242098, 468754, 524491, 553124 (1, 5, 6, 8)

Fagaceae 참나무과

Castanea crenata Siebold \& Zucc. 밤나무; 305511, 387624, 441679, 481114, 574913, 590142, 599646 (2, 3, 4, 5, 7, 9, 10)

Quercus acutissima Carruth. 상수리나무; 242274, 395899, 441113, 468793, $520814(1,3,4,5,6)$

Quercus aliena Blume 갈참나무; 234978, 309903, 394352, 468716, 520776, 577994, 590630 (1, 2, 3, 5, 6, 7, 10)

Quercus dentata Thunb. 떡갈나무; 235490, 395895, 441179, 481164, 520918, 551727, 554110, 578038, 580346 (1, 3, 4, 5, 6, 7, 8, 9, 10)

Quercus mongolica Fisch. ex Ledeb. 신갈나무; 245196, 284323, 395831, 441278, 468976, 520934, 552282, 577797, 590037 (1, 2, 3, 4, 5, 6, 7, 8, 10)

Quercus serrata Murray 졸참나무; 235624, 284773, 394118, 468977, 520915 (1, 2, 3, 5, 6)

Quercus variabilis Blume 굴참나무; 236839, 305611, 395829, 441693, 468719, 578055, 583063, 585483 (1, 2, 3, 4, 5, 7, 9, 10)

Betulaceae 자작나무과

Alnus hirsuta Turcz. ex Rupr. 물오리나무; 235349, 284437, 359300, 433255, 468892, 552069, 583028, 598955 (1, 2, 3, 4, 5, 8, 9, 10)

Alnus japonica (Thunb.) Steud. 오리나무; 583103 (9)

Betula chinensis Maxim. 개박달나무(III); 235416, 284587, 385687, 441110, 468941, 552288, 574520, 578110, 585486 (1, 2, 3, 4, 5, 8, 9, 10)

Betula costata Trautv. 거제수나무(III); 578000 (10)

Betula dahurica Pall. 물박달나무(III); 305631, 394244, 524586, 568263, 577059, $577816(2,3,6,7,9,10)$

Betula ermanii Cham. 사스래나무(II); 577924 (10)

Betula schmidtii Regel 박달나무(III); 243210, 284468, 359422, 446407, 495863, 552390, 577058, $577749(1,2,3,4,5,8,9,10)$

Carpinus cordata Blume 까치박달; 243187, 284524, 387410, 441495, 495324, 578145, $585371(1,2,3,4,5,7,10)$

Carpinus laxiflora (Siebold \& Zucc.) Blume 서어나무; 284557, 472690, 583112 (2, 5, 9)

Carpinus turczaninowii Hance 소사나무(I); 236849, 284655, 387827, 433235, 566094, 569699 (1, 2, 3, 4, 7, 9,)

Corylus heterophylla Fisch. ex Trautv. 개암나무; 235598, 387750, 433139, 472593, 552006, 574893, 577537 (1, 3, 4, 5, 8, 9, 10)

Corylus sieboldiana Blume 참개암나무; 394192, 441104, 472726, 553291, $578820(3,4,5,8,10)$

Corylus sieboldiana var. mandshurica (Maxim.) C. K. Schneid. 물개암나무; 305455, 579069, $585353(2,7,10)$

Phytolaccaceae 자리공과

Phytolacca acinosa Roxb. 자리공(IV, A); 305619, 449924 (2, 4)

Phytolacca americana L. 미국자리공(A); 305446, 472585, $598970(2,5,10)$

Chenopodiaceae 명아주과

Chenopodium album L. 명아주(A); 244528, 324024, 387848, 451113, 482388, 536453, 574916, 590527, 599835 (1, 2, 3, 4, 5, 6, 7, 9, 10)

Chenopodium aristatum L. 바늘명아주(IV, NT); 555669 (1)

Chenopodium ficifolium Sm. 좀명아주(A); 242378, 441804, 468744, 523837, 552887, $569448(1,4,5,6,8,9)$

Salsola collina Pall. 솔장다리(III); 590692 (7)

Amaranthaceae 비름과

Achyranthes bidentata var. japonica Miq. 쇠무릎; 242250, 310103, 481787, 528416 (1, 2, 5, 6)

Amaranthus hybridus L. 긴털비름(A); 235742, 324095, 387609, 451531, 472788, 528332, 576434, 591152, 599836 (1, 2, 3, 4, 5, 6, 7, 9, 10)

Amaranthus lividus L. 개비름(A); 242415, 395956, $590545(1,3,7)$

Amaranthus retroflexus L. 털비름(A); 773270 (1)

Portulacaceae 쇠비름과

Portulaca oleracea L. 쇠비름; 242408, 305315, 387612, 446404, 472797, 552556, $585920(1,2,3,4,5,7,8)$

Molluginaceae 석류풀과

Mollugo stricta L. 석류풀; 242162, 472863, $528346(1,5,6)$

Caryophyllaceae 석죽과

Arenaria serpyllifolia L. 벼룩이자리; 2344973, 359192, 441180, 463970, 520815, 552221, 566053, 577988 (1, 3, 4, 5, 6, 7, 8, 10)

Cerastium fontanum subsp. vulgare (Hartm.) Greuter \& Burdet 점나도나물; 234925, 284349, 359109, 520819, 552387, 566172, 575817 , $577768(1,2,3,6,7,8,9,10)$

Cerastium glomeratum Thuill. 유럽점나도나물(A); 441402, 468857, 579193, 583020 (4, 5, 7, 9)

Dianthus chinensis L. 패랭이꽃; 236911, 305567, 449373, 552850, $599589(1,2,4,8,10)$

Dianthus longicalyx Miq. 술패랭이꽃; $524511,576698,579086(6,9,10)$

Gypsophila oldhamiana Miq. 대나물; 237006, 310128, 482272, 552856, 585911, 598864 (1, 2, 5, 7, 8, 10)

Gypsophila pacifica Kom. 가는대나물(NT); 738443

Lychnis cognata Maxim. 동자꽃(II); 235645, 387503, 446611, 495656, 574786, 586083, 599389 (1, 3, 4, 5, 7, 9, 10)

Minuartia verna var. leptophylla (Rchb.) Nakai 삼수개미자리; 340628 (2)

Moehringia lateriflora (L.) Fenzl 개벼룩(IV, LC); 234931, $578189(1,10)$

Pseudostellaria davidii (Franch.) Pax 덩굴개별꽃; 235028, 566115, 578024, 583154, $359406(1,3,7,9,10)$

Pseudostellaria heterophylla (Miq.) Pax 개별꽃; 463993, 520771, 552373, 578061, 354964 (3, 5, 6, 8, 10)

Pseudostellaria japonica (Korsh.) Pax 긴개별꽃; $575922,578043(9,10)$

Pseudostellaria palibiniana (Takeda) Ohwi 큰개별꽃; 235202, 284560, 359103, 433242, 469067, 565922, 577684, 583124 (1, 2, 3, 4, 5, 7, 9, 10)

Pseudostellaria setulosa Ohwi 숲개별꽃(E, IV); 577734, $583037(9,10)$

Sagina japonica (Sw.) Ohwi 개미자리; 481137, 553297, $575851(5,8,9)$

Silene alba (Mill.) E. H. L. Krause 달맞이장구채(A); 385626, $575549,585739(4,7,9)$ 
Appendix 1. Continued.

Silene armeria L. 끈끈이대나물(A); 235511, 284608, 441648, 482329, 537591, 575525 (1, 2, 4, 5, 6, 9)

Silene baccifera (L.) Roth 덩굴별꽃(I); 305489, 488030, 552663, 574483, 599137 (2, 5, 8, 9, 10)

Silene capitata Kom. 분홍장구채(V, VU); 242158 (1)

Silene firma Siebold \& Zucc. 장구채; 236942, 324018, 395916, 449442, 482072, 528400, 590166, 599023 (1, 2, 3, 4, 5, 6, 7, 10)

Silene koreana Kom. 끈끈이장구채(III, LC); 449718 (4)

Silene seoulensis Nakai 가는장구채; 235709, 387536, 451884, 482124, 574952, 590061, $599259(1,3,4,5,7,9,10)$

Stellaria alsine var. undulata (Thunb.) Ohwi 벼룩나물; 284381, 359268, 495239, 552359, 568248, $577767(2,4,5,7,8,10)$

Stellaria aquatica (L.) Scop. 쇠별꽃; 235013, 359223, 441474, 468760, 566099, 578867 (1, 3, 4, 5, 7, 10)

Stellaria media (L.) Vill. 별꽃(A); 244400, 284576, 354982, 433126, 463971, 577116, 577670 (1, 2, 3, 4, 5, 9, 10)

Polygonaceae 마디풀과

Aconogonon alpinum (All.) Schkuhr 싱아; 576446, 599012 (9, 10)

Aconogonon microcarpum (Kitag.) H. Hara 참개싱아(E, IV); 235702, $449513(1,4)$

Bistorta officinalis Delarbre 넓은잎범꼬리(II); 236951, 553278, 575594, $599618(1,8,9,10)$

Fallopia ciliinervis (Nakai) K. Hammer 나도하수오; 446501, 574851, $599545(4,9,10)$

Fallopia dentatoalata (F. Schmidt) Holub 큰닭의덩굴; 242285, 323860, 395845, 451244, 481783, 536462, 574872, 590489, 599867 (1, 2, 3, 4, 5, 6, 7, 9, 10)

Fallopia dumetorum (L.) Holub 닭의 덩굴; 309967, 395945, 472864, 524472, 585865, $599077(2,3,5,6,7,10)$

Persicaria dissitiflora (Hemsl.) H. Gross ex T. Mori 가시여뀌; 235784, 309896, 387575, 446685, 553271, 574539, 585894 (1, 2, 3, 4, 7, 8, 9)

Persicaria filiformis (Thunb.) Nakai ex T. Mori 이삭여뀌; 242434, 310120, $482695(1,2,5)$

Persicaria hydropiper (L.) Delarbre 여뀌; 244353, 323939, 451309, 482355, 599748 (1, 2, 4, 5, 10)

Persicaria japonica (Meisn.) H. Gross ex Nakai 흰꽃여뀌; 242121, 324180, 388075 (1, 2, 4)

Persicaria lapathifolia (L.) Delarbre 흰여뀌; 244409, 309985, 388014, 449409, 472874, 524026, 575551, 590180, 599686 (1, 2, 3, 4, 5, 6, 7, 9, 10)

Persicaria longiseta (Bruijn) Kitag. 개여뀌; 242421, 310080, 387631, 446825, 481775, 524581, 590677, 599733 (1, 2, 3, 4, 5, 6, 7, 10)

Persicaria maculosa Gray 봄여뀌; 236948, 385620, 575557, $578851(1,4,9,10)$

Persicaria muricata (Meisn.) Nemoto 넓은잎미꾸리낚시; 551768 (9)

Persicaria nepalensis (Meisn.) H. Gross 산여뀌; 244359, 309953, 388011, 449780, 495686, 552695, 574485, 590745, 599006 (1, 2, 3, 4, 5, 7, 8, 9, 10)

Persicaria orientalis (L.) Spach 털여뀌(A); 599669 (10)

Persicaria perfoliata (L.) H. Gross 며느리배꼽; $243658,451749(1,4)$

Persicaria posumbu (Buch.-Ham. ex D. Don) H. Gross 장대여뀌; 244131, 309955, 390306, 451118, 482816, 574538, 590518, 599053 (1, 2, 3, 4, 5, 7, 9, 10)

Persicaria pubescens (Blume) H. Hara 바보여뀌; 552467 (8)

Persicaria sagittata var. sieboldii (Meisn.) Nakai 미꾸리낚시; 236947, 451175, 472703, 551766, 552463, 599015 (1, 4, 5, 8, 9, 10)

Persicaria senticosa (Meisn.) H. Gross ex Nakai 며느리밑씻개; 235642, 309893, 390328, 451638, 472558, 552551, 576416, 585377, 598958

$(1,2,3,4,5,7,8,9,10)$

Persicaria thunbergii (Siebold \& Zucc.) H. Gross 고마리; 243240, 323891, 449494, 482353, 599099 (1, 2, 4, 5, 10)

Persicaria viscofera (Makino) H. Gross 끈끈이여뀌; 243242 (1)

Persicaria viscofera var. robusta (Makino) Makino 큰끈끈이여뀌; 482137, $599833(5,10)$

Polygonum aviculare L. 마디풀; 235454, 305664, 387623, 441599, 481103, 552612, 576429, 599774 (1, 2, 3, 4, 5, 8, 9, 10)

Rumex acetosa $\mathrm{L}$. 수영; 235120, 284281, 359178, 441093, 468838, 523995, 569711, 578080 (1, 2, 3, 4, 5, 6, 9, 10)

Rumex acetosella L. 애기수영(A); 284411, 441558, 575721, $578528(2,4,9,10)$

Rumex crispus L. 소리쟁이(A); 235452, 284860, 441611, 468721, 523796, 569641, $578544(1,2,4,5,6,9,10)$

Rumex japonicus Houtt. 참소리쟁이; 235566, 305345, 441732, 481080, 523768, 552838 (1, 2, 4, 5, 6, 8)

Rumex maritimus L. 금소리쟁이; 523863 (6)

Rumex obtusifolius $\mathrm{L}$. 돌소리쟁 이(A); 305464, 481461, $524357(2,5,6)$

Rumex patientia L. 부령소리쟁이(A); 385589, 467809, 575543, 578539, $585200(3,6,7,9,10)$

Paeoniaceae 작약과

Paeonia japonica (Makino) Miyabe \& Takeda 백작약(II, LC); 284343, 359382, 583039, $591716(2,3,7,9)$

Paeonia lactiflora var. trichocarpa (Bunge) Stern 참작약(IV, NT); 284591 (2)

Paeonia obovata Maxim. 산작약(V, EN); 235446, Photo002 (1, 3)

Actinidiaceae 다래과

Actinidia arguta (Siebold \& Zucc.) Planch. ex Miq. 다래; 305591, 385413, 441208, 472763, 523999, 575702, 585168, 599483 (2, 3, 4, 5, 6, 7, 9, 10) Actinidia kolomikta (Maxim. \& Rupr.) Maxim. 쥐다래(III); 236898, 385480, 441321, 495462, 569671, 585749, 599143 (1, 3, 4, 5, 7, 9, 10)

Actinidia polygama (Siebold \& Zucc.) Maxim. 개다래; 244436, 305487, 385407, 441264, 472693, 575441, 578450, 585503 (1, 2, 3, 4, 5, 7, 9, 10)

Clusiaceae 물레나물과

Hypericum ascyron L. 물레나물; 235611, 305599, 387504, 446682, 472531, 524570, 585966, 599403 (1, 2, 3, 4, 5, 6, 7, 10)

Hypericum attenuatum Fisch. ex Choisy 채고추나물(II, LC); 528523 (6)

Hypericum erectum Thunb. 고추나물; 235658, 305454, 387513, 446480, 472589, 528442, 551890, 552656, 590979, 599007 (1, 2, 3, 4, 5, 6, $7,8,9,10)$

Tiliaceae 피나무과

Corchoropsis psilocarpa Harms \& Loes. 까치깨(III); 310111, 528501, 552607, 574417, 599208 (2, 6, 8, 9, 10)

Corchoropsis tomentosa (Thunb.) Makino 수까치깨; 245359, 309890, 390366, 451372, 472869, 530403, 574412, 590032, 599158 (1, 2, 3, 4, 5, 6, 7, 9, 10) 
Appendix 1. Continued.

Tilia amurensis Rupr. 피나무(II); 245197, 390337, 441503, 495438, 569614, 586012, $599346(1,3,4,5,7,9,10)$

Tilia mandshurica Rupr. \& Maxim. 찰피나무(II); 242157, 305293, 385498, 441883, 482205, 523890, 574873, 585996 (1, 2, 3, 4, 5, 6, 7, 9)

Malvaceae 아욱과

Abutilon theophrasti Medik. 어저귀(A); 243144, $528404(1,6)$

Hibiscus trionum L. 수박풀(A); 244042, 310086, 387492, 450001, 530358, 552589, 574942, 590092, 598944 (1, 2, 3, 4, 6, 7, 8, 9, 10)

Violaceae 제비꽃과

Viola acuminata Ledeb. 졸방제비꽃; 235293, 284333, 359082, 441342, 468833, 520781, 552226, 577182, 580342 (1, 2, 3, 4, 5, 6, 7, 8, 9)

Viola albida Palib. 태백제비꽃; 243941, 468989, 552392, 577148, $577740(1,5,8,9,10)$

Viola albida var. chaerophylloides (Regel) F. Maek. 남산제비꽃; 284450, 433261, 469029, 552086, 565946, 577060, 577683 (2, 4, 5, 7, 8, 9, 10)

Viola betonicifolia var. albescens (Nakai) F. Maek. \& T. Hashim. 흰들제비꽃; 520857, $578137(6,10)$

Viola breviflora J. Lee \& M. Kim 방울제비꽃(E); 593886 (3)

Viola collina Besser 둥근털제비꽃; 244442, 284304, 354908, 433092, 469073, 520317, 552036, 566056, 577553, 583017 (1, 2, 3, 4, 5, 6, 7, 8, 9, 10)

Viola diamantiaca Nakai 금강제비꽃(III, LC); 359386, 495878, 577733, $583036(3,5,9,10)$

Viola hirtipes S. Moore 흰털제비꽃; $468988,583067(5,9)$

Viola keiskei Miq. 잔털제비꽃; 235136, 284522, 354912, 463997, 552269, 577077, $577775(1,2,3,5,8,9,10)$

Viola lactiflora Nakai 흰젖제비꽃; 468842 (5)

Viola mandshurica W. Becker 제비꽃; 234922, 359381, 433146, 469058, 520355, 566054, 577751 (1, 3, 4, 5, 6, 7, 10)

Viola mirabilis $\mathrm{L}$. 넓은잎제비꽃(V, EN); 235138 (1)

Viola orientalis (Maxim.) W. Becker 노랑제비꽃(II); 235339, 284289, 359130, 433214, 468949, 552287, 569717, 577732 (1, 2, 3, 4, 5, 8, 9, 10)

Viola phalacrocarpa Maxim. 털제비꽃; 468986, 520284, 552256, 565925, 577752, 583121 (5, 6, 7, 8, 9, 10)

Viola rossii Hemsl. 고깔제비꽃; 284301, 468987, 552356, 577160, 577742, 520923 (2, 5, 6, 8, 9, 10)

Viola selkirkii Pursh ex Goldie 뫼제비꽃; 244001, 284475, 359104, $577145(1,2,3,9)$

Viola seoulensis Nakai 서울제비꽃(E); 235135, 284848, 354910, 433328, 463968, 520277, 552009, 565983, 577812, 583019 (1, 2, 3, 4, 5, 6, 7, 8, 9, 10)

Viola tokubuchiana var. takedana (Makino) F. Maek. 민둥뫼제비꽃(II); 235299, 354988, 469072, 552053, 565924, 577061, 577687 (1, 5, 7, 8, 9, 10)

Viola variegata Fisch. ex Link 알록제비꽃; 235014, 284298, 359455, 441432, 463981, 520307, 552033, 565923, 577175, 577776 (1, 2, 3, 4, $5,6,7,8,9,10)$

Viola verecunda A. Gray 콩제비꽃; 235116, 284305, 441554, 495679, 577772, 583068 (1, 2, 4, 5, 9, 10)

Viola websteri Hemsl. 왕제비꽃(V, VU); 235486 (1)

Viola yedoensis Makino 호제비꽃; 284412, 359175, 463983, 520356, 552100, 565984, 577581 (2, 3, 5, 6, 7, 8, 10)

Cucurbitaceae 박과

Schizopepon bryoniifolius Maxim. 산외(IV); 244136, 387653, 449918, 495712, 590967, 599493 (1, 3, 4, 5, 7, 10)

Sicyos angulatus L. 가시박(A); 242303, 482298, $599684(1,5,10)$

Trichosanthes kirilowii Maxim 하늘타리; 241997, 310205, 472808, 524534 (1, 2, 5, 6)

Salicaceae 버드나무과

Populus davidiana Dode 사시나무; 243762, 396064, 449739, $577853(1,3,4,10)$

Salix babylonica L. 수양버들; 284424, $468848(2,5)$

Salix caprea L. 호랑버들; 234927, 284474, 354959, 433320, 469053, 520322, 552024, 568272, 577702, 583026 (1, 2, 3, 4, 5, 6, 7, 8, 9, 10)

Salix chaenomeloides Kimura 왕버들(I); 235008, $468845(1,5)$

Salix gracilistyla Miq. 갯버들; 235105, 284302, 354903, 433179, 469054, 552011, 566046, 577712, 583029 (1, 2, 3, 4, 5, 7, 8, 9, 10)

Salix koriyanagi Kimura ex Goerz 키버들(E); 245146, 284353, 354905, 433322, 463984, 520853, 552067, 566031, 577101, 577704 (1, 2, 3 , $4,5,6,7,8,9,10)$

Salix pierotii Miq. 버드나무; 234947, 284313, 354904, 433109, 495824, 520295, 566034, 577150, $577562(1,2,3,4,5,6,7,9,10)$

Salix rorida Laksch. 분버들(III); 433108 (4)

Salix siuzevii Seemen 참오글잎버들(III); 433107 (4)

Salix triandra subsp. nipponica (Franch. \& Sav.) A. K. Skvortsov 선버들; 234948, 354906, 433149, 495211, 566045, 577722 (1, 3, 4, 5, 7, 10)

Salix xerophila Flod. 여우버들(III); 237034 (3)

Brassicaceae 십자화과

Arabis gemmifera (Matsum.) Makino 산장대; 441164, 578392, $583010(4,9,10)$

Arabis glabra (L.) Bernh. 장대나물; 235436, 284826, 385587, 441153, 468798, 520885, 553857, 575925, 578059, 580386 (1, 2, 3, 4, 5, 6, 7, 8, 9, 10)

Arabis hirsuta (L.) Scop. 털장대; 234992, 359061, 441242, 575692, 578026, $580387(1,3,4,7,9,10)$

Arabis pendula L. 느러진장대(III); 242443, 305574, 390330, 449348, 482815, $599333(1,2,3,4,5,10)$

Barbarea orthoceras Ledeb. 나도냉이; 284322, 359256, 433122, 468789, 566035, $578216(2,3,4,5,7,10)$

Barbarea vulgaris R. Br. 유럽나도냉이(A); 359187, 441330, 577753, 583125, 585134 (3, 4, 7, 9, 10)

Berteroella maximowiczii (Palib.) O. E. Schulz 장대냉이; 305533, 387618, 446819, 482340, 528405, 552854, 576701, 578996, 585913 (2, 3, 4, 5, 6, 7, 8, 9, 10)

Capsella bursa-pastoris (L.) Medik. 냉이; 284366, 359168, 433095, 463991, 520335, 552039, 566029, 577766, 583025 (2, 3, 4, 5, 6, 7, 8, 9, 10)

Cardamine fallax (O. E. Schulz) Nakai 좁쌀냉이; 359228, 464008, 520778, 552163, 566127, 577179, 577765 (3, 5, 6, 7, 8, 9, 10)

Cardamine flexuosa With. 황새냉이; 284269, 394083, 451819, 463973, 577180, 599071 (2, 3, 4, 5, 9, 10)

Cardamine impatiens L. 싸리냉이; 284348, 359062, 441550, 495396, 577764, 580345, 583009 (2, 3, 4, 5, 7, 9, 10)

Cardamine komarovii Nakai 는쟁이냉이(III); 577156 (9) 
Appendix 1. Continued.

Cardamine leucantha (Tausch) O. E. Schulz 미나리냉이; 284372, 359105, 441769, 495272, 520833, 552229, 566117, 577806, 583061 (2, 3, 4, 5, 6, $7,8,9,10)$

Descurainia sophia (L.) Webb ex Prantl 재쑥(A); 284330, $468746(2,5)$

Dontostemon dentatus (Bunge) Ledeb. 가는장대; 387625, 441771, $599591(3,4,10)$

Draba nemorosa L. 꽃다지; 284360, 354915, 433090, 463972, 520304, 552041, 565970, 577114, $577769(2,3,4,5,6,7,8,9,10)$

Erysimum macilentum Bunge 쑥부지깽이(III, LC); 523782, $592919(6,9)$

Lepidium campestre (L.) R. Br. 들다닥냉이(A); 441774 (4)

Lepidium densiflorum Schrad. 길다닥냉이(A); 585735 (7)

Lepidium virginicum $\mathrm{L}$. 콩다닥냉이(A); 385531, 441669, 468800, 575940, 578141, $585355(3,4,5,7,9,10)$

Nasturtium officinale W. T. Aiton 물냉이(A); 523794, 552994, $578877(6,8,10)$

Rorippa globosa (Turcz. ex Fisch. \& C. A. Mey.) Hayek 구슬갓냉이(III); 245274, 552834, 579131 (1, 8, 10)

Rorippa indica (L.) Hiern 개갓냉이; 235560, 284824, 441091, 468885, 523766, 575560 (1, 2, 4, 5, 6, 9)

Rorippa palustris (L.) Besser 속속이풀; 235570, 359257, 441183, 472793, 523856, 568246, $578848(1,3,4,5,6,7,10)$

Rorippa sylvestris (L.) Besser 가새잎개갓냉이(A); 441798 (4)

Sisymbrium luteum (Maxim) O. E. Schulz 노란장대(I); 284662, 359258, 441318, 495430, 569716, $585381(2,3,4,5,7,9)$

Thlaspi arvense L. 말냉이(A); 234914, 284700, 354947, 433318, 463976, 520331, 552045, 566187, 577117, 577730 (1, 2, 3, 4, 5, 6, 7, 8, 9, 10)

Ericaceae 진달래과

Rhododendron micranthum Turcz. 꼬리진달래(IV); 235670, 468937, 520319, 553032, $575785(1,5,6,8,9)$

Rhododendron mucronulatum Turcz. 진달래; 243917, 309917, 354922, 433304, 468969, 520323, 552051, 565936, 577700, 583098 (1, 2, 3, 4, 5, 6, 7, 8, 9, 10)

Rhododendron schlippenbachii Maxim. 철쭉; 235316, 284286, 359120, 441106, 468971, 553533, 575706, 577798, 585482 (1, 2, 3, 4, 5, 7, 8, 9, 10)

Rhododendron yedoense f. poukhanense (H. Lév.) M. Sugim. 산철쭉; 245144, 441884, 469017, 520876, 583042 (1, 4, 5, 6, 9)

Vaccinium hirtum var. koreanum (Nakai) Kitam. 산앵도나무(III); 235329, 359146, 441463, 468940, 553026, 575920, 598985 (1, 3, 4, 5, 8, 9, 10)

Pyrolaceae 노루발과

Chimaphila japonica Miq. 매화노루발; 243333, 390471, 433368, 468980, 520312, 575819, 599645 (1, 3, 4, 5, 6, 9, 10)

Pyrola japonica Klenze ex Alef. 노루발; 235669, 305750, 385665, 441293, 468982, 552640, 575818, 578344, 585491 (1, 2, 3, 4, 5, 8, 9, 10)

Monotropaceae 수정난풀과

Monotropa hypopitys L. 구상난풀(V, LC); 236922, 305285, 387387, 495847, $574884(1,2,3,5,9)$

Monotropastrum humile (D. Don) H. Hara 나도수정초(II, LC); 578835 (10)

Ebenaceae 감나무과

Diospyros lotus L. 고욤나무; 235705, 305321, 472824, 523771, 553033 (1, 2, 5, 6, 8)

Styracaceae 때죽나무과

Styrax japonicus Siebold \& Zucc. 때죽나무; 481418 (5)

Styrax obassis Siebold \& Zucc. 쪽동백나무; 284536, 446917, 469064, 578363 (2, 4, 5, 10)

Symplocaceae 노린재나무과

Symplocos sawafutagi Nagam. 노린재나무; 243232, 441678, 468932, 575919, 599541 (1, 4, 5, 9, 10)

Primulaceae 앵초과

Androsace filiformis Retz. 애기봄맞이; 599244 (10)

Androsace umbellata (Lour.) Merr. 봄맞이꽃; 234924, 284413, 359173, 464009, 520330, 552149, 566057, 575794, 577770 (1, 2, 3, 5, 6, 7, 8, 9, 10)

Lysimachia barystachys Bunge 까치수염(I); 243323, 305559, 524371, $553269(1,2,6,8)$

Lysimachia clethroides Duby 큰까치수염; 235536, 305304, 387495, 446535, 472590, 524499, 552935, 576688, 585960, 599538 (1, 2, 3, 4, 5, 6, 7, 8, 9, 10)

Lysimachia coreana Nakai 참좁쌀풀(E, IV, LC); 235617, 387496, 446423, $579175(1,3,4,10)$

Lysimachia davurica Ledeb. 좁쌀풀(III); 245207, 446370, 495726, 552940, 576423, 599608 (1, 4, 5, 8, 9, 10)

Primula jesoana var. pubescens (Takeda) Takeda \& H. Hara 큰앵초(II); 385387, 495467, $569623(3,5,9)$

Hydrangeaceae 수국과

Deutzia glabrata Kom. 물참대(I); 235459, 284639, 359127, 441312, 495297, 553840, 569695, 578045, 580362 (1, 2, 3, 4, 5, 7, 8, 9, 10) Deutzia parviflora Bunge 말발도리(I); 245204, 305629, 385529, 441249, 468820, 523969, 569691, 578170, 585151 (1, 2, 3, 4, 5, 6, 7, 9, 10) Deutzia uniflora Shirai 매화말발도리(I); 234906, 359116, 433121, 481163, 520827, 552258, 565991, $577141(1,3,4,5,6,7,8,9)$

Hydrangea serrata var. acuminata (Siebold \& Zucc.) Nakai 산수국; 235472, 324127, 449416, 472769, $599369(1,2,4,5,10)$

Philadelphus tenuifolius Rupr. 엷은잎고광나무; 235145, 284541, 385410, 441248, 495400, 523983, 553892, 575924, 578372, 580335 (1, 2, 3, 4, 5, 6, $7,8,9,10)$

\section{Grossulariaceae 까치밥나무과}

Ribes fasciculatum var. chinense Maxim. 까마귀밥나무; 449711 (4)

Ribes komarovii Pojark. 꼬리까치 밥나무; 433163, 495478, 569728, 577682, 585133 (4, 5, 7, 9, 10)

Ribes mandshuricum (Maxim.) Kom. 까치밥나무(III); 385423, $578407(3,10)$

Crassulaceae 돌나물과

Hylotelephium erythrostictum (Miq.) H. Ohba 뀡의비름; 451240, 495788, 551767, 599735 (4, 5, 9, 10)

Hylotelephium viviparum (Maxim.) H. Ohba 새끼뀡의비름(II); 387936, 446747, 552661, $575533(3,4,8,9)$

Orostachys chongsunensis Y. N. Lee 정선바위솔(E); 398633, $551739(3,9)$

Orostachys japonica (Maxim.) A. Berger 바위솔; 394152, $482626(3,5)$ 
Appendix 1. Continued.

Orostachys minuta (Kom.) A. Berger 좀바위솔; 243934, 451499, $599737(1,4,10)$

Penthorum chinense Pursh 낙지다리(II, LC); 237035, 324174, 441736, 552897, 599756 (1, 2, 4, 8, 10)

Sedum aizoon L. 가는기린초; 236957, 284657, 387500, 441546, 481820, 552933, 575783, 578529, 585152 (1, 2, 3, 4, 5, 8, 9, 10)

Sedum kamtschaticum Fisch. \& C. A. Mey. 기린초; 235554, 284708, 385514, 441260, 472811, 523975, 569642, 580400, 599447 (1, 2, 3, 4, 5, 6, 7, 9, 10)

Sedum latiovalifolium Y. N. Lee 태백기린초(E, IV); 385756, $446582(3,4)$

Sedum polytrichoides Hemsl. 바위채송화; 243886, 387433, 451279, 481374, 552497, 574980, 598902 (1, 3, 4, 5, 8, 9, 10)

Sedum sarmentosum Bunge 돌나물; 235460, 284709, 385396, 441698, 523877, 553171, 569658, 578600, 585193 (1, 2, 3, 4, 6, 8, 9, 10)

Saxifragaceae 범의귀과

Astilbe chinensis (Maxim.) Franch. \& Sav. 노루오줌; 235630, 305289, 387406, 446381, 472611, 552944, 576686, 585903, 599549 (1, 2, 3, 4, 5, 7, 8, 9, 10) Astilbe koreana (Kom.) Nakai 숙은노루오줌; 245222, 284874, 387526, $578855(1,2,3,10)$

Astilboides tabularis (Hemsl.) Engl. 개병풍(V, NT); 385417 (3)

Chrysosplenium barbatum Nakai 흰털갱이눈(E); $385428,577545(3,4)$

Chrysosplenium flagelliferum F. Schmidt 애기괭이눈; 245126, 354948, 433173, 495278, 552052, 577686, 580480, 583109 (1, 3, 4, 5, 7, 8, 9, 10)

Chrysosplenium japonicum (Maxim.) Makino 산괭이눈(I); 245137, 433228, 552004, 577693, 583151 (1, 4, 8, 9, 10)

Chrysosplenium pseudofauriei H. Lév. 선괭이눈(I); 235113, 284681, 359098, 433116, 495488, 565950, 577701, 583013 (1, 2, 3, 4, 5, 7, 9, 10)

Chrysosplenium ramosum Maxim. 가지괭이눈(IV); 234902, $385429(1,3)$

Chrysosplenium valdepilosum (Ohwi) S. H. Kang \& J. W. Han 천마괭이눈(II); 433171, 577691 (4, 10)

Mukdenia rossii (Oliv.) Koidz. 돌단풍(II); 234910, 284337, 354971, 433128, 464010, 524479, 552112, 565942, 577170, 577698 (1, 2, 3, 4, 5, 6, 7, 8, 9, 10)

Rodgersia podophylla A. Gray 도깨비부채(IV, LC); 235348, 284554, 385398, 441239, 575690, 578484, $585794(1,2,3,4,7,9,10)$

Saxifraga fortunei var. alpina (Matsum. \& Nakai) Nakai 바위떡풀; 243219, 451710, 495855, 551736, 599096 (1, 4, 5, 9, 10)

Parnassiaceae 물매화과

Parnassia palustris var. multiseta Ledeb. 물매화; 245366, 323950, 395811, 451731, 482623, 530333, 590806, 599724 (1, 2, 3, 4, 5, 6, 7, 10)

\section{Rosaceae 장미과}

Agrimonia coreana Nakai 산짚신나물; 236996, 305456, 387556, 446551, 496054, 524575, 586082, 599539 (1, 2, 3, 4, 5, 6, 7, 10)

Agrimonia pilosa Ledeb. 짚신나물; 235606, 305627, 387573, 449378, 472538, 530279, 552609, 574956, 585843, 599464 (1, 2, 3, 4, 5, 6, 8, 9, 10)

Aruncus dioicus var. kamtschaticus (Maxim.) H. Hara 눈개승마(III); 235247, 359091, 441406, 553867, 575862, 578396, 580385 (1, 3, 4, 7, 8, 9, 10)

Cotoneaster integerrimus Medik. 개야광나무(V); 441446, $574516(4,9)$

Crataegus pinnatifida Bunge 산사나무; 441529, 523919, 576425, 578380, 580360 (4, 6, 7, 9, 10)

Duchesnea indica (Andr.) Focke 뱀딸기; 235056, 284391, 359063, 468861, 520792, 553829, 575699, 580388, 599068 (1, 2, 3, 5, 6, 7, 8, 9, 10)

Exochorda serratifolia S. Moore 가침박달(III, LC); 235031, 359236, 441100, 495354, $552976(1,3,4,5,8)$

Filipendula glaberrima Nakai 터리풀(I); 284530, 441581, 495681, $599443(2,4,5,10)$

Geum aleppicum Jacq. 큰뱀무; 236917, 284616, 385591, 441107, 472762, 524440, 552937, 569680, 578839, 585873 (1, 2, 3, 4, 5, 6, 8, 9, 10)

Geum japonicum Thunb. 뱀무; 235563, 385504, 446714, $495740(1,3,4,5)$

Malus baccata (L.) Borkh. 야광나무(I); 235339, 284660, 359066, 441125, 495250, 520768, 552261, 568254, 574411, 577978 (1, 2, 3, 4, 5, 6, 7, 8, 9, 10)

Neillia uyekii Nakai 나도국수나무(III, LC); 235243, 468715, 523907, $552844(1,5,6,8)$

Physocarpus amurensis (Maxim.) Maxim. 산국수나무(VU); 479014 (3)

Potentilla centigrana Maxim. 좀딸기(III); 235500, 359283, $578183(1,4,10)$

Potentilla chinensis Ser. 딱지꽃; 245279, 305355, 387534, 446660, 472764, 524370, 552906, 574899, 579121, 585925 (1, 2, 3, 4, 5, 6, 7, 8, 9, 10)

Potentilla cryptotaeniae Maxim. 물양지꽃(III); 236900, 387582, 446388, 495714, 576409, 578849, $585887(1,3,4,5,7,9,10)$

Potentilla dickinsii Franch. \& Sav. 돌양지꽃(II); 235667, 305745, 394072, 481381, 553165, 575810, $577989(1,2,3,5,8,9,10)$

Potentilla discolor Bunge 솜양지꽃(LC); 495525 (5)

Potentilla fragarioides L. 양지 꽃; 235081, 284415, 359101, 433290, 468959, 520297, 552034, 565945, 577107, 577711 (1, 2, 3, 4, 5, 6, 7, 8, 9, 10)

Potentilla freyniana Bornm. 세잎양지 ᄁᄁㅗㅊ; 235045, 520947, $552293(1,6,8)$

Potentilla kleiniana Wight \& Arn. 가락지나물; 235507, $481422(1,5)$

Potentilla rosulifera $\mathrm{H}$. Lév. 민눈양지꽃(II); 235143, 359353, $578040(1,3,10)$

Potentilla rugulosa Kitag. 당양지 꽃; 242130, 284604, 387779, 441713, 524517, 552858, 569617, 585328, 598948 (1, 2, 3, 4, 6, 7, 8, 9, 10)

Potentilla squamosa Soják 털양지꽃(E); 284514, 433380, 468962, 520790, 566168, $577174(2,4,5,6,7,9)$

Potentilla supina L. 개소시랑개비(A); 441729, 552842, $576430(4,8,9)$

Prunus choreiana Nakai ex H. T. Im 복사앵도(E, IV, NT); 245255, 305753, 394185, 433367, $574556(1,2,3,4,9)$

Prunus jamasakura Siebold ex Koidz. 벚나무; 284410, 441677, 481136, 520989, 577885, 583128, 585825 (2, 4, 5, 6, 7, 9, 10)

Prunus japonica var. nakaii (H. Lév.) Rehder 이스라지; 235060, 469046, 552274, 577859 (1, 5, 8, 10)

Prunus maackii Rupr. 개벚지나무(III); 441567, 578220, 583052 (4, 9, 10)

Prunus mandshurica (Maxim.) Koehne 개살구나무(III); 385412, 433113, 552291, 577154 (3, 4, 8, 9)

Prunus padus L. 귀룽나무; 235146, 284686, 359072, 441485, 566118, $577773(1,2,3,4,7,10)$

Prunus persica (L.) Batsch. 복사나무(A); 235022, 305529, 354966, 463965, 520836, 552268, 565953, 577755, 592922 (1, 2, 3, 5, 6, 7, 8, 9, 10)

Prunus sargentii Rehder 산벚나무(III); 234915, 469020, $577831(1,5,10)$

Prunus serrulata var. pubescens (Makino) Nakai 잔털벚나무; 245261, 359153, 468924, 520829, 552265, 566059, 577746, 583096 (1, 3, 5, 6, 7, 8, 9, 10) Prunus sibirica L. 시베리아살구나무(IV, LC); 235033, 284296, 354972, 520955, 552032, 577171, 578125, 580445 (1, 2, 3, 6, 7, 8, 9, 10) Prunus tomentosa Thunb. 앵 도나무(A); 235083, 433387, 481125, 523966, 566067, 577169, $577866(1,4,5,6,7,9,10)$ 
Appendix 1. Continued.

Pyrus ussuriensis Maxim. 산돌배나무(I); 284624, 394184, 441349, 495452, 523956, 565976, 577763, 583158 (2, 3, 4, 5, 6, 7, 9, 10)

Rhodotypos scandens (Thunb.) Makino 병아리꽃나무(III); 284802, $495339(2,5)$

Rosa acicularis Lindl. 인가목(II); 394300 (3)

Rosa davurica Pall. 생열 귀나무(IV); 451867, $599682(4,10)$

Rosa multiflora Thunb. 찔레나무; 284619, 385585, 441096, 468717, 523799, 552987, 569679, 578421 (2, 3, 4, 5, 6, 8, 9, 10)

Rosa spinosissima L. 둥근인가목(IV); 585496 (7)

Rubus coreanus Miq. 복분자딸기; 235549, 481072, 523805, $553261(1,5,6,8)$

Rubus crataegifolius Bunge 산딸기; 235160, 284678, 359483, 441196, 468757, 523908, 575897, 580358, 599449 (1, 2, 3, 4, 5, 6, 7, 9, 10)

Rubus oldhamii Miq. 줄딸기; 235212, 284282, 359215, 441192, 468783, 520832, 566039, 577795, 583120 (1, 2, 3, 4, 5, 6, 7, 9, 10)

Rubus parvifolius L. 멍석딸기; 242100, 284671, 385588, 441745, 468714, 523843, 552983, 569472, 578547, 590110 (1, 2, 3, 4, 5, 6, 7, 8, 9, 10)

Rubus phoenicolasius Maxim. 붉은가시딸기; 245231, 305421, 387661, 441544, 472668, 575628, 578860, 585756 (1, 2, 3, 4, 5, 7, 9, 10)

Sanguisorba officinalis L. 오이풀; 243795, 309883, 390297, 449446, 482185, 528390, 552484, 574903, 586046, 599157 (1, 2, 3, 4, 5, 6, 7, 8, 9, 10)

Sanguisorba tenuifolia Fisch. ex Link 가는오이풀(I); 244493 (1)

Sorbaria sorbifolia (L.) A. Braun 쉬땅나무(III); 396043, 441778, $599470(3,4,10)$

Sorbus alnifolia (Siebold \& Zucc.) K. Koch 팥배나무; 446646, 495907, 578499, 591111 (4, 5, 7, 10)

Sorbus commixta Hedl. 마가목(II); 495852, $578377(5,10)$

Spiraea blumei G. Don 산조팝나무(I); 235021, 284854, 359471, 441193, 468752, 523928, 553156, 575936, 578109, 585194 (1, 2, 3, 4, 5, 6, 8, 9, 10)

Spiraea chamaedryfolia L. 인가목조팝나무(III); 441572 (4)

Spiraea chinensis Maxim. 당조팝나무(III); 235037, 305323, 359190, 441148, 495345, 520968, 554070, 575591, 578025, 580357 (1, 2, 3, 4, 5, 6, 7, 8, 9, 10)

Spiraea fritschiana C. K. Schneid. 참조팝나무(III); 284546, 441560, $495359(2,4,5)$

Spiraea prunifolia var. simpliciflora (Nakai) Nakai 조팝나무; 234940, 284405, 359262, 441482, 468922, 520846, 552360, 577758, 565969 (1, 2, 3, 4, 5, 6, 7, 8, 10)

Spiraea pubescens Turcz. 아구장나무(I); 359117, $468818(3,5)$

Spiraea salicifolia L. 꼬리조팝나무(II); 245298, 441784, $599046(1,4,10)$

Spiraea trichocarpa Nakai 갈기조팝나무(IV); 235252, 284805, 385391, 441094, 523803, 553897, 569638, 578418 (1, 2, 3, 4, 6, 8, 9, 10)

Stephanandra incisa (Thunb.) Zabel 국수나무; 235284, 305603, 385405, 441228, 468794, 523846, 569469, 578367, 585173 (1, 2, 3, 4, 5, 6, 7, 9, 10)

Waldsteinia ternata (Stephan) Fritsch 나도양지꽃(IV); 433203 (4)

Fabaceae 콩과

Aeschynomene indica L. 자귀풀; 244385 (1)

Amorpha fruticosa L. 족제비싸리(A); 235448, 284609, 385337, 441147, 472844, 523835, 569442, 579198, 599843 (1, 2, 3, 4, 5, 6, 7, 9, 10)

Amphicarpaea bracteata subsp. edgeworthii (Benth.) H. Ohashi 새콩; 243457, 390317, 449592, 495762, 574509, 590590, 599138, 552582 (1, 3, 4, 5, 7, 8, 9, 10) Astragalus penduliflorus var. dahuricus (DC.) X. Y. Zhu 황기; 396041

Astragalus sikokianus Nakai 강화황기(III, LC); 284867, 385557, 441533, $569640(2,3,4,9)$

Astragalus sinicus L. 자운영(A); 235386 (1)

Caragana fruticosa (Pall.) Besser 참골담초(IV); 235254, 385533, $568251(1,3,7)$

Chamaecrista nomame (Siebold) H. Ohashi 차풀; 242366, 387892, 451330, 482344, 530285, 552654, 574852, 590109, 599049 (1, 3, 4, 5, 6, 7, 8, 9, 10)

Crotalaria sessiliflora L. 활나물; 552614 (8)

Gleditsia japonica Miq. 주엽나무; 235228 (1)

Glycine soja Siebold \& Zucc. 돌콩; 242229, 309949, 388023, 449372, 481846, 530282, 574858, 590177, 598950 (1, 2, 3, 4, 5, 6, 7, 9, 10)

Hylodesmum oldhamii (Oliv.) H. Ohashi \& R. R. Mill 큰도둑놈의갈고리; 242289, 323907, 495869, 574948, 585987, 598910 (1, 2, 5, 7, 9, 10)

Hylodesmum podocarpum (DC.) H. Ohashi \& R. R. Mill 개도둑놈의갈고리; 242261, 309870, 395826, 449754, 528526, 574860, 590078, $598924(1,2,3,4,6,7,9,10)$

Hylodesmum podocarpum subsp. oxyphyllum (DC.) H. Ohashi \& R. R. Mill 도둑놈의갈고리; 244093, 310122, 446596, 552601, 574943,

$585853,599397(1,2,4,7,8,9,10)$

Indigofera bungeana Walp. 큰낭아초(A); 528355, $553115(6,8)$

Indigofera kirilowii Maxim. ex Palib. 땅비싸리; 242071, 468814, 523800, $552978(1,5,6,8)$

Kummerowia stipulacea (Maxim.) Makino 둥근매듭풀; 242375, 472544, 530329, 599307 (1, 5, 6, 10)

Kummerowia striata (Thunb.) Schindl. 매듭풀; 387814, 449763, 481843, 552611, 591003, 598951 (3, 4, 5, 7, 8, 10)

Lathyrus davidii Hance 활량나물; 245339, 310045, 387498, 441490, 482719, 528441, 575701, 585860, 599319 (1, 2, 3, 4, 5, 6, 7, 9, 10)

Lathyrus quinquenervius (Miq.) Litv. 연리초(III); 235758 (1)

Lathyrus vaniotii $\mathrm{H}$. Lév. 산새콩; 235445, 284341, 359113, 441181, 569714, 578732, 580333 (1, 2, 3, 4, 7, 9, 10)

Lespedeza bicolor Turcz. 싸리; 235729, 305521, 387619, 446503, 481815, 524407, 552659, 576454, 585828, 599390 (1, 2, 3, 4, 5, 6, 7, 8, 9, 10)

Lespedeza cuneata (Dum. Cours.) G. Don. 비수리; 242368, 310024, 388061, 449919, 487772, 590133, 599840 (1, 2, 3, 4, 5, 7, 10)

Lespedeza cyrtobotrya Miq. 참싸리; 237021, 305747, 387905, 446432, 472568, 528517, 574965, 585930, 599391 (1, 2, 3, 4, 5, 6, 7, 9, 10)

Lespedeza davurica (Laxm.) Schindl. 호비수리(III); 242219, 528365, $556083(1,6,8)$

Lespedeza lichiyuniae T. Nemoto, H. Ohashi \& T. Itoh 자주비수리(A); 390382 (3)

Lespedeza maximowiczii C. K. Schneid. 조록싸리; 243884, 309934, 387630, 441746, 472587, 523944, 553030, 575777, 585366 (1, 2, 3, 4, 5, 6, 7, 8, 9)

Lespedeza thunbergii (DC.) Nakai 풀싸리; 390230, 449589, 472610, 599749 (3, 4, 5, 10)

Lespedeza tomentosa (Thunb.) Siebold ex Maxim. 개싸리; 242210, 310014, 390460, 530271, 590966, $599080(1,2,3,6,7,10)$

Lespedeza virgata (Thunb.) DC. 좀싸리; 243781, 309861, 482196, $530390(1,2,5,6)$ 
Appendix 1. Continued.

Lotus corniculatus L. 서양벌노랑이(A); 305368, 441792, $585731(2,4,7)$

Lotus corniculatus var. japonicus Regel 벌노랑이; 387745, 446832, 495511, 524483, 552985 (3, 4, 5, 6, 8)

Maackia amurensis Rupr. 다릅나무; 385408, 441388, 472620, 585474 (3, 4, 5, 7)

Medicago lupulina L. 잔개자리(A); 284611, 385380, 441250, 523848, 553916, 569712, 578285, 579208 (2, 3, 4, 6, 7, 8, 9, 10)

Medicago polymorpha L. 개자리(A); 385526 (3)

Medicago sativa L. 자주개자리(A); 243283, 305367, 385357, 441696, $575852(1,2,3,4,9)$

Melilotus albus Medik. 흰전동싸리(A); 235539, 305480, 385379, 441219, 524448, 552945, 569449, 585384, 599581 (1, 2, 3, 4, 6, 7, 8, 9, 10)

Melilotus suaveolens Ledeb. 전동싸리(A); 235763, 305479, 387634, 446811, 472781, 530434, 552564, 575788, 585886 (1, 2, 3, 4, 5, 6, 7, 8, 9)

Pueraria lobata (Willd.) Ohwi 칡; 235774, 309873, 446406, 472849, 524533, 574892, 585932, 599501 (1, 2, 4, 5, 6, 7, 9, 10)

Robinia pseudoacacia L. 아까시나무(A); 235384, 305498, 385555, 441199, 468718, 523984, 553855, 569688, 580398, 598965 (1, 2, 3, 4, 5, 6, 7, 8, 9, 10)

Sophoraflavescens Aiton 고삼; 235528, 305583, 385704, 446933, 481115, 524368, 552878, 575779, 578882, 591856 (1, 2, 3, 4, 5, 6, 7, 8, 9, 10)

Trifolium pratense L. 붉은토끼풀(A); 235214, 340635, 394355, 441156, 481139, 575911, 578761, 585408 (1, 2, 3, 4, 5, 7, 9, 10)

Trifolium repens L. 토끼풀(A); 235149, 385535, 441089, 468748, 553901, 575704, 578186, $585153(1,3,4,5,7,8,9,10)$

Vicia amoena Fisch. ex Ser. 갈퀴나물; 237043, 528360, 552909, $569657(1,6,8,9)$

Vicia amurensis Oett. 벌완두; 244503, 305503, 385567, 441355, 481158, 528471, 576700, 578875, 585388 (1, 2, 3, 4, 5, 6, 7, 9, 10)

Vicia bungei Ohwi 들완두(IV); 284331, $441613(2,4)$

Vicia chosenensis Ohwi 노랑갈퀴(E, III); 235249, 284571, 359121, 441341, 495445, 553020, 569710, 578733, 580453 (1, 2, 3, 4, 5, 7, 8, 9, 10)

Vicia nipponica Matsum. 네잎갈퀴나물; 551725 (9)

Vicia pseudorobus Fisch. \& C. A. Mey. 큰등갈퀴(I); 244468, 390459, 482088, 590758, 599365 (1, 3, 5, 7, 10)

Vicia sativa subsp. nigra (L.) Ehrh. 가는살갈퀴; 468872, 523792, $578083(5,6,10)$

Vicia tetrasperma (L.) Schreb. 얼치기완두; 245150, 495529, $520866(1,5,6)$

Vicia unijuga A. Braun 나비나물; 242256, 305366, 387540, 441200, 488051, 530347, 576412, 585445, $598964(1,2,3,4,5,6,7,9,10)$

Vicia venosa var. cuspidata Maxim. 광릉갈퀴; 235664, 387545, 575632, $578460(1,3,9,10)$

Vicia villosa Roth 벳지(A); 245284 (1)

Vigna angularis var. nipponensis (Ohwi) Ohwi \& H. Ohashi 새팥; 242077, 310125, 530283, 552655, 590183, 599771 (1, 2, 6, 7, 8, 10)

Vigna minima (Roxb.) Ohwi \& H. Ohashi 좀돌팥; 481793 (5)

Elaeagnaceae 보리수나무과

Elaeagnus umbellata Thunb. 보리수나무; 235234, 284808, 395950, 441115, 469024, 523873, 554097, 575917, 580338 (1, 2, 3, 4, 5, 6, 7, 8, 9)

Lythraceae 부처꽃과

Lythrum anceps (Koehne) Makino 부처꽃; 449969, 599229 (4, 10)

Lythrum salicaria L. 털부처꽃; $243671,446442,552948,599230(1,4,8,10)$

Thymelaeaceae 팥꽃나무과

Daphne pseudomezereum var. koreana (Nakai) Hamaya 두메 닥나무(IV, NT); 354984, $433224(3,4)$

Diarthron linifolium Turcz. 아마풀(V, NT); 235537, 324136, 387990, 524462, 552911 (1, 2, 3, 6, 8)

Onagraceae 바늘꽃과

Circaea alpina L. 쥐털이슬(II); 552499 (8)

Circaea canadensis subsp. quadrisulcata (Maxim.) Boufford 말털이슬(II); 236875, $449820(1,4)$

Circaea cordata Royle 쇠털이슬(I); 242311, 305628, 387510, 449380, 552489, $574785(1,2,3,4,8,9)$

Circaea erubescens Franch. \& Sav. 붉은털이슬(III); 574962 (9)

Circaea mollis Siebold \& Zucc. 털이슬; 244004, 305449, 449595, 495872, 552664, 586065, 599128 (1, 2, 4, 5, 7, 8, 10)

Epilobium amurense subsp. cephalostigma (Hausskn.) C. J. Chen, Hoch \& P. H. Raven 돌바늘꽃; 236889, 310070, 390235, 449495, 495770, $551971,590974,599370(1,2,3,4,5,7,9,10)$

Epilobium hirsutum L. 큰바늘 꽃(V, NT); 387641 (3)

Epilobium pyrricholophum Franch. \& Sav. 바늘꽃; 236937, $449462(1,4)$

Ludwigia epilobioides Maxim. 여뀌바늘; 237044, 481833, 556081, 599764 (1, 5, 8, 10)

Oenothera biennis L. 달맞이꽃(A); 243244, 305466, 387633, 446375, 472782, 528304, 552560, 574922, 585876, 599548 (1, 2, 3, 4, 5, 6, 7, 8, 9, 10)

Alangiaceae 박쥐나무과

Alangium platanifolium var. trilobum (Miq.) Ohwi 박쥐나무; 235732, 305557, 385490, 441225, 495328, 523889, 575646, 578850, 580364 (1, 2, 3, 4, 5, 6, 7, 9, 10) Cornaceae 충충나무과

Cornus controversa Hemsl. 층층나무; 235778, 284651, 387397, 441297, 469061, 524027, 553859, 569670, 578520 (1, 2, 3, 4, 5, 6, 8, 9, 10) Cornus walteri Wangerin 말채나무; 235174, 305328, 394173, 441238, 495640, 523802, 575823, 578768 (1, 2, 3, 4, 5, 6, 9, 10)

Santalaceae 단향과

Thesium chinense Turcz. 제비꿀; 237034, 324151, 359059, 441846, 468964, 520938, 553910, 568243, 569476, 578028 (1, 2, 3, 4, 5, 6, 7, 8, 9, 10)

Viscum coloratum (Kom.) Nakai 겨우살이; 235304, 359139, 433154, 577062, 577741, 586044 (1, 3, 4, 7, 9, 10)

Celastraceae 노박덩굴과

Celastrus flagellaris Rupr. 푼지나무; 390483, 441499, 472645, 553837, 575935, $578103(3,4,5,8,9,10)$

Celastrus orbiculatus Thunb. 노박덩굴; 235432, 305305, 385414, 446939, 468791, 523992, 551909, 553905, 580366, 599450 (1, 2, 3, 4, 5, 6, 7, 8, 9, 10)

Euonymus alatus (Thunb.) Siebold 화살나무; 244058, 305507, 359250, 451693, 468710, 520777, 554086, 577178, 577830, 580372 (1, 2, 3, 4, 5, 6, 7, 8, 9, 10)

Euonymus hamiltonianus Wall. 참빗살나무; 244406, 385657, 441665, $578828(1,3,4,10)$ 
Appendix 1. Continued.

Euonymus hamiltonianus var. maackii (Rupr.) Kom. 좁은잎참빗살나무(I); 244349, 310215, 537585, 552849, 578424 (1, 2, 6, 8, 10)

Euonymus macropterus Rupr. 나래회나무(II); 235301, 284531, 359160, 495496, 575932, 577782 (1, 2, 3, 5, 9, 10)

Euonymus oxyphyllus Miq. 참회나무; 243937, 305764, 385673, 441438, 469023, 569734, 586035, 599730 (1, 2, 3, 4, 5, 7, 9, 10)

Euonymus pauciflorus Maxim. 회목나무(II); 245213, 309957, 359123, 441439, 495395, 552646, 569732, 585147 (1, 2, 3, 4, 5, 7, 8, 9)

Euonymus sachalinensis (F. Schmidt) Maxim. 회나무(I); 446777, 574827, $578463(4,9,10)$

Tripterygium regelii Sprague \& Takeda 미역줄나무(II); 243217, 305374, 387454, 441358, 481388, 552938, 575716, $578845(1,2,3,4,5,8,9,10)$

Buxaceae 회양목과

Buxus microphylla var. koreana Nakai ex Rehder 회양목(I); 234895, 284599, 385747, 433435, 463987, 520316, 552170, 565932, 569618, $577719(1,2,3,4,5,6,7,8,9,10)$

Euphorbiaceae 대극과

Acalypha australis L. 깨풀; 235727, 309960, 388038, 449369, 482787, 599844 (1, 2, 3, 4, 5, 10)

Euphorbia ebracteolata Hayata 붉은대극(III); 284259, $463988(2,5)$

Euphorbia fischeriana Steud. 낭독(DD); 815549

Euphorbia helioscopia L. 등대풀; 284356 (2)

Euphorbia humifusa Willd. 땅빈대; 244391, 309924, 387476, 446877, 472839, 528410, 552914, 585888, 599203 (1, 2, 3, 4, 5, 6, 7, 8, 10) Euphorbia hypericifolia L. 큰땅빈대(A); 235632, 310151, 396046, 472804, 528363, 552598, 576461, 585941, 599772 (1, 2, 3, 5, 6, 7, 8, 9, 10)

Euphorbia maculata L. 애기땅빈대(A); 237049, 472546, 524029, 574921, $599575(1,5,6,9,10)$

Euphorbia pekinensis Boiss. 대극(I); 235058, 520303, $554104(1,6,8)$

Euphorbia sieboldiana C. Morren \& Decne. 개감수; 235203, 387516, 441461, 495372, 552105, 565999, 576692, 577708 (1, 3, 4, 5, 7, 8, 9, 10)

Flueggea suffruticosa (Pall.) Baill. 광대싸리; 235618, 385598, 441537, 472825, 524422, 552986, 576410, 585877, 599842 (1, 3, 4, 5, 6, 7, 8, 9, 10)

Phyllanthus ussuriensis Rupr. \& Maxim. 여우주머니; 242425, 310038, 472557, 574838, 599292 (1, 2, 5, 9, 10)

Rhamnaceae 갈매나무과

Hovenia dulcis Thunb. 헛개나무(I); 284661, 395834, $575625(2,3,9)$

Rhamnus parvifolia Bunge 돌갈매나무(IV); 242069, 284580, 385370, 495464, $585487(1,2,3,5,7)$

Rhamnus ussuriensis J.-J. Vassal 참갈매나무(III); 235433, 482347, 523801, 554075, 580354, 599795 (1, 5, 6, 7, 8, 10)

Rhammus yoshinoi Makino 짝자래나무; 245288, 284699, 390384, 441098, 481122, 520839, 554084, 569729, 578032, 586066 (1, 2, 3, 4, 5, 6, 7, 8, 9, 10)

Vitaceae 포도과

Ampelopsis brevipedunculata (Maxim.) Trautv. 개머루; 242431, 310099, 395968, 449489, 472740, 524406, 552616, 575793, 590101, $599045(1,2,3,4,5,6,7,8,9,10)$

Parthenocissus tricuspidata (Siebold \& Zucc.) Planch. 담쟁이덩굴; 305364, 441670, 472588, $523950(2,4,5,6)$

Vitis amurensis Rupr. 왕머루; 235288, 359226, 441241, 469021, 553263, 578234, $580369(1,3,4,5,7,8,10)$

Vitis flexuosa Thunb. 새머루; 235547, 394220, 446886, 472780, 523998, 578992, $590052(1,3,4,5,6,7,10)$

Linaceae 아마과

Linum stelleroides Planch. 개아마(IV); 242213, 309855, 390444, 482702, 530297, 574537, 590779, 599153 (1, 2, 3, 5, 6, 7, 9, 10)

Polygalaceae 원지과

Polygala japonica Houtt. 애기풀; 245228, 310197, 468951, $552974(1,2,5,8)$

Polygala sibirica L. 두메애기풀(IV); 235245, 575904, 585454, $599569(1,7,9,10)$

Polygala tatarinowii Regel 병아리풀(IV, LC); 242057, 323943, 390457, 488052, 530334, 552610, 574495, 585856, 599075 (1, 2, 3, 5, 6, 7, 8, 9, 10)

Staphyleaceae 고추나무과

Staphylea bumalda DC. 고추나무; 235171, 284539, 385493, 441112, 495323, 520825, 575641, 585361, 599494 (1, 2, 3, 4, 5, 6, 7, 9, 10)

Aceraceae 단풍나무과

Acer barbinerve Maxim. 청시닥나무(III); 385424, $583015(3,9)$

Acer komarovii Pojark. 시닥나무(III); 359414, $495848(3,5)$

Acer mandshuricum Maxim. 복장나무(III); 390336, $578004(3,10)$

Acer pictum var. mono (Maxim.) Franch. 고로쇠나무; 235350, 284849, 359205, 441255, 472770, 520981, 577184, 577759, 585195 (1, 2, 3, 4, 5, 6, 7, 9, 10) Acer pseudosieboldianum (Pax) Kom. 당단풍나무; 235318, 305422, 395897, 441333, 472735, 553524, 577783, 583117, 585386 (1, 2, 3, 4, 5, 7, 8, 9, 10)

Acer tataricum subsp. ginnala (Maxim.) Wesm. 신나무; 235192, 305481, 394388, 441149, 468792, 523816, 554101, 575717, 580332,

$599823(1,2,3,4,5,6,7,8,9,10)$

Acer tegmentosum Maxim. 산겨릅나무(IV); 385447, $578236(3,10)$

Acer triflorum Kom. 복자기(III); 245208, 284473, 385720, 441348, 495492, 552138, 568260, $577846(1,2,3,4,5,7,8,10)$

Anacardiaceae 옻나무과

Rhus javanica L. 붉나무; 236986, 309865, 387606, 446411, 481782, 528450, 552590, 574496, 586041, 598952 (1, 2, 3, 4, 5, 6, 7, 8, 9, 10)

Toxicodendron trichocarpum (Miq.) Kuntze 개옻나무; 235527, 284517, 359154, 441133, 468930, 523931, 552991, 569629, 585180, 598959 (1, 2, 3, 4, 5, 6, 7, 8, 9, 10)

Simaroubaceae 소태나무과

Ailanthus altissima (Mill.) Swingle 가중나무(A); 236940, 284868, 446365, 524395, 553054, $578546(1,2,4,6,8,10)$

Picrasma quassioides (D. Don) Benn. 소태나무; 235796, 305283, 394264, 441496, 468755, 523821, 553257, 578006, 585530 (1, 2, 3, 4, 5, 6, 7, 8, 10)

Rutaceae 운향과

Dictamnus dasycarpus Turcz. 백선(I); 235373, 310034, 468712, 523779, 554076, $599571(1,2,5,6,8,10)$

Phellodendron amurense Rupr. 황벽나무(II); 446765 (4) 
Appendix 1. Continued.

Tetradium daniellii (Benn.) T. G. Hartley 쉬나무; 387717, 482731, $528354(3,5,6)$

Zanthoxylum piperitum DC. 초피나무; 323876, $468846(2,5)$

Zanthoxylum schinifolium Siebold \& Zucc. 산초나무; 235677, 284834, 394373, 449940, 472594, 524546, 574859, 585829, 599502 (1, 2, 3, 4, 5, 6, 7, 9, 10) Oxalidaceae 갱이밥과

Oxalis corniculata L. 괭이밥; $481101,553146,575845(5,8,9)$

Oxalis dillenii Jacq. 들괭이밥(A); $578730,591918(7,10)$

Oxalis obtriangulata Maxim. 큰괭이밥; 235255, 359453, 569737, $577685(1,3,9,10)$

Oxalis stricta L. 선괭이밥; 284698, 468806, $585521(2,5,7)$

Geraniaceae 쥐손이풀과

Geranium koreanum Kom. 둥근이질풀(II); $574958,599386(9,10)$

Geranium sibiricum L. 쥐손이풀; 242064, 324026, 449865, 481789, 524431, 551904, 590491, 599029 (1, 2, 4, 5, 6, 7, 9, 10)

Geranium thunbergii Siebold ex Lindl. \& Paxton 이질풀; 235770, 305581, 387377, 446659, 472779, 528485, 574971, 590103, 598922 (1, 2, 3, 4, 5, 6, 7, 9, 10)

Geranium wilfordii Maxim. 세잎쥐손이; 243456, 390334, 449933, 528419, 551969, 591039, 598963 (1, 3, 4, 6, 7, 9, 10)

Balsaminaceae 봉선화과

Impatiens nolitangere L. 노랑물봉선(I); 235555, 309950, 387576, 441691, 495402, 536352, 552651, 586067, 599022 (1, 2, 3, 4, 5, 6, 7, 8, 10)

Impatiens textori Miq. 물봉선; 236903, 309951, 387660, 446908, 488067, 530354, 551722, 590038, 599021 (1, 2, 3, 4, 5, 6, 7, 9, 10)

Araliaceae 두릅나무과

Aralia cordata var. continentalis (Kitag.) Y. C. Chu 독활; 235635, 305590, 387394, 446581, 482227, 537668, 574977, 585948, 599042 (1, 2 , $3,4,5,6,7,9,10)$

Aralia elata (Miq.) Seem. 두릅나무; 235620, 387371, 441758, 468942, 556089, 574439, 590058, $599025(1,3,4,5,7,8,9,10)$

Eleutherococcus divaricatus (Siebold \& Zucc.) S. Y. Hu 개가시오갈피나무(V); 390265 (3)

Eleutherococcus senticosus (Rupr. \& Maxim.) Maxim. 가시오갈피나무(V, VU); 359293 (3)

Eleutherococcus sessiliflorus (Rupr. \& Maxim.) S. Y. Hu 오갈피나무(I); 244046, 305469, 395953, 446856, 495456, 551778, 580330 (1, 2, 3, 4, 5, 7, 9)

Kalopanax septemlobus (Thunb.) Koidz. 음나무; 359085, 451561, 495924, 590143 (3, 4, 5, 7)

Panax ginseng C. A. Mey. 인삼(V, NA); 591684 (7)

Apiaceae 미나리과

Aegopodium alpestre Ledeb. 왜방풍(IV); 236926, $578832(1,10)$

Angelica amurensis Schischk. 지리강활; 446604 (4)

Angelica cartilaginomarginata (Makino ex Y. Yabe) Nakai 처녀바디; 482079, 530301, 552602, $599200(5,6,8,10)$

Angelica czernaevia (Fisch. \& C. A. Mey.) Kitag. 잔잎바디; 242186, 388034, 449573, 574846, 586033, 599211 (1, 3, 4, 7, 9, 10)

Angelica dahurica (Fisch. ex Hoffm.) Benth. Hook. f. ex Franch. \& Sav. 구릿대; 236890, 310060, 387502, 446748, 481803, 530472, 574550, $590821(1,2,3,4,5,6,7,9)$

Angelica decursiva (Miq.) Franch. \& Sav. 바디나물; 243248, 310216, 390253, 449826, 482147, 530412, 551724, 591632, 599401 (1, 2, 3, 4, 5, 6, 7, 9, 10) Angelica gigas Nakai 당귀(III); 310044, 390275, $599097(2,3,10)$

Angelica polymorpha Maxim. 궁궁이; 242393, 323905, 388025, 449773, 495911, 551770, 590734, 599031 (1, 2, 3, 4, 5, 7, 9, 10)

Angelica reflexa B. Y. Lee 강활(E); 599364 (10)

Anthriscus sylvestris (L.) Hoffm. 전호; 235248, 359174, 441117, 468787, 553057, 569452, 577864, 579204 (1, 3, 4, 5, 8, 9, 10)

Bupleurum komarovianum Lincz. 시호; 237010, 324133, 395856, 482191, 528474, 574391, 585834, 598905 (1, 2, 3, 5, 6, 7, 9, 10)

Bupleurum longiradiatum Turcz. 개시호(II); 390298, 446623, 495664, $599410(3,4,5,10)$

Cnidium monnieri (L.) Cusson 벌사상자(III); 390344, 449545, 523858, 552500, 590538 (3, 4, 6, 7, 8)

Conioselinum tenuissimum (Nakai) Pimenov \& Kljuykov 고본(II); 449939 (4)

Cryptotaenia japonica Hassk. 파드득나물; 305554, 387560, 446396, 481117, 585857, 599039 (2, 3, 4, 5, 7, 10)

Cymopterus melanotilingia (H. Boissieu) C. Y. Yoon 큰참나물(II); 243206, 324132, 390290, 449610, 482122, 591069 (1, 2, 3, 4, 5, 7)

Heracleum moellendorffii Hance 어수리; 236840, 390280, 449621, 495742, 574963, 585946, 599388 (1, 3, 4, 5, 7, 9, 10)

Libanotis seseloides (Fisch. \& C. A. Mey. ex Turcz.) Turcz. 가는잎방풍(IV); 388040, $451786(3,4)$

Oenanthe javanica (Blume) DC. 미나리; 237040, 449694, 528507, 552883, 574940, $599796(1,4,6,8,9,10)$

Osmorhiza aristata (Thunb.) Rydb. 긴사상자; 385474, 441422, 578907 (3, 4, 10)

Ostericum grosseserratum (Maxim.) Kitag. 신감채; 242187, 309888, 390329, 446547, 482226, 530393, 552600, 574877, 590043, 599038 (1, 2, 3, 4, $5,6,7,8,9,10)$

Ostericum sieboldii (Miq.) Nakai 묏미나리; 242307, 449539, 482343, 537607, 590602, 599677 (1, 4, 5, 6, 7, 10)

Peucedanum terebinthaceum (Fisch. ex Trevir.) Ledeb. 기름나물; 242066, 309915, 390343, 446676, 482157, 530469, 574779, 586058, $599105(1,2,3,4,5,6,7,9,10)$

Pimpinella brachycarpa (Kom.) Nakai 참나물; 236994, 324117, 387916, 449601, 495687, 574794, 586027, 599383 (1, 2, 3, 4, 5, 7, 9, 10) Sanicula chinensis Bunge 참반디; 244421, 305447, 387565, 446792, 524443, 552409, 575606, 578904, 585818 (1, 2, 3, 4, 6, 7, 8, 9, 10)

Sanicula rubriflora F. Schmidt ex Maxim. 붉은참반디(II); 441418 (4)

Sanicula tuberculate Maxim. 애기참반디(III); 235330 (1)

Sillaphyton podagraria (H. Boissieu) Pimenov 덕우기름나물(E, IV); 236845, 309916, 390255, 446527, 495683, $576689,585952,599002$ $(1,2,3,4,5,7,9,10)$

Torilis japonica (Houtt.) DC. 사상자; 243687, 305491, 388051, 446519, 468763, 523921, 552565, 575850, 585905 (1, 2, 3, 4, 5, 6, 7, 8, 9) 
Appendix 1. Continued.

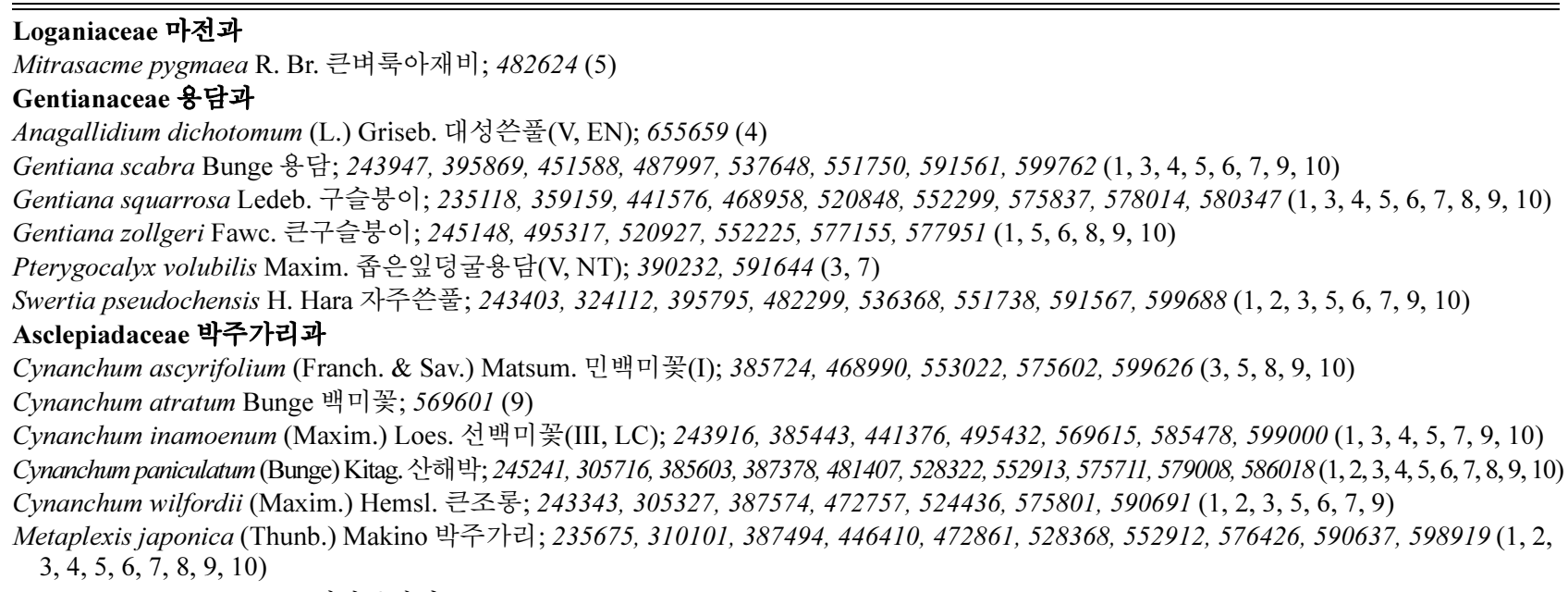

Tylophora floribunda Miq. 왜박주가리(I, LC); 310132, 390472, $451295(2,3,4)$

Solanaceae 가지과

Datura stramonium L. 독말풀(A); 528494 (6)

Nicandra physalodes (L.) Gaertn. 페루꽈리(A); 236974 (1)

Physaliastrum echatum (Yatabe) Makino 가시꽈리; 528531, $579001(6,10)$

Physalis angulata L. 땅꽈리(A); 536401 (6)

Scopolia japonica Maxim. 미치광이풀(III); 495299, $578130(5,10)$

Solanum americanum Mill. 미국까마중(A); 451474, 574377, 591787, 599753 (4, 7, 9, 10)

Solanum lyratum Thunb. 배풍등; 309880, 487876, $524471(2,5,6)$

Solanum nigrum L. 까마중; 244419, 324188, 449917, 472858, 536326, 552698, 576432, 590583, $599829(1,2,4,5,6,7,8,9,10)$

\section{Convolvulaceae 메꽃과}

Calystegia dahurica (Herb.) Choisy 선메꽃(III); 599653 (10)

Calystegia hederacea Wall. 애기메꽃; 235575, 387721, 446372, 523836, $578449(1,3,4,6,10)$

Calystegia pubescens Lindl. 메꽃; 235688, 390305, 472842, 556078, 574868, 599160 (1, 3, 5, 8, 9, 10)

Cuscuta campestris Yunck. 미국실새삼(A); 235733, 305612, 446823, 472816, 524450, 552966, 586042, 599226 (1, 2, 4, 5, 6, 7, 8, 10)

Cuscuta japonica Choisy. 새삼; 243241, 310088, 387884, 449998, 482328, 574432, 590034, 599041 (1, 2, 3, 4, 5, 7, 9, 10)

Ipomoea hederacea Jacq. 미국나팔꽃(A); 472878, 528377, 590662, $599767(5,6,7,10)$

Ipomoea lacunosa L. 애기나팔꽃(A); 243284, 482369, 530296, $598877(1,5,6,10)$

Ipomoea purpurea (L.) Roth 둥근잎나팔꽃(A); 237017, 310131, 390310, 451321, 472806, 530433, 590749, 599766 (1, 2, 3, 4, 5, 6, 7, 10)

Ipomoea rubriflora O'Donell 둥근잎유홍초(A); 244488, 472805, 528376, 552919, 599845 (1, 5, 6, 8, 10)

Boraginaceae 지치과

Bothriospermum tenellum (Hornem.) Fisch. \& C. A. Mey. 꽃받이; 385628, 395954, 468769, 585342 (3, 4, 5, 7)

Brachybotrys paridiformis Maxim. ex Oliv. 당개지치(III); 235106, 359162, 441593, 495490, 575895, 578049, 580396 (1, 3, 4, 5, 7, 9, 10)

Lithospermum arvense L. 개지치(LC); 284326, $468731(2,5)$

Lithospermum erythrorhizon Siebold \& Zucc. 지치(LC); 245233, 284601, 387544, 441281, 481371, 523814, 554049, 575869, 578447, $580448(1,2,3,4,5,6,7,8,9,10)$

Lithospermum zollingeri A. DC. 반디지치(I); 284342, 495237, $520858(2,5,6)$

Symphytum officinale L. 컴프리(A); 236880, 385530, 441633, 575914, 585183, $599024(1,3,4,7,9,10)$

Trigonotis peduncularis (Trevir.) Steven ex Palib. 꽃마리; 234920, 284378, 359219, 433316, 468767, 520351, 552042, 577080, 577771 (1, 2, 3, 4, 5, 6, 8, 9, 10) Trigonotis radicans (Turcz.) Steven 거센털꽃마리(III); 578119 (10)

Trigonotis radicans var. sericea Thunb. 참꽃마리; 235523, 566120, $577781(1,7,10)$

Verbenaceae 마편초과

Callicarpa japonica Thunb. 작살나무; 235546, 284527, 451492, 472669, 524588, 552653, 574423, 590146, 599819 (1, 2, 4, 5, 6, 7, 8, 9, 10) Clerodendrum trichotomum Thunb. 누리장나무; 235676, 323927, 472597, 524539, 552649, 585969, 599498 (1, 2, 5, 6, 7, 8, 10),

Tripora divaricata (Maxim.) P. D. Cantino 누린내풀; 242400, 310184, 552412, 574436, 598875 (1, 2, 8, 9, 10)

Vitex negundo var. heterophylla (Franch.) Rehder 좀목형(III); 472672 (5)

Phrymaceae 파리풀과

Phryma leptostachya var. oblongifolia (Koidz.) Honda 파리풀; 243862, 305435, 387514, 446563, 472533, 528426, 552968, 574945, 585880, 599398 (1, 2, 3, 4, $5,6,7,8,9,10)$

Lamiaceae 꿀풀과

Agastache rugosa (Fisch. \& C. A. Mey.) Kuntze 배초향; 243251, 309869, 390228, 446769, 482116, 530398, 552485, 574924, 590523, $599372(1,2,3,4,5,6,7,8,9,10)$ 
Appendix 1. Continued.

Ajuga multiflora Bunge 조개나물; 284445, $469000(2,5)$

Ajuga spectabilis Nakai 자란초(E, II); 235683 (1)

Amethystea caerulea L. 개차즈기; 242061, 324161, 390247, 451251, 472865, 536202, 574386, 590081, 599190 (1, 2, 3, 4, 5, 6, 7, 9, 10)

Clinopodium chinense var. parviflorum (Kudô) H. Hara 층층이꽃; 242114, 309862, 387491, 446568, 482282, 528385, 552605, 574426,

$585855,599652(1,2,3,4,5,6,7,8,9,10)$

Clinopodium chinense var. shibetchense (H. Lév.) Koidz. 산층층이; 236938, 390266, 449905, 482690, 528483, 574923, 590184, 599010 (1, $3,4,5,6,7,9,10)$

Dracocephalum rupestre Hance 벌깨풀(V, NT); 738444

Elsholtzia ciliata (Thunb.) H. Hyl. 향유; 243778, 323880, 395800, 451471, 482372, 536282, 551732, 591498, 599090 (1, 2, 3, 4, 5, 6, 7, 9, 10)

Elsholtzia splendens Nakai ex F. Maek. 꽃향유; 243816, 323914, 395870, 451686, 537621, 551760, 552486, 591480, 599093 (1, 2, 3, 4, 6, 7, 8, 9, 10)

Glechoma grandis (A. Gray) Kuprian. 긴병 꽃풀; 245142 (1)

Isodon excisus (Maxim.) Kudô 오리방풀; 243305, 387508, 449578, $599381(1,3,4,10)$

Isodon inflexus (Thunb.) Kudô 산박하; 235685, 324150, 394417, 451376, 482176, 552617, 574880, 585956, 598960 (1, 2, 3, 4, 5, 7, 8, 9, 10)

Isodon japonicus (Burm. f.) H. Hara 방아풀; 244451, 309961, 390234, 449549, 481799, 536208, 590028, 599871 (1, 2, 3, 4, 5, 6, 7, 10)

Lamium album var. barbatum (Siebold \& Zucc.) Franch. \& Sav. 광대수염; 235244, 284644, 385453, 441229, 468780, 577807, 580482, $583047(1,2,3,4,5,7,9,10)$

Lamium amplexicaule L. 광대나물; 284272, 395960, 463979, 520346, 552157, 566092, 577093, 577571 (2, 3, 5, 6, 7, 8, 9, 10)

Leonurus japonicus Houtt. 익모초; 235749, 309998, 387790, 449371, 472826, 530281, 552599, 574542, 585900, 599026 (1, 2, 3, 4, 5, 6, 7, 8, 9, 10)

Leonurus macranthus Maxim. 송장풀; 237019, 309858, 388022, 449565, 481818, 528532, 574506, 590169 (1, 2, 3, 4, 5, 6, 7, 9)

Lycopus charkeviczii Prob. 산쉽싸리; 243249, 495767, 574910, 598997 (1, 5, 9, 10)

Lycopus lucidus Turcz. ex Benth. 쉽싸리; 446497 (4)

Meehania urticifolia (Miq.) Makino 벌깨덩굴; 245156, 359166, 441294, 577778, 580373, $583152(1,3,4,7,9,10)$

Mentha canadensis L. 박하; 237041, 310043, 395947, 449357, 472867, 574857, 590723, $599685(1,2,3,4,5,7,9,10)$

Mosla dianthera (Buch.-Ham. ex Roxb.) Maxim. 쥐깨풀; 243113 (1)

Mosla punctulata (J. F. Gmel.) Nakai 들깨풀; 242388, 390423, 451200, 482674, 536306, 574430, 590594, 598953 (1, 3, 4, 5, 6, 7, 9, 10)

Nepeta cataria L. 개박하(DD); 305645, 395943, $481132(2,3,5)$

Phlomis umbrosa Turcz. 속단; 235640, 310192, 387530, 574960, 599394 (1, 2, 3, 9, 10)

Prunella asiatica Nakai 꿀풀; 235421, 284607, 385483, 441090, 481352, 523778, 552989, 569444, 578531, $585137(1,2,3,4,5,6$, 7, 8, 9, 10)

Salvia chanryoenica Nakai 참배암차즈기(E, IV, LC); 305749, 387522, 495692, 575857, 585999, $599311(2,3,5,7,9,10)$

Salvia plebeia R. Br. 배암차즈기; 235578, 305568, 472798, $523842(1,2,5,6)$

Scutellaria dependens Maxim. 애기골무꽃(II); 599247 (10)

Scutellaria pekinensis var. transitra (Makino) H. Hara 산골무꽃; 235428, 284602, 385310, 441397, 481400, 523899, 553153, 575815, $578551,585811(1,2,3,4,5,6,7,8,9,10)$

Scutellaria pekinensis var. ussuriensis (Regel) Hand.-Mazz. 호골무꽃; 495373, 569664, 578852, $585420(5,7,9,10)$

Stachys japonica Miq. 석잠풀; 244522, 305579, 387499, 441602, 481152, 575723, 578883, $585884(1,2,3,4,5,7,9,10)$

Teucrium japonicum Houtt. 개곽향; 235720, 309968, 388024, 446963, 472650, 528417, 552880, 574379, 585833 (1, 2, 3, 4, 5, 6, 7, 8, 9)

Teucrium veronicoides Maxim. 곽향(III); 417606 (1)

Teucrium viscidum var. miquelianum (Maxim.) H. Hara 덩굴곽향; 235609, 472660, 599040 (1, 5, 10)

Thymus quinquecostatus Čelak. 백리향(III); 284585, 441371 (2, 4)

Plantaginaceae 질경이과

Plantago asiatica L. 질경이; 235218, 310189, 395893, 446930, 468735, 575826, $578357(1,2,3,4,5,9,10)$

Plantago depressa Willd. 털질경이; 242419, 385532, 441220, 481082, 523789, 575532, $585376(1,3,4,5,6,7,9)$

Plantago lanceolata L. 창질경이(A); 305373, $551804(2,9)$

Oleaceae 물푸레나무과

Forsythia ovata Nakai 만리화(E, V, NT); 354921, 433244, $585998(3,4,7)$

Forsythia saxatilis (Nakai) Nakai 산개나리(E, IV, NT); 245140, 387439, 433141, $520332(1,3,4,6)$

Fraxinus rhynchophylla Hance 물푸레나무; 305516, 441159, 482271, 520942, 575588, 578525, 580371 (2, 4, 5, 6, 7, 9, 10)

Fraxinus sieboldiana Blume 쇠물푸레; 305555, 441375, 468967, 569682, 578411 (2, 4, 5, 9, 10)

Ligustrum obtusifolium Siebold \& Zucc. 쥐똥나무; 244084, 305658, 481098, 523812, $552990(1,2,5,6,8)$

Syringa fauriei H. Lév. 버들개회나무(IV); 385371 (3)

Syringa pubescens subsp. patula (Palib.) M. C. Chang \& X. L. Chen 털개회나무(I); 236984, 305441, 385742, 441381, 495268, 553865, $569672,578108,580458(1,2,3,4,5,7,8,9,10)$

Syringa reticulata subsp. amurensis (Rupr.) P. S. Green \& M. C. Chang 개회나무(III, LC); 235542, 309891, 441218, 575635, 578772, 580365 $(1,2,4,7,9,10)$

Syringa wolfii C. K. Schneid. 꽃개회나무(IV); 235738 (1)

Scrophulariaceae 현삼과

Lindernia dubia (L.) Pennell 미국외풀(A); 599179 (10)

Lindernia procumbens (Krock.) Borbás 밭둑외풀; $552843,599180(8,10)$

Mazus pumilus (Burm. f.) Steenis 주름잎; 243946, 284455, 359206, 441185, 488113, 520811, 552384, 568241, 575548, 578085 (1, 2, 3, 4, 5, 6, 7, 8, 9, 10) 
Appendix 1. Continued.

Melampyrum roseum Maxim. 꽃며느리밥풀; 235614, 309946, 387547, 446688 (1, 2, 3, 4)

Melampyrum roseum var. ovalifolium (Nakai) Nakai ex Beauverd 알며느리밥풀; 324140, 387824, 482268, 524561, 556090, 574967, 585923, $599037(2,3,5,6,7,8,9,10)$

Melampyrum setaceum (Maxim. ex Palib.) Nakai 애기며느리밥풀(III); 309911 (2)

Melampyrum setaceum var. nakaianum (Tuyama) T. Yamaz. 새며느리밥풀(E, III); 242068, 449677, $495661(1,4,5)$

Mimulus nepalensis Benth. 물꽈리아재비; 284828, 387898, 553298, 574488, 599269 (2, 3, 8, 9, 10)

Paulownia tomentosa (Thunb.) Steud. 참오동나무(A); 243959, 305497, 387885, 441885, 468784, $574869(1,2,3,4,5,9)$

Pedicularis resupinata L. 송이풀; 390277, 446684, 495887, $599387(3,4,5,10)$

Phtheirospermum japonicum (Thunb.) Kanitz 나도송이풀; 236977, 323854, 390322, 451199, 530338, 551726, 591040, 599100 (1, 2, 3, 4, 6, 7, 9, 10)

Pseudolysimachion linariifolium (Pallas ex Link) Holub 꼬리풀; 242245, 309856, 482127, 528455, 556077, 598976 (1, 2, 5, 6, 8, 10)

Pseudolysimachion rotundum var. subintegrum T. Yamaz. 산꼬리풀; 599553 (10)

Scrophularia kakudensis Franch. 큰개현삼(II); 599414 (10)

Siphonostegia chinensis Benth. 절국대; 245335, 310096, 388084, 482100, $556095(1,2,4,5,8)$

Verbascum thapsus L. 우단담배풀(A); 585917 (7)

Veronica anagallis-aquatica L. 큰물칭 개나물(A); 235567, 305346, 441509, 468772, 523762, 575523, 578881 (1, 2, 4, 5, 6, 9, 10)

Veronica arvensis L. 선개불알풀(A); 284689, 468727, 520962, $578124(2,5,6,10)$

Veronica peregrina $\mathrm{L}$. 문모초(A); 523807 (6)

Veronica persica Poir. 큰개불알풀(A); 235115, 284327, 464014, 552162, $577085(1,2,5,8,9)$

Veronica undulata Wall. 물칭 개나물; 481156, 552993, $585817(5,7,8)$

Veronicastrum sibiricum (L.) Pennell 냉초(II); 235686, 305740, 396020, 599671 (1, 2, 4, 10)

Orobanchaceae 열당과

Phacellanthus tubiflorus Siebold \& Zucc. 가지더부살이(II); 574908, 585963 (7, 9)

Acanthaceae 쥐꼬리망초과

Justicia procumbens L. 쥐꼬리망초; $310199,482230(2,5)$

Campanulaceae 초롱꽃과

Adenophora divaricata Franch. \& Sav. 넓은잔대; 235698, 309867, 388048, 446678, 482104, 530372, 556091, 574950, 586043 (1, 2, 3, 4, 5, 6, 7, 8, 9) Adenophora polyantha Nakai 수원잔대; 243935 (1)

Adenophora remotiflora (Siebold \& Zucc.) Miq. 모시대; 245331, 387538, 449581, 495684, 574543, 591038, 599379 (1, 3, 4, 5, 7, 9, 10)

Adenophora verticillata Fisch. 층층잔대; 243933, 387777, 441555, 482685, 530380, 574390, $590773(1,3,4,5,6,7,9)$

Adenophora verticillata var. hirsuta F. Schmidt 털잔대; 243302, $530477(1,6)$

Asyneuma japonicum (Miq.) Briq. 영아자; 235628, 305604, 387966, 449898, 495967, 574911, 585838, 599374 (1, 2, 3, 4, 5, 7, 9, 10)

Campanula glomerata subsp. speciosa (Hornem. ex Spreng.) Domin 자주꽃방망이(III); 244489, 390299, 530383, 591148, 599076 (1, 3, 6, 7, 10)

Campanula punctata Lam. 초롱꽃(I); 235458, 284695, 385402, 441105, 495355, 523951, 569674, 578269, 585321 (1, 2, 3, 4, 5, 6, 7, 9, 10)

Codonopsis lanceolata (Siebold \& Zucc.) Trautv. 더덕; 235712, 284865, 359141, 530423, 574389, 580344, 599127 (1, 2, 3, 6, 7, 9, 10)

Lobelia chinensis Lour. 수염가래꽃; 472856, $599510(5,10)$

Platycodon grandiflorum (Jacq.) A. DC. 도라지; 235657, 305515, 387615, 446890, 472554, 528415, 552596, 574895, 585881, 599523 (1, 2, 3, 4, 5, 6, 7, 8, 9, 10)

Rubiaceae 꼭두선이과

Galium boreale L. 긴잎갈퀴(IV, LC); 284677, 446674, 552846, $578997(2,4,8,10)$

Galium bungei var. trachyspermum (A. Gray) Cufod. 네잎갈퀴; 305638, 441458, 552970, 599808 (2, 4, 8, 10)

Galium dahuricum Turcz. ex Ledeb. 큰잎갈퀴; 242279, 309885, 387570, 451219, 575709, 578859, 585790 (1, 2, 3, 4, 8, 9, 10)

Galium kinuta Nakai \& H. Hara 민둥갈퀴(II); 244096, 305281, 387509, 441394, 524547, 553166, 575856, 585849, 599149 (1, 2, 3, 4, 6, 7, 8, 9, 10)

Galium maximowiczii (Kom.) Pobed. 개갈퀴; 235531, 305451, 387655, 446538, 472608, 551902, 585859, 599373 (1, 2, 3, 4, 5, 7, 9, 10)

Galium odoratum (L.) Scop. 선갈퀴(III); 359110, $441573(3,4)$

Galium paradoxum Maxim. 두메갈퀴(II); 385386, 441429, $578481(3,4,10)$

Galium pogonanthum Franch. \& Sav. 산갈퀴; 235438, 305320, 385560, 441433, 469049, 523892, 575781, 578854, 585145 (1, 2, 3, 4, 5, 6, 7, 9, 10)

Galium spurium L. 갈퀴덩굴; 441251, $468743(4,5)$

Galium verum var. asiaticum Nakai 솔나물; 245280, 305654, 387611, 446578, 481424, 524382, 552830, 576406, 579078, 585870 (1, 2, 3, 4, $5,6,7,8,9,10)$

Rubia argyi (H. Lév. \& Vaniot) H. Hara ex Lauener \& D. K. Ferguson 꼭두선이; 236901, 310108, 387865, 446929, 537669, 574835, 591838, $599605(1,2,3,4,6,7,9,10)$

Rubia chinensis Regel \& Maack 큰꼭두선이; 243861, 284572, 387583, 441403, 495283, 569631, 578483, 585437 (1, 2, 3, 4, 5, 7, 9, 10)

Rubia cordifolia L. 갈퀴꼭두선이; 236924, 310026, 388017, 446403, 481798, 524542, 552595, 574834, $590097(1,2,3,4,5,6,7,8,9)$

\section{Linnaeaceae 린네풀과}

Zabelia biflora (Turcz.) Makino 털 댕강나무(III); 235020, 310037, 359261, 441099, 495208, 554108, 574896, 578054, 580329 (1, 2, 3, 4, 5, 7, 8, 9, 10)

Zabelia densipila M. P. Hong, Y. C. Kim \& B. Y. Lee 긴털댕강나무(E); 235088, 359466, 590711 (1, 3, 7)

Zabelia tyaihyonii (Nakai) Hisauti \& H. Hara 줄댕강나무(E, V, VU); 235382, $554047(1,8)$

Diervillaceae 병꽃나무과

Weigela florida (Bunge) A. DC. 붉은병꽃나무(II); 235035, 284319, 359125, 441486, 468931, 520935, 553284, 575592, 578078,580331 (1, $2,3,4,5,6,7,8,9,10)$ 
Appendix 1. Continued.

Weigela subsessilis (Nakai) L. H. Bailey 병꽃나무(E); 244453, 284597, 441449, 469048, 577792 (1, 2, 4, 5, 10)

Caprifoliaceae 인동과

Lonicera japonica Thunb. 인동; 244371, 284710, 394098, 441747, 481155, 575787, 578885, 585812 (1, 2, 3, 4, 5, 7, 9, 10)

Lonicera maackii (Rupr.) Maxim. 괴불나무(I); 235213, 305432, 385459, 441134, 537638, 553833, 575916, 580352 (1, 2, 3, 4, 6, 7, 8, 9)

Lonicera praeflorens Batal 올괴불나무; 235274, 284404, 354954, 433372, 468933, 520283, 552023, 566000, 577592, 583030 (1, 2, 3, 4, 5, 6, 7, 8, 9, 10)

Lonicera subsessilis Rehder 청괴불나무(E, II); 235320, 305722, 385717, 441345, 495308, 552639, 569731, 578100, 580451 (1, 2, 3, 4, 5, 7, 8, 9, 10)

Lonicera tatarinowii Maxilm. 흰괴불나무(IV); 665752

Lonicera vesicaria Kom. 구슬댕댕이(III); 385389, 441409, $495658(3,4,5)$

Lonicera vidalii Franch. \& Sav. 왕괴불나무(II); 235089, $577980(1,10)$

Viburnaceae 산분꽃나무과

Viburnum burejaeticum Regel \& Herd. 산분꽃나무(V, NT); 235114 (1)

Viburnum carlesii var. bitchiuense (Makino) Nakai 분꽃나무; 235018, 309995, 359065, 441119, 552264, 565957, 577173, 577828, 495329, $520835(1,2,3,4,5,6,7,8,9,10)$

Viburnum erosum Thunb. 덜뀡나무; 469056 (5)

Viburnum opulus var. sargentii (Koehne) Takeda 백당나무(I); 235185, 385392, 441387, 495491, 575928, 578161, 580463 (1, 3, 4, 5, 7, 9, 10)

Viburnum wrightii Miq. 산가막살나무; 385745 (3)

Adoxaceae 연복초과

Adoxa moschatellina L. 연복초(I); 235042, 284299, 354926, 433091, 552091, 566137, 577084, $577694(1,2,3,4,7,8,9,10)$

Sambucus williamsii Hance 딱총나무; 235365, 284548, 359075, 441313, 495483, 575712, 578409, 585748 (1, 2, 3, 4, 5, 7, 9, 10)

Valerianaceae 마타리과

Patrinia rupestris (Pall.) Juss. 돌마타리(IV); 236931, 305662, 387352, 441790, 472817, 528388, 552594, 574497, 586014, 598869 (1, 2, 3, 4, 5, 6, 7, 8, 9, 10)

Patrinia scabiosifolia Fisch. ex Trevir. 마타리; 235655, 309948, 388047, 446698, 472731, 528437, 574976, 585847, 599366 (1, 2, 3, 4, 5, 6, 7, 9, 10)

Patrinia villosa (Thunb.) Juss. 뚝갈; 243306, 310041, 387669, 446673, 472599, 528413, 552604, 574826, 586004, 599317 (1, 2, 3, 4, 5, 6, 7, 8, 9, 10)

Valeriana fauriei Briq. 쥐오줌풀; 245152, 340630, 359126, 441187, 495463, 520838, 553835, 565948, 577172, 577756 (1, 2, 3, 4, 5, 6, 7, 8, 9, 10)

Dipsacaceae 산토끼꽃과

Dipsacus japonicus Miq. 산토끼꽃(III, LC); 237037, 309882, 449518, 472790, 574856, 598929 (1, 2, 4, 5, 9 ,10)

Scabiosa tschiliensis Grüng 솔체꽃(III); 236930, 324106, 446677, 528509, 552592, 586047, $599150(1,2,4,6,7,8,10)$

Asteraceae 국화과

Achillea alpina L. 톱풀(II); 387324, 449964, 495607, $574919(3,4,5,9)$

Achillea alpina var. discoidea (Regel) Kitam. 산톱풀; 395810, 449849, $590732(3,4,7)$

Achillea millefolium L. 서양톱풀(A); 574435 (9)

Adenocaulon himalaicum Edgew. 멸가치; 242430, 324110, 390415, 449689, 574793, 592003, 599395 (1, 2, 3, 4, 7, 9, 10)

Ainsliaea acerifolia var. subapoda Nakai 가야단풍취; 243185, 390263, 446701, 482259, 586029, 599392 (1, 3, 4, 5, 7, 10)

Ambrosia artemisiifolia L. 돼지풀(A); 242181, 323859, 449419, 552691, 590111, 599747 (1, 2, 4, 7, 8, 10)

Ambrosia trifida L. 단풍잎돼지풀(A); 590553 (7)

Artemisia annua L. 개똥쑥; 481781, 530350, $591051(5,6,7)$

Artemisia capillaris Thunb. 사철쑥; 245119, 323923, 390438, 449399, 481808, 530331, 556082, 576424, 585891, 599794 (1, 2, 3, 4, 5, 6, 7, 8, 9, 10)

Artemisia codonocephala Diels 참쑥; 243179, 390316, 449512, 482113, 530473, 590699, $599185(1,3,4,5,6,7,10)$

Artemisia gmelinii Weber ex Stechm. 더위지기; 241998, 310031, 390324, 449715, 482399, 536210, 551801, 590033, 599727 (1, 2, 3, 4, 5, 6, 7, 9, 10)

Artemisia indica Willd. 쑥; 235765, 310160, 390321, 449410, 482304, 536198, 552613, 590639, $599781(1,2,3,4,5,6,7,8,10)$

Artemisia japonica Thunb. 제비쑥; 243678, 324141, 390239, 449702, 482195, 530340, 552491, 591163, 599036 (1, 2, 3, 4, 5, 6, 7, 8, 10)

Artemisia keiskeana Miq. 맑은대쑥; 243180, 310116, 390369, 449836, 472684, 536360, 552696, 590534, 599827 (1, 2, 3, 4, 5, 6, 7, 8, 10)

Artemisia lancea Vaniot 뺑쑥; 242280, 309921, 387844, 449379, 495738, 530414, 574926, 590698, $599789(1,2,3,4,5,6,7,9,10)$

Artemisia rubripes Nakai 덤불쑥(I); 242246, 309976, 390325, 449364, 482418, 530352, 574928, 590022, 599014 (1, 2, 3, 4, 5, 6, 7, 9, 10)

Artemisia sieversiana Ehrh. ex Willd. 산흰ㅆㄱㄱ(IV, LC); 451247, $591666(4,7)$

Artemisia stolonifera (Maxim.) Kom. 넓은잎외잎쑥; 243716, 324128, 390294, 449547, 488065, 528516, 574533, 590130, 599034 (1, 2, 3, 4, 5, 6, 7, 9, 10)

Aster ageratoides Turcz. 까실쑥부쟁이; 242291, 324167, 390240, 449577, 482324, 530406, 551764, 590082, 599662 (1, 2, 3, 4, 5, 6, 7, 9, 10)

Aster hispidus Thunb. 갯쑥부쟁이; 243220, 324181, 390326, 482302, 536246, 552910, 585892, 599092 (1, 2, 3, 5, 6, 7, 8, 10)

Aster incisus Fisch. 가새쑥부쟁이; 236902, 323899, 472845, 528391, $599813(1,2,5,6,10)$

Aster maackii Regel 좀개미취(III); 243447, 395990, 449877, 590712, 598884 (1, 3, 4, 7, 10)

Aster meyendorffii (Regel \& Maack) Voss 개쑥부쟁이; 598884 (4)

Aster pilosus Willd. 미국쑥부쟁이(A); 244500, 324160, 395875, 451370, 495943, 536235, 552689, 574549, 590055, 599094 (1, 2, 3, 4, 5, 6, 7, 8, 9, 10)

Aster scaber Thunb. 참취; 235659, 309920, 388018, 446696, 472745, 530467, 552603, 574504, 590025, 599102 (1, 2, 3, 4, 5, 6, 7, 8, 9, 10)

Aster subulatus Michx. 비짜루국화(A); 242325, 324099, 451813, 482313 $(1,2,4,5)$

Aster tataricus L. f. 개미취; 242180, 309866, 388007, 449490, 495711, 552583, 574440, 590106, $599030(1,2,3,4,5,7,8,9,10)$

Atractylodes ovata (Thunb.) DC. 삽주; 235644, 309929, 387427, 446539, 488047, 524518, 574523, 586005, 598861 (1, 2, 3, 4, 5, 6, 7, 9, 10)

Bidens bipinnata L. 도깨비바늘; $472786,599828(5,10)$

Bidens biternata (Lour.) Merr. \& Sherff 털도깨비바늘; 244523, 323922, 387988, 481841, 537583, 576433, 590087, 599166 (1, 2, 3, 5, 6, 7, 9, 10)

Bidens frondosa L. 미국가막사리(A); 242371, 324175, 395906, 451204, 482362, 524449, 591478, 599089 (1, 2, 3, 4, 5, 6, 7, 10) 
Appendix 1. Continued.

Bidens parviflora Willd. 까치발; 243397, 390487, 482346, 590059, $599765(1,3,5,7,10)$

Bidens pilosa L. 울산도깨비바늘(A); 324182, 482378, $536397(2,5,6)$

Bidens tripartita L. 가막사리; 244384, 482382, $599678(1,5,10)$

Breea segeta (Bunge) Kitam. 조뱅이; 244040, 284675, 385703, 441184, 468810, 523790, 553145, 569651, 578887, 579201 (1, 2, 3, 4, 5, 6, 7, 8, 9, 10) Carduus crispus L. 지느러미엉겅퀴(A); 235053, 284811, 359180, 441157, 468771, 523765, 553114, 569446, 578378, 579211 (1, 2, 3, 4, 5, 6, 7, 8, 9, 10) Carpesium abrotanoides L. 담배풀; 243850, $310208(1,2)$

Carpesium cernuum L. 좀담배풀; 309947, 387929, 482341, 530363, 556092, 574413, 591564, 599304 (2, 3, 5, 6, 7, 8, 9, 10)

Carpesium divaricatum Siebold \& Zucc. 긴담배풀; 235634, 310193, 388066, 472789, 590049, 599400 (1, 2, 3, 5, 7, 10)

Carpesium macrocephalum Franch. \& Sav. 여우오줌(I); 242435, 390315, 446514, 551966, 591975, $599047(1,3,4,7,9,10)$

Carpesium triste Maxim. 두메 담배풀; 390238, 449785, 495763, 591089, 599120 (3, 4, 5, 7, 10)

Centipeda minima (L.) A. Braun \& Aschers. 중대가리풀; 243969, 310169, 395955, 472855, 528334, 552836, 5744443, 590822, 599527 (1, 2, 3, 5, 6, 7, 8, 9, 10)

Cirsium japonicum var. maackii (Regel) Kitam. 엉겅퀴; 235450, 284682, 385559, 441673, 468901, 523753, 575708, 585181, 598956 (1, 2, 3, 4, 5, 6, 7, 9, 10)

Cirsium pendulum Fisch. ex DC. 큰엉겅퀴(I); 242194, 390500, 449753, 482394, 530349, 552688, 591529, 599095 (1, 3, 4, 5, 6, 7, 8, 10)

Cirsium setidens (Dunn) Nakai 고려엉겅퀴(E, I); 242176, 310010, 388049, 449626, 487973, 528489, 551729, 590681, 599052 (1, 2, 3, 4, 5, 6, 7, 9, 10)

Conyza canadensis (L.) Cronquist 망초(A); 244532, 310106, 388043, 446878, 472872, 528302, 552561, 574782, 585885 (1, 2, 3, 4, 5, 6, 7, 8, 9)

Coreopsis lanceolata L. 큰금계국(A); 284820, 441735, 468961, 575828, 579116, 585406 (2, 4, 5, 7, 9, 10)

Coreopsis tinctoria Nutt. 기생초(A); 446883, $579118(4,10)$

Crepidiastrum chelidoniifolium (Makino) Pak \& Kawano 까치고들 빼기; 243208, 390276, 451425, 482662, 551730, 599826 (1, 3, 4, 5, 9, 10)

Crepidiastrum denticulatum (Houtt.) Pak \& Kawano 이고들빼기; 243237, 309984, 390376, 449837, 482348, 536376, 551775, 591157, 599091 (1, 2, 3 , $4,5,6,7,9,10)$

Crepidiastrum sonchifolium (Bunge) Pak \& Kawano 고들 빼기; 234976, 284618, 359230, 441188, 468770, 520796, 568273, 569460, 578068 (1, 2, 3, 4, $5,6,7,9,10)$

Dendranthema boreale (Makino) Ling 산국; 244513, 323919, 395823, 451482, 488037, 537589, 551742, 552490, 591477, 599785 (1, 2, 3, 4, 5, 6, 7, 8, 9, 10)

Dendranthema indicum (L.) Des Moul. 감국; 395890, $591955(3,7)$

Dendranthema jeongseonensis M. Kim \& H. Jo 정선국화(E); 395995, 451592, 551743, 591481 (3, 4, 7, 9)

Dendranthema zawadskii (Herbich) Tzvelev 산구절초; 243207, 487832, 536366 (1, 5, 6)

Dendranthema zawadskii var. latilobum (Maxim.) Kitam. 구절초; 243769, 323949, 395797, 451601, 482361, 536274, 551744, 591504 (1, 2, 3, 4, 5, 6, 7, 9)

Dendranthema zawadskii var. tenuisectum (Kitag.) Pak 가는잎구절초; 243955, 552488, $599719(1,8,10)$

Echinops setifer Iljin 절굿대; 243985, 323944, 395853, 451892, $598906(1,2,3,4,10)$

Eclipta prostrata (L.) L. 한련초; 237047, 310015, 472854, 556079, 590688, $599283(1,2,5,7,8,10)$

Erechtites hieracifolia (L.) Raf. ex DC. 붉은서나물(A); 243438, 482367, 536406, 590532, $599732(1,5,6,7,10)$

Erigeron annuus (L.) Pers. 개망초(A); 235424, 284577, 385394, 441155, 468736, 523971, 553110, 575816, 585142, 599459 (1, 2, 3, 4, 5, 6, 7, 8, 9, 10)

Erigeron philadelphicus $\mathrm{L}$. 봄망초(A); 578431 (10)

Eupatorium lindleyanum DC. 골등골나물; 244434, 387782, 472742, 528381, 552566 (1, 3, 5, 6, 8)

Eupatorium makinoi var. oppositifolium (Koidz.) Kawah. \& Yahara 등골나물; 236950, 309930, 387487, 446412, 472548, 524551, 552606, 574964, 590119, $599499(1,2,3,4,5,6,7,8,9,10)$

Eupatorium tripartitum (Makino) Murata \& H. Koyama 향등골나물; 482636, 574900, $585862(5,7,9)$

Galinsoga parviflora Cav. 별꽃아재비(A); 395835, 446484, 575545, 578865, 586075 (3, 4, 7, 9, 10)

Galinsoga quadriradiata Ruiz \& Pav. 털별꽃아재비(A); 235783, 309988, 387889, 446361, 481161, 575782, 599445 (1, 2, 3, 4, 5, 9, 10)

Gnaphalium uliginosum L. 왜떡쑥; 396089 (4)

Helianthus tuberosus L. 뚱딴지(A); 243751, 323886, 451462, $482411(1,2,4,5)$

Hemistepta lyrata Bunge 지칭 개; 234999, 284693, 359255, 441152, 468768, 523759, 568245, 569466, 578246 (1, 2, 3, 4, 5, 6, 7, 9, 10)

Hieracium umbellatum L. 조밥나물; 243214, 388044, 449667, 482111, 530376, 574832, 590154, 599768 (1, 3, 4, 5, 6, 7, 9, 10)

Inula britannica var. japonica (Thunb.) Franch. \& Sav. 금불초; 242244, 310081, 388016, 449492, 482077, 528411, 552618, 574854, 590179, $599129(1,2,3,4,5,6,8,9,10)$

Inula salicina L. 버들금불초; 482197, 524559, $574395,598862(5,6,9,10)$

Ixeridium dentatum (Thunb.) Tzvelev 씀바귀; 385729, 441888, 472815, 568284, 575842, 578554 (3, 4, 5, 7, 9, 10)

Ixeris chinensis (Thunb.) Kitag. 노랑선씀바귀; 234975, 284338, 359239, 451459, 468739, 520877, 575811, 577852, 579202 (1, 2, 3, 4, 5, 6, 7, 9, 10)

Ixeris chinensis subsp. strigosa (H. Lév. \& Vaniot) Kitam. 선씀바귀; 495522, $552980(5,8)$

Ixeris polycephala Cass. 벌씀바귀; 234974, 359316, 441759, 468778, 520789, 552165, 578067, 580376 $(1,3,4,5,6,7,8,10)$

Lactuca indica L. 왕고들빼기; 242347, 310158, 390262, 449356, 481777, 530481, 551769, 590129, 599815 (1, 2, 3, 4, 5, 6, 7, 9, 10)

Lactuca raddeana Maxim. 산씀바귀; 243264, 390338, 446905, 482139, 528520, 551809, $599368(1,3,4,5,6,9,10)$

Lactuca scariola L. 가시상추(A); 310157, $482309(2,5)$

Lactuca triangulata Maxim. 두메고들 빼기; 387434, 446542, 495421, 591036, 599058 (3, 4, 5, 7, 10)

Leibnitzia anandria (L.) Turcz. 솜나물; 245154, 284316, 359426, 433240, 468960, 520314, 552018, 565917, 577750, 583111 (1, 2, 3, 4, 5, 6, 7, 8, 9, 10)

Leontopodium coreanum Nakai 솜다리(E, V); 236929 (1)

Leucanthemum vulgare Lam. 불란서국화(A); 235530, 585405, $594611(1,7,9)$

Ligularia fischeri (Ledeb.) Turcz. 곰취(II); 243709, 305639, 387527, 449485, 591538, 599377 (1, 2, 3, 4, 7, 10)

Matricaria matricarioides (Less.) Porter ex Britton 족제비쑥(A); 578383 (9) 
Appendix 1. Continued.

Parasenecio auriculatus var. kamtschaticus (Maxim.) H. Koyama 나래박쥐나물(III); 599057 (10)

Parasenecio firmus (Kom.) Y. L. Chen 병풍쌈(IV); 395924 (3)

Petasites japonicus (Siebold \& Zucc.) Maxim. 머위; 284258, 354949, 433362, 481131, 520828, 552047, 577103, 577865, 580393 (2, 3, 4, 5, 6, 7, 8, 9, 10)

Picris hieracioides subsp. japonica (Thunb.) Hand.-Mazz. 쇠서나물; 236928, 305490, 395903, 446746, 487969, 530465, 574527, 590675, $599032(1,2,3,4,5,6,7,9,10)$

Rhaponticum uniflorum (L.) DC. 배꾹채(I); 235041, 284402, 359243, 441128, 468983, 520869, 554106, 566040, 578053, 583056 (1, 2, 3, 4, 5, 6, 7, 8, 9, 10)

Saussurea calcicola Nakai 사창분취(E, IV); 243451, 390257, 495718, 591063, $599087(1,3,5,7,10)$

Saussurea chabyoungsanica H. T. Im 자병취(E, IV); 243704, 390447, 446558, $585994(1,3,4,7)$

Saussurea eriophylla Nakai 솜분취(E); 449643 (4)

Saussurea gracilis Maxim. 은분취; 482208 (5)

Saussurea grandifolia Maxim. 서덜취; 323917, 390333, 451680, 551797, 590495, 599051 (2, 3, 4, 7, 9, 10)

Saussurea macrolepis (Nakai) Kitam. 각시서덜취(E); 243235, 390252, 449772, 495814 (1, 3, 4, 5)

Saussurea maximowiczii Herder 버들분취; 451792 (4)

Saussurea mongolica (Franch.) Franch. 북분취; 323947, 387924, 449596, 495670, 551813, 591067, 599872 (2, 3, 4, 5, 7, 9, 10)

Saussurea odontolepis Sch. Bip. ex Herder 빗살서덜취(I); 243334, 323864, 390283, 449664, 482713, 536434, 551811, 590807 (1, 2, 3, 4, 5, 6, 7, 9)

Saussurea pulchella (Fisch.) Fisch. ex Colla 각시취; 243289, 323910, 395993, 449499, 495804, 536248, 590162, 599124 (1, 2, 3, 4, 5, 6, 7, 10)

Saussurea tanakae Franch. \& Sav. ex Maxim. 당분취; 244432, 390249, 449777, 495662, $599864(1,3,4,5,10)$

Scorzonera albicaulis Bunge 쇠채; 236932, 284628, 385706, 523757, 552992, 569652, 578548, 585938 (1, 2, 3, 6, 7, 8, 9, 10)

Senecio argunensis Turcz. 쑥방망이(I, LC); 245368, 324159, 390494, 536250, 551912, 599197 (1, 2, 3, 6, 9, 10)

Senecio vulgaris L. 개쑥갓(A); 234996, 284376, 395844, 433311, 468779, 552860, 566098, 574973, 599574 (1, 2, 3, 4, 5, 7, 8, 9, 10)

Serratula coronata subsp. insularis (Iljin) Kitam. 산비장이; 245343, 323875, 390295, 449941, 482215, 574402, 590795, 599009 (1, 2, 3, 4, 5, 7, 9, 10)

Sigesbeckia glabrescens (Makino) Makino 진득찰; 243319, 482775, 536340, $591949(1,5,6,7)$

Sigesbeckia pubescens (Makino) Makino 털진득찰; 242262, 323872, 395840, 449473, 482409, 536324, 551774, 591026, 599013 (1, 2, 3, 4, 5, 6, 7, 9, 10)

Solidago virgaurea subsp. asiatica Kitam. ex H. Hara 미역취; 243211, 390281, 451084, 482611, 536387, 552642, 574429, 591494, 599011 (1, 3, 4, 5, 6, 7, 8, 9, 10)

Sonchus asper (L.) Hill 큰방가지똥(A); 284806, 387603, 446826, 482314, $537598(2,3,4,5,6)$

Sonchus brachyotus DC. 사데풀; 243759, 388058, 487963, 530396, 574905, 591005, 599873 (1, 3, 5, 6, 7, 9, 10)

Sonchus oleraceus L. 방가지똥(A); 243780, 446855, $472877(1,4,5)$

Syneilesis palmata (Thunb.) Maxim. 우산나물; 244013, 305459, 387512, 446532, 472622, 552953, 576450, 585139, 599820 (1, 2, 3, 4, 5, 7, 8, 9, 10)

Synurus excelsus (Makino) Kitam. 큰수리취; 243679, 309938, 395801, 446626, 482136, 530420, 551719, 590075, 599098 (1, 2, 3, 4, 5, 6, 7, 9, 10)

Tagetes minuta L. 만수국아재비(A); 323937, $482714(2,5)$

Taraxacum coreanum Nakai 흰민들레; 245139, 284293, 354938, 468803, 520343, 552153, 566042, 577761, 583021 (1, 2, 3, 5, 6, 7, 8, 9, 10)

Taraxacum laevigatum (Willd.) DC. 붉은씨서양민들레(A); 235224, 441138, 468765, 520365, $565989(1,4,5,6,7)$

Taraxacum officinale F. H. Wigg. 서양민들레(A); 234929, 284350, 354937, 433097, 463989, 520363, 552044, 566028, 577804, 583018 (1, 2, 3, 4, 5, $6,7,8,9,10)$

Taraxacum ohwianum Kitam. 산민들레; 245138, 359263, 433099, 552386, 566060, 577075, 577899 (1, 3, 4, 7, 8, 9, 10)

Tephroseris kirilowii (Turcz. ex DC.) Holub 솜방망이; 235063, 284416, 359068, 433376, 468912, 520774, 552217, 565992, 577754, 583114 (1, 2 , $3,4,5,6,7,8,9,10)$

Tephroseris phaeantha (Nakai) C. Jeffrey \& Y. L. Chen 바위솜나물(V, LC); 235183, 359473 (1, 3)

Tephroseris pierotii (Miq.) Holub 솜쑥방망이; 235471, 284513, $578153(1,2,10)$

Tragopogon dubis Scop. 쇠채아재비(A); 553106 (8)

Verbesina alternifolia (L.) Britton ex Kearney 나래가막사리(A); 243654, 524540, $599683(1,6,10)$

Xanthium orientale L. 큰도꼬마리(A); 243122, 324179, 390425, 482726, 536199, 590658 (1, 2, 3, 5, 6, 7)

Xanthium strumarium L. 도꼬마리(A); 242270, 590634, $599209(1,7,10)$

Youngia japonica subsp. elstonii (Hochr.) Babc. \& Stebbins 뽀리뱅이; 235156, 359274, 359315, 468741, 520779, 578117, 579216 (1, 3, 4, 5, 6, 7, 10)

Alismataceae 택사과

Alisma canaliculatum A. Braun \& C. D. Bouché 택사(II); 451306 (4)

Alisma orientale (Sam.) Juz. 질경이택사(II); 388085, $552891(4,8)$

Sagittaria trifolia L. 벗풀; 244416, 310017, 449464, 599242 (1, 2, 4, 10)

Potamogetonaceae 가래과

Potamogeton distinctus A. Benn. 가래; 244517, 446463, $599514(1,4,10)$

Potamogeton perfoliatus L. 넓은잎말(VU); 441856 (4)

Potamogeton wrightii Morong 대가래; 235725, $599530(1,10)$

Najadaceae 나자스말과

Najas marina L. 민나자스말; 244521, $446958,599535(1,4,10)$

Araceae 천남성과

Arisaema amurense Maxim. 둥근잎천남성; 234983, 284448, 359115, 495285, 569632, 578133, 580483 (1, 2, 3, 5, 7, 9, 10)

Arisaema amurense f. serratum (Nakai) Kitag. 천남성; 235311, 284308, 577818, 580475 (1, 2, 7, 10)

Arisaema serratum (Thunb.) Schott 점백이천남성; 243942, 284526, 359299, 441417, 495437, 569681, 578374, 580476 (1, 2, 3, 4, 5, 7, 9, 10)

Pinellia ternata (Thunb.) Ten. ex Breitenb. 반하; 243135, 284680, 359211, 468737, 552552, 577940, $580495(1,2,3,5,7,8,10)$ 
Appendix 1. Continued.

Symplocarpus koreanus J. S. Lee, S. H. Kim \& S. C. Kim 한국앉은부채(E, III); 284290 (2)

Symplocarpus nipponicus Makino 애기앉은부채(III, LC); 433270 (4)

Lemnaceae 개구리밥과

Lemna perpusilla Torr. 좀개구리밥; 305318, 441819, 481170, $528351(2,4,5,6)$

Commelinaceae 닭의장풀과

Commelina communis L. 닭의장풀; 243380, 305524, 387316, 446820, 472809, 552905, 574847, 590529, 599542 (1, 2, 3, 4, 5, 7, 8, 9, 10)

Murdannia keisak (Hassk.) Hand.-Mazz. 사마귀풀; 451385, $599082(4,10)$

Streptolirion volubile Edgew. 덩굴닭의장풀; 242149, 309881, 394361, 449931, 482249, 530409, 574418, 590493, 599140 (1, 2, 3, 4, 5, 6, 7, 9, 10)

Juncaceae 골풀과

Juncus decipiens (Buchenau) Nakai 골풀; 243726, 396044, 441124, 553142, 575522, 578489, 585821 (1, 3, 4, 7, 8, 9, 10)

Juncus diastrophanthus Buchenau 별날개골풀; 446488, 552923, 590959, $599759(4,7,8,10)$

Juncus papillosus Franch. \& Sav. 청비녀골풀; 236936, 387780, 446470, $472700(1,3,4,5)$

Juncus tenuis Willd. 길골풀; 236879, 441109, 553140, 575546, $578840(1,4,8,9,10)$

Luzula capitata Kom. 뀡의 밥; $284275,433374,468891,578329(2,4,5,10)$

Luzula multiflora (Ehrh.) Lej. 산꿩의밥(II); 235410, $575898(1,9)$

Cyperaceae 사초과

Bolboschoenus fluviatilis (Torr.) Soják 큰매자기; $310165,441850(2,4)$

Bulbostylis barbata (Rottb.) C. B. Clarke 모기골; 528347 (6)

Carex augustinowiczii Meinsh. ex Korsh. 북사초(II); 235280, 284663, 354953, 441309, 566169, 577705 (1, 2, 3, 4, 7, 10)

Carex biwensis Franch. 솔잎사초; 245122 (1)

Carex bostrychostigma Maxim. 길뚝사초; 235181, 284634, 359136, 441476, 469010, 523942, 578050, 585453, $588541(1,2,3,4,5,6,7,9,10)$

Carex breviculmis R. Br. 청사초; 245168, 284692, 359057, 433151, 468887, 520360, 565977, 577760, 589697 (1, 2, 3, 4, 5, 6, 7, 9, 10)

Carex brevispicula G. H. Nam \& G. Y. Chung 좀목포사초; 284562, 359089, 433237, 468947, 577744, 585149, 588530 (2, 3, 4, 5, 7, 9, 10)

Carex brownii Tuck. 흰꼬리사초(I); 235532 (1)

Carex ciliatomarginata Nakai 털대사초; 235322, 305365, 354914, 433239, 468943, 520920, 565997, 577953, 588529 (1, 2, 3, 4, 5, 6, 7, 9, 10)

Carex cinerascens Kük. 회색사초(II); 234932 (1)

Carex dimorpholepis Steud. 이삭사초; $553300(8)$

Carex egena H. Lév. \& Vaniot 나래사초; 359295, 569724, 577697 (3, 9, 10)

Carex erythrobasis H. Lév. \& Vaniot 한라사초(E, II); 577696, $588542(9,10)$

Carex fernaldiana H. Lév. \& Vaniot 실사초; 588543 (9)

Carex forficula Franch. \& Sav. 산뚝사초; 245167, 284268, 441514, 520807, 577706, $588527(1,2,4,6,9,10)$

Carex fusanensis Ohwi 부산사초; 245123, 354920, 433285, $553915(1,3,4,8)$

Carex gibba Wahlenb. 나도별사초; 235512, 284564, 481427, $575528(1,2,5,9)$

Carex glabrescens (Kük.) Ohwi 곱슬사초; 235393, $441217(1,4)$

Carex heterolepis Bunge 산비늘사초; 284687, 441252, 520784, 566027, 578027, 588526 (2, 4, 6, 7, 9, 10)

Carex holotricha Ohwi 난사초(III); 284394, 359119, $433156(2,3,4)$

Carex humilis var. nana (H. Lév. \& Vaniot) Ohwi 가는잎그늘사초; 234905, 284257, 354916, 433104, 463992, 552002, 566009, 569604, 5777448(1, 2 , $3,4,5,7,8,9,10)$

Carex jaluensis Kom. 참삿갓사초(II); 385500, 441483, 578837, $588535(3,4,9,10)$

Carex japonica Thunb. 개찌버리사초; 235148, 284575, 359079, 441214, 495419, 523939, 553286, 578039, 580394, 588548 (1, 2, 3, 4, 5, 6, 7, 8, 9, 10) Carex laevissima Nakai 애갱이사초; 236388, 385592, 569660, $578494(1,3,9,10)$

Carex lanceolata Boott 그늘사초; 234961, 284287, 394106, 433135, 463974, 520305, 565966, 577743, 588545 (1, 2, 3, 4, 5, 6, 7, 9, 10)

Carex leiorhyncha C. A. Mey. 산괭이사초; 235172, 359264, 441262, 469006, 523954, 575829, 578843, 585509 (1, 3, 4, 5, 6, 7, 9, 10)

Carex longirostrata var. pallida (Kitag.) Ohwi 실피사초(IV); 359137, 520861 (3, 6)

Carex maackii Maxim. 타래사초; 235569 (1)

Carex mira Kük. 꼬랑사초; 235328, 354962, 433101, 566062, 577533, $588536(1,3,4,7,9,10)$

Carex mitrata var. aristata Ohwi 까락겨사초(I); 284365, 359183, 385640, 520875, $580361(2,3,4,6,7)$

Carex miyabei Franch. 융단사초; 245275, 385684, 433129, 468850, 520803, 577990 (1, 3, 4, 5, 6, 10)

Carex nervata Franch. \& Sav. 양지사초; $359244,468880(3,5)$

Carex neurocarpa Maxim. 괭이사초; 441845, 523839, 552921, 578884 (4, 6, 8, 10)

Carex onoei Franch. \& Sav. 바늘사초(II); 235468, 385479, 433363, $578048(1,3,4,10)$

Carex pediformis var. pedunculata Maxim. 왕그늘사초(II); 359078, 359284, 520281, 565985, $578034(3,4,6,7,10)$

Carex pilosa Scop. 털사초(III); 385452, $577737(3,10)$

Carex planiculmis Kom. 그늘흰사초(II); 359150, 446904, 495498, 578838, 579199, 588544 (3, 4, 5, 7, 9, 10)

Carex poculisquama Kük. 장군대사초(II); 523763 (6)

Carex polyschoena H. Lév. \& Vaniot 가지청사초; 234956, 284408, 359087, 433153, 463978, 520813, 565929, 577774, 588532 (1, 2, 3, 4, 5, 6, 7, 9, 10)

Carex quadriflora (Kük.) Ohwi 녹빛사초(II); 245135, 354958, 566176, $577604(1,3,7,10)$

Carex remotiuscula Wahlenb. 층실사초(IV); 385505, 441274, 575855, $580477(3,4,7,9)$

Carex sabynensis Less. ex Kunth 실청사초; 245129, $578016(1,10)$ 
Appendix 1. Continued.

Carex siderosticta Hance 대사초; 234904, 284472, 359058, 441385, 469066, 520924, 565918, 569663, 577564 (1, 2, 3, 4, 5, 6, 7, 9, 10) Carex splendentissima U. Kang \& J. M. Chung 반들대사초(E); 356730, 385444, $591102(1,3,7)$

Carex stipata Muhl. ex Willd. 양덕사초(IV); 441524 (4)

Carex subebracteata (Kük.) Ohwi 부리실청사초; 235142, 284420, $577738(1,2,10)$

Carex tegulata H. Lév. \& Vaniot 구슬사초(III); 578138 (10)

Carex ussuriensis Kom. 싸라기사초(III); 235396, 284345, 354917, 433155, 520308, 565973, 578029, 588528 (1, 2, 3, 4, 6, 7, 9, 10)

Cyperus amuricus Maxim. 방동사니; 243275, 390347, 446808, 481826, 528342, 552555, 590720, 599134 (1, 3, 4, 5, 6, 7, 8, 10)

Cyperus difformis L. 알방동사니; 244056, 310150, 482384, 591920, $599763(1,2,5,7,10)$

Cyperus flavidus Retz. 드렁 방동사니; 243116, 310164, 552464, $599760(1,2,8,10)$

Cyperus glomeratus L. 물방동사니; 243110, 310179, 451344, $599757(1,2,4,10)$

Cyperus iria L. 참방동사니; 236944, 387808, 446947, $481842(1,3,4,5)$

Cyperus microiria Steud. 금방동사니; 236935, 324100, 387893, 446865, 481832, 530360, 552554, 574840, 590088, 599135 (1, 2, 3, 4, 5, 6, 7, 8, 9, 10)

Cyperus nipponicus Franch. \& Sav. 푸른방동사니; 242324, 396082, 481834, $599172(1,4,5,10)$

Cyperus orthostachyus Franch. \& Sav. 쇠방동사니; 451290, 482252, 599761 (4, 5, 10)

Eleocharis kuroguwai Ohwi 올방개; 451389, $482349(4,5)$

Fimbristylis dichotoma (L.) Vahl 하늘지기; 242318, $575654(1,9)$

Fimbristylis stauntonii Debeaux \& Franch. 밭하늘지기; 244535, $310178(1,2)$

Kyllinga brevifolia var. leiolepis (Franch. \& Sav.) H. Hara 파대가리; 244531, 388081, 482263, 552466, $599758(1,4,5,8,10)$

Schoenoplectiella hotarui (Ohwi) J. Jung \& H. K. Choi 좀올챙 이골; 446473, $599239(4,10)$

Schoenoplectiella juncoides (Roxb.) Lye 올챙 이고랭이; 243133, 441821, 482383, 579186 (1, 4, 5, 10)

Scirpus karuizawensis Makino 솔방울고랭이; 451796 (4)

Scirpus orientalis Ohwi 검은도루박이(IV, NT); $579126(10)$

Scirpus radicans Schkuhr 도루박이; 235572, $441808(1,4)$

Scirpus wichurae Boeckeler 방울고랭이; $310114,446465(2,4)$

Trichophorum polygamum D. C. Son \& K. S. Chang 동강고랭이(E, IV); 234890, 385683, 552177, 568252, $578419(1,3,7,8,10)$

\section{Poaceae 벼과}

Agrostis clavata var. nukabo Ohwi 겨이삭; 284701, 385552, 441121, 495493, 523938, 575719, 578833, 580497 (2, 3, 4, 5, 6, 7, 9, 10)

Agrostis gigantea Roth 흰겨이삭(A); 235767, $441543(1,4)$

Alopecurus aequalis Sobol. 뚝새풀(A); 234997, 359203, 468733, 523844, 553841, 569677, 578496, 585436 (1, 3, 5, 6, 7, 8, 9, 10)

Alopecurus japonicus Steud. 털뚝새풀(A); 235513 (1)

Alopecurus pratensis L. 큰뚝새풀(A); 359286, 575677, $585717(4,7,9)$

Arthraxon hispidus (Thunb.) Makino 조개풀; 243250, 323862, 390318, 536290, 591934, 599722 (1, 2, 3, 6, 7, 10)

Arundinella hirta (Thunb.) Tanaka 새; 472847, 530302, 552588 (5, 6, 8)

Arundinella hirta var. ciliata (Thunb.) Koidz. 털새; 235653, 284844, 387785, 446433, 482366, 528380, 576420, 576420, 599155 (1, 2, 3, 4, 5, 6, 7, 9, 10)

Beckmannia syzigachne (Steud.) Fernald 개피; 235476, 441269, 523878, 552840, $579133(1,4,6,8,10)$

Bothriochloa ischaemum (L.) Keng 바랭이새; 310102, 487887, 528534 (2, 5, 6)

Bromus catharticus Vahl 큰이삭풀(A); 310095 (2)

Bromus inermis Leyss. 좀참새귀리(A); 579031 (10)

Bromus japonicus Thunb. 참새귀리; 235457, 284813, 385517, 441141, 468725, 523786, 552904, 569645, 578542, 585140 (1, 2, 3, 4, 5, 6, 7, 8, 9, 10)

Bromus mollis L. 털참새귀리(A); 578880 (10)

Bromus remotiflorus (Steud.) Ohwi 꼬리새; 235574, 305440, 387319, 446821, 481452, 524438, 585879, 599637 (1, 2, 3, 4, 5, 6, 7, 10)

Bromus rigidus Roth 긴까락빕새귀리(A); 284377 (2)

Bromus sterilis L. 까락빕새귀리(A); 578261 (10)

Bromus tectorum L. 털빕새귀리(A); 235376, 284380, 359182, 441222, 468795, 553912, 575631, 578033, 579188 (1, 2, 3, 4, 5, 7, 8, 9, 10)

Bromus tectorum var. glabratus Spenn. 민둥빕새귀리; 284388 (2)

Calamagrostis arundinacea (L.) Roth 실새풀; 242173, 323888, 390289, 449662, 482106, 536265, 590138, 599790 (1, 2, 3, 4, 5, 6, 7, 10)

Calamagrostis epigeios (L.) Roth 산조풀; 387358, 446863, 481426, 552879, $574902(3,4,5,8,9)$

Capillipedium parviflorum (R. Br.) Stapf 나도기름새; 530321 (6)

Chloris virgata $\mathrm{Sw}$. 나도바랭이(A); 242327 (1)

Cleistogenes hackelii (Honda) Honda 대새풀; 242089, 309990, 390427, 451257, 482386, 528323, 590054, 599156 (1, 2, 3, 4, 5, 6, 7, 10)

Cymbopogon goeringii (Steud.) A. Camus 개솔새; 242092, 310042, 481784, 530322, 599798 (1, 2, 5, 6, 10)

Dactylis glomerata L. 오리새(A); 235220, 284382, 385538, 441135, 468867, 523973, 575694, 579054, 579218 (1, 2, 3, 4, 5, 6, 7, 9, 10)

Diarrhena fauriei (Hack.) Ohwi 광릉용수염; 387460, 446520, 574829, 578888, $585826(3,4,7,9,10)$

Diarrhena mandshurica Maxim. 껍질용수염; 235482, 305761, 387459, 446600, 575535, 578896, 585907 (1, 2, 3, 4, 7, 9, 10)

Digitaria ciliaris (Retz.) Koeler 바랭이; 242230, 449403, 481836, 528317, 574864, 586073, 598916 (1, 4, 5, 6, 7, 9, 10)

Digitaria violascens Link 민 바랭이; 243365, 310130, 390319, 451842, 482811, 599723 (1, 2, 3, 4, 5, 10)

Echinochloa crus-galli (L.) P. Beauv. 돌피; 243437, 446852, 481828, 524580, 552468, $574853(1,4,5,6,8,9)$

Echinochloa crus-galli var. praticola Ohwi 좀돌피; 590660, $599516(7,10)$

Eleusine indica (L.) Gaertn. 왕바랭이; 242267, 472794, 524420, 552462, 574865, 599243 (1, 5, 6, 8, 9, 10) 
Appendix 1. Continued.

Elymus ciliaris (Trin.) Tzvelev 속털개밀; 235422, 284574, 385519, 441160, 468777, 569646, 579058, 585144 (1, 2, 3, 4, 5, 7, 9, 10)

Elymus repens (L.) Gould 구주개밀(A); 235443, 284843, 385590, 441176, 481165, 524530, 575554, 578866, 585897 (1, 2, 3, 4, 5, 6, 7, 9, 10) Elymus tsukushiensis Honda 개밀; 235475, 284664, 387622, 441520, 523817, 575607, 578543, 585185 (1, 2, 3, 4, 6, 7, 9, 10)

Eragrostis cilianensis (All.) Vignolo ex Janch. 참새그령; 310163, 481780, $536318(2,5,6)$

Eragrostis curvula (Schrad.) Nees 능수참새그령(A); 481444 (5)

Eragrostis ferruginea (Thunb.) P. Beauv. 그령; 235687, 323887, 395966, 446658, 481805, 524017, 590766, 599136 (1, 2, 3, 4, 5, 6, 7, 10)

Eragrostis minor Host 좀새그령; 472631, $530300(5,6)$

Eragrostis multicaulis Steud. 비노리; 242369, 387620, 451188, 472880, 528344, 590686, $599173(1,3,4,5,6,7,10)$

Eragrostis pilosa (L.) P. Beauv. 큰비노리; 243272, 395952, 446861, 482406, 551905, $590663(1,3,4,5,7,9)$

Eriochloa villosa (Thunb.) Kunth 나도개피; 235693, 309963, 387794, 446951, 472801, 524358, 576417, 585863, 599181 (1, 2, 3, 4, 5, 6, 7, 9, 10)

Eulalia speciosa (Debeaux) Kuntze 개억새; 244352, $324170(1,2)$

Festuca arundinacea Schreb. 큰김의털(A); 245229, 284712, 385518, 441170, 468773, 523936, 569643, 578376, 579191 (1, 2, 3, 4, 5, 6, 7, 9, 10)

Festuca extremiorientalis Ohwi 왕김의털아재비; $385506,441352(3,4)$

Festuca heterophylla Lam. 사방김의털(A); 305358, 441788, 575526, $578816(2,4,9,10)$

Festuca japonica Makino 산묵새(IV); 385677 (3)

Festuca ovina L. 김의털; $385501,441122,468954,580447(3,4,5,7)$

Festuca parvigluma Steud. 김의털아재비; 284814, 385503, 441101, 468868, 523869, $575531(2,3,4,5,6,8)$

Festuca rubra L. 왕김의털(IV); 585813 (7)

Glyceria leptolepis Ohwi 왕미꾸리광이(II); 237036 (1)

Hemarthria sibirica (Gand.) Ohwi 쇠치기풀; 236888, 388001, 481778, $528533(1,3,5,6)$

Hierochloe odorata (L.) P. Beauv. 향모; 235001, 284369, 359209, 433100, 520925, 552110, 577090, 580485 (1, 2, 3, 4, 6, 7, 8, 9)

Imperata cylindrica (L.) Raeusch. 띠; 235239, 441243, 523760, 552988, $578598(1,4,6,8,10)$

Isachne globosa (Thunb.) Kuntze 기장대풀; 387696 (4)

Koeleria macrantha (Ledeb.) Schult. 도랭이피; 468957, $523832(5,6)$

Lolium multiflorum Lam. 쥐보리(A); 284519, 575831, 578822 (2, 9, 10)

Lolium perenne L. 호밀풀(A); 446707, 481102, 524354, 575555, $578842(4,5,6,9,10)$

Melica grandiflora Koidz. 청쌀새; 359220, $577739(3,10)$

Melica nutans L. 왕쌀새(II); 234908, 359152, 433193, 578051, $588549(1,3,4,9,10)$

Melica onoei Franch. \& Sav. 쌀새; 244030, 305616, 388010, 449425, 482190, 590063, 599159 (1, 2, 3, 4, 5, 7, 10)

Melica scabrosa Trin. 참쌀새(III); 481129 (5)

Microstegium vimineum var. polystachyum (Franch. \& Sav.) Ohwi 큰듬성이삭새; 243196, 323857, 451106, 482677, 536314, 590726, 599852 $(1,2,4,5,6,7,10)$

Milium effusum L. 나도겨이삭; 235217, 359100, 575923, $578403(1,3,9,10)$

Miscanthus sacchariflorus (Maxim.) Hack. 물억새; 244506, 323889, $449429(1,2,4)$

Miscanthus sinensis Andersson 억새; 242120, 310064, 390282, 449388, 482099, 530336, 551728, 590175, 599035 (1, 2, 3, 4, 5, 6, 7, 9, 10)

Molinia japonica Hack. 진퍼리새; 576440 (9)

Muhlenbergia huegelii Trin. 큰쥐꼬리새; 245332, 309909, 388006, 449386, 482818, 536482, 574783, 585889 (1, 2, 3, 4, 5, 6, 7, 9)

Muhlenbergia japonica Steud. 쥐꼬리새; 243427, $599145(1,10)$

Oplismenus undulatifolius (Ard.) Roem. \& Schult. 주름조개풀; 235604, 310170, 387798, 451092, 472549, 528445, 574862, 590147, 599048 $(1,2,3,4,5,6,7,9,10)$

Oplismenus undulatifolius var. japonicus (Steud.) Koidz. 민주름조개풀; 599165 (10)

Panicum bisulcatum Thunb. 개기장; 242380, 310051, 387894, 451421, 482391, 574830, 591160, $599132(1,2,3,4,5,7,9,10)$

Panicum dichotomiflorum Michx. 미국개기장(A); 451293, 528394, 590705, 599176 (4, 6, 7, 10)

Paspalum thunbergii Kunth ex Steud. 참새피; 243961, 310126, $482089(1,2,5)$

Pennisetum alopecuroides (L.) Spreng. 수크령; 245329, 387807, 449904, 495862, 530276, 552585, 590710, 599199 (1, 3, 4, 5, 6, 7, 8, 10)

Phalaris arundinacea L. 갈풀; 235429, 305291, 385486, 441212, 481167, 523871, 552965, 569451, 578815, $585367(1,2,3,4,5,6,7,8,9,10)$

Phleum pratense L. 큰조아재비(A); 235437, 385566, 441531, 576449, $578878(1,3,4,9,10)$

Phragmites japonica Steud. 달뿌리풀; 242238, 309987, 390303, 446873, 472838, 530337, 585883, 599793 (1, 2, 3, 4, 5, 6, 7, 10)

Poa acroleuca Steud. 실포아풀; $385338,441478,472572,585390(3,4,5,7)$

Poa annua L. 새포아풀; 284384, 395969, 441136, 464002, $588556(2,3,4,5,9)$

Poa hisauchii Honda 구내풀; 578042, 585356, $588552(7,9,10)$

Poa nemoralis L. 선포아풀(IV); $575538,585500(7,9)$

Poa nipponica Koidz. 큰꾸러미풀; 575544 (9)

Poa pratensis L. 왕포아풀(A); 234935, 284389, 359222, 441168, 468732, 523829, 575808, 578134, 580446 (1, 2, 3, 4, 5, 6, 7, 9, 10)

Poa sphondylodes Trin. 포아풀; 235158, 284665, 385399, 441150, 468742, 523830, 552964, 579190, $600669(1,2,3,4,5,6,7,8,9)$

Schizachne purpurascens subsp. callosa (Turcz. ex Griseb.) T. Koyama \& Kawano 호오리새(II); 235198, $385344(1,3)$

Setaria faberi R. A. W. Herrm. 가을강아지풀; 235728, 388037, 528375, $590700(1,3,6,7)$

Setaria pallide-fusca (Schumach.) Stapf \& C. E. Hubb. 가는금강아지풀; 599028 (10)

Setaria pumila (Poir.) Roem. \& Schult. 금강아지풀; 242410, 309925, 395967, 449423, 482187, 528398, 591159, 598911 (1, 2, 3, 4, 5, 6, 7, 10) 
Appendix 1. Continued.

Setaria pycnocoma (Steud.) Henrard ex Nakai 수강아지풀; 236973, 310053, 387600, 449767, 481849, 530342, 575847, 590036, 599027 (1, 2, 3, 4, 5, 6, 7, 9, 10) Setaria viridis (L.) P. Beauv. 강아지풀; 242231, 309986, 385599, 446358, 472829, 524351, 551735, 552553, $585837(1,2,3,4,5,6,7,8,9)$ Spodipogon cotulifer (Thunb.) Hack. 기름새; 242265, 309974, 482090, 530305, 591749 (1, 2, 5, 6, 7)

Spodipogon sibiricus Trin. 큰기름새; 242005, 310011, 390267, 446833, 481830, 530379, 574836, 586038, 599033 (1, 2, 3, 4, 5, 6, 7, 9, 10) Stipa pekinensis Hance 나래새; 242151, 310087, 390261, 449604, 481816, 530400, 590139, $599125(1,2,3,4,5,6,7,10)$

Themeda triandra Forssk. 솔새; 234898, 305651, 395855, 449997, 472830, 528319, 590789, 599152 (1, 2, 3, 4, 5, 6, 7, 10)

Trisetum bifidum (Thunb.) Ohwi 잠자리피; 235354, 284837, 385545, 441162, 468722, 523880, 569633, 578857, 585135 (1, 2, 3, 4, 5, 6, 7, 9, 10)

Vulpia myuros (L.) C. C. Gmel. 들묵새(A); 578862 (10)

Typhaceae 부들과

Typha angustifolia L. 애기부들; 446461, 552885, $599791(4,8,10)$

Typha orientalis C. Presl. 부들; 243106, 446460, 552882, $579136(1,4,8,10)$

Pontederiaceae 물옥잠과

Monochoria vaginalis (Burm. f.) C. Presl 물달개비; 242328, 472859, 556085, 599278 (1, 5, 8, 10)

Haemodoraaceae 지모과

Anemarrhena asphodeloides Bunge 지모; 593891 (1)

Liliaceae 백합과

Allium longistylum Baker 강부추(LC); 244076 (1)

Allium macrostemon Bunge 산달래; 235510, 284696, 385701, 441594, 468728, 523868, 553113, 569656, 578530, 585402 (1, 2, 3, 4, 5, 6, 7, 8, 9, 10)

Allium monanthum Maxim. 달래; 354981, 433164, 566005, 577690, 583034 (3, 4, 7, 9, 10)

Allium sacculiferum Maxim. 참산부추; 243685, 395989, 449855, 488063, $599782(1,3,4,5,10)$

Allium thunbergii G. Don 산부추; 243922, 395794, 451856, 482601, 551733, 599817 (1, 3, 4, 5, 9, 10)

Allium tuberosum Rottler ex Spreng. 부추(A); 242193, 309876, 387987, 449376, 530326, 574437, 590149, 599151 (1, 2, 3, 4, 6, 7, 9, 10)

Asparagus oligoclonos Maxim. 방울비짜루(I); 235002, 324137, 359198, 441488, 495571, 523924, 554091, 569686, 578172, 580359 (1, 2, 3, 4, 5, 6, 7, 8, 9, 10)

Asparagus schoberioides Kunth 비짜루; 390279, 441356, 468836, 575843, 599681 (3, 4, 5, 9, 10)

Barnardia japonica (Thunb.) Schult. \& Schult. f. 무릇; 236913, 310107, 388046, 449362, 481823, 528314, 551892, 552587, 590640, 598975 (1, 2, 3, 4, $5,6,7,8,9,10)$

Convallaria keiskei Miq. 은방울꽃; 245242, 359163, 441452, 524016, 569713, 599008 (1, 3, 4, 6, 9, 10)

Disporum smilacinum A. Gray 애기나리; 235233, 284533, 359099, 469076, 569707, $578182(1,2,3,5,9,10)$

Disporum uniflorum Baker 윤판나물; 234971, 305325, 359292, 520844, 552158, 577937, $580368(1,2,3,6,7,8,10)$

Disporum viridescens (Maxim.) Nakai 큰애기나리; 359143, 569665, 585465, $599670(3,7,9,10)$

Erythronium japonicum Decne. 얼레지; 284344, 433168, 569726, 577709 (2, 4, 9, 10)

Gagea nakaiana Kitag. 중의무릇; 354986, 433190, $577736(3,4,10)$

Heloniopsis koreana S. Fuse, N. S. Lee \& M. N. Tamura 처녀치마(E, II); 243873, 284666, 354950, 552049, 577066, 577551, 591562 (1, 2, 3, 7, 8, 9,10)

Hemerocallis hakuunensis Nakai 백 운산원추리(E); 242125, 305728, 446373, 472776, 524468, 552920, 574878, 585868, 599345 (1, 2, 4, 5, 6, 7, 8, 9, 10)

Hemerocallis middendorffii Trautv. \& C. A. Mey. 큰원추리(IV); 385656, $495459(3,5)$

Hosta capitata (Koidz.) Nakai 일월비비추(I); 243257, 387670, 446683, 472746, 576695, 586001, 599309 (1, 3, 4, 5, 7, 9, 10)

Hosta clausa Nakai 주걱비비추(III); 243098, 388005, 449439, $590787(1,3,4,7)$

Hosta minor (Baker) Nakai 좀비비추(E, I); 387650, $574843(3,9)$

Lilium amabile Palib. 털중나리; 245243, 305280, 394421, 441739, 481083, 524346, 553063, 575437, 578807, 585810 (1, 2, 3, 4, 5, 6, 7, 8, 9, 10)

Lilium cernuum Kom. 솔나리(IV, LC); 387531, 446697, 495717, 576687, $586019(3,4,5,7,9)$

Lilium concolor var. pulchellum (Fisch.) Baker 하늘나리(I); 245220, 441131, 575609, $578975(1,4,9,10)$

Lilium distichum Nakai 말나리(III, LC); 599044 (10)

Lilium lancifolium Thunb. 참나리; 235776, 446420, 472820, 574845, 585832, 599258 (1, 4, 5, 7, 9, 10)

Lilium leichtlinii var. maximowiczii (Regel) Baker 중나리(IV); 242099 (1)

Lilium tsingtauense Gilg 하늘 말나리; 235646, 305725, 387506, 446500, 482206, 528468, 552951, 579180, 585981 (1, 2, 3, 4, 5, 6, 7, 8, 10)

Liriope spicata (Thunb.) Lour. 개맥문동; $310118,472850,586081(2,5,7)$

Lloydia triflora (Ledeb.) Baker 나도개감채(II); 284351, 552097, $578022(2,8,10)$

Maianthemum japonicum (A. Gray) La Frankie 풀솜대; 385422, 441416, 495386, 565954, 578031 (3, 4, 5, 7, 10)

Paris verticillata M. Bieb. 삿갓나물; 236990, 359297, 441363, 495453, 578406, 582992, 585804 (1, 3, 4, 5, 7, 9, 10)

Polygonatum humile Fisch. ex Maxim. 각시둥굴레; 234939, 359060, 441172, 520908, 575927, 578094 (1, 3, 4, 6, 9, 10)

Polygonatum inflatum Kom. 퉁둥굴레; 235325, 284518, 359134, 441585, 495288, 583053, 585438, 599020 (1, 2, 3, 4, 5, 7, 9, 10)

Polygonatum involucratum (Franch. \& Sav.) Maxim. 용둥굴레; 235162, 284637, 359207, 441336, 495252, 524564, 553294, 566069, 575647 , $578046(1,2,3,4,5,6,7,8,9,10)$

Polygonatum lasianthum Maxim. 죽대; 243846, 481414, $553288(1,5,8)$

Polygonatum odoratum var. pluriflorum (Miq.) Ohwi 둥굴레; 234982, 284586, 359081, 441139, 468952, 520979, 553527, 577177, 578121, $580363(1,2,3,4,5,6,7,8,9,10)$

Polygonatum stenophyllum Maxim. 층층둥굴레(IV, LC); 235477 (1)

Polygonatum thunbergii C. Morren \& Decne. 산둥굴레; 235526, 284632, 387423, 441687, 468775, $520864(1,2,3,4,5,6)$

Streptopus ovalis (Owhi) F. T. Wang \& Y. C. Tang 금강죽대아재비(II); 235341, 359097, 441414, 553281, 578391, 593690 (1, 3, 4, 8, 9, 10) 
Appendix 1. Continued.

Tricyrtis macropoda Miq. 뻐꾹나리(I, LC); 243425, 395807, 574494, 599868 (1, 3, 9, 10)

Trillium camschatcense Ker Gawl. 연영초(IV, LC); 578412 (10)

Tulipa edulis (Miq.) Baker 산자고; 284399, 359111, 463998, $520358(2,3,5,6)$

Veratrum maackii Regel 여로(III); 235665, 387542, 446575, 495455, $599415(1,3,4,5,10)$

Veratrum maackii var. parviflorum (Maxim. ex Miq.) H. Hara 파란여로(IV); 235643, 387419, 446608, 482767, 552635, 574951 (1, 3, 4, 5, 8, 9)

Veratrum nigrum L. 참여로(III); 243740, 390418, 449554, 551958, 591092 (1, 3, 4, 7, 9)

Veratrum oxysepalum Turcz. 박새(I); 578511 (10)

Veratrum versicolor Nakai 흰여로; $528439,585991(6,7)$

Zigadenus sibiricus (L.) A. Gray 나도여로(V, CR); 592792

Iridaceae 붓꽃과

Iris domestica (L.) Goldblatt \& Mabb. 범부채(I, LC); 388035, $528367(3,6)$

Iris minutoaurea Makino 금붓꽃(I, LC); 359392 (3)

Iris odaesanensis Y. N. Lee 노랑무늬붓꽃(E, IV, LC); 359131, 446652, 495793, 583011 (3, 4, 5, 9)

Iris rossii Baker 각시붓꽃; 235019, 284320, 354940, 468979, 520849, 552259, 565937, 577176, $577810(1,2,3,5,6,7,8,9,10)$

Iris sanguinea Donn ex Hornem. 붓꽃; 235529, $441781,578155(1,4,10)$

Smilacaceae 청미래덩굴과

Smilax china L. 청미래덩굴; $284873,468965(2,5)$

Smilax nipponica Miq. 선밀나물; 235321, 359107, 441368, 468939, 578106, 580442 (1, 3, 4, 5, 9, 10)

Smilax riparia A. DC. 밀나물; 235383, 284429, 359350, $580442(1,2,3,7)$

Smilax sieboldii Miq. 청 가시덩굴; 243807, 385597, 441097, 468919, 523804, 554072, 575866, 578425, $580337(1,3,4,5,6,7,8,9,10)$

Dioscoreaceae 마과

Dioscorea coreana (Prain \& Burkill) R. Knuth 푸른마(E); 235719, 310203, $396050(1,2,3)$

Dioscorea nipponica Makino 부채마; 235718, 305429, 394248, 446395, 495619, 524470, 575439, 578976, 585844 (1, 2, 3, 4, 5, 6, 7, 9, 10)

Dioscorea polystachya Turcz. 마; 243331, 472833, 528330, 552908, 574831, 590815, $598954(1,5,6,7,8,9,10)$

Orchidaceae 난초과

Amitostigma gracile (Blume) Schltr. 병아리난초; 235649, 305502, 387753, 446400, 472704, 524507, 552637, 576407 (1, 2, 3, 4, 5, 6, 8, 9)

Cephalanthera erecta (Thunb.) Blume 은난초; 305734, 359122, 441455, 469002, 569727 (2, 3, 4, 5, 9)

Cephalanthera longibracteata Blume 은대난초; 235232, 284529, 385475, 441103, 468955, 523952, 554082, 569667, 578370, 585425 (1, 2 , $3,4,5,6,8,9,10)$

Cephalanthera longifolia (L.) Fritsch 김의난초(III); 520943, $575931(6,9)$

Cymbidium macrorhizon Lindl. 대흥란(V, VU); 310094 (2)

Cypripedium macranthos Sw. 복주머니란(V, VU); Photo003 (3)

Epipactis papillosa Franch. \& Sav. 청닭의난초(IV, NT); 243394, 284852, 387541, 446627, 495608, 524460, 574508, 585955 (1, 2, 3, 4, 5, 6, 7, 9)

Goodyera rosulacea Y. N. Lee 로젯사철란; 236983, 387754, 488001, 524458, $586078(1,3,5,6,7)$

Herminium monorchis (L.) R. Br. 나도씨눈란(IV, NT); 387385, $528498(3,6)$

Liparis kumokiri F. Maek. 옥잠난초; 237015, 305741, 387559, 446443, 576696, 578903, $585949(1,2,3,4,7,9,10)$

Liparis makinoana Schltr. 나리난초(I); 576453 (9)

Neottianthe cucullata (L.) Schltr. 구름병아리난초(V, EN); 593996

Oreorchis patens (Lindl.) Lindl. 감자난초; 359132, 441360, 569723, $578467(3,4,9,10)$

Platanthera chlorantha (Custer) Rchb. f. 제비난초; 235538, 385711, 441456, 468963, 553304 (1, 3, 4, 5, 8)

Platanthera japonica (Thunb.) Lindl. 갈매기란(NT); 578738 (10)

Platanthera mandarinorum Rchb. f. 산제비란; 576404 (9)

Pogonia minor (Makino) Makino 방울새란(NT); 387646 (3)

Spiranthes sinensis (Pers.) Ames 타래난초; 235597, 310055, 387667, 472591, 576405, 579181 (1, 2, 3, 5, 9, 10)

[Abbreviation] E, endemic plants; CR, critically endangered plants; EN, endangered plants; VU, vulnerable plants; NT, near threatened plants; LC, least concern plants; DD, data deficient plants; NA, not applicableplants; I-V, grade of floristic target plants; A, alien plants; Italic numbers are voucher specimens; 1, Taehwa mountain; 2, Osip stream; 3, Goyang mountain; 4, Samtae mountain; 5, Golji stream; 6, Wonpung stream; 7, Jungnyeom mountain; 8, Dumu mountain; 9, Baeki mountain; 10, Nambyeong mountain. 